\title{
Aid, Politics, Culture, and Growth
}

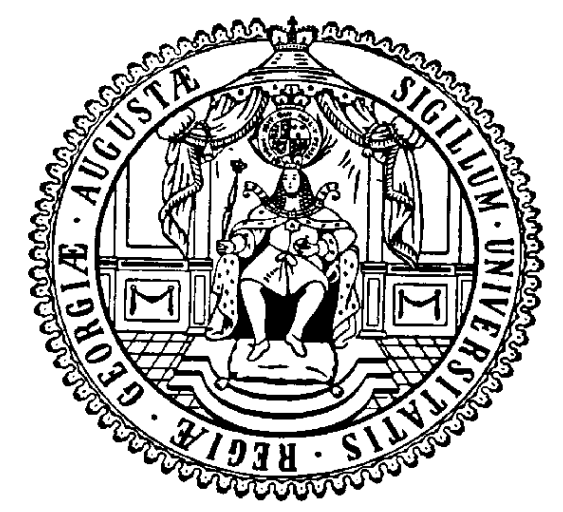

Dissertation zur Erlangung des wirtschaftswissenschaftlichen Doktorgrades der Wirtschaftswissenschaftlichen Fakultät an der Universität Göttingen

vorgelegt von

Anna Minasyan

aus Kapan, Armenien

Göttingen, 2015 
Erstgutacher: Prof. Dr. Axel Dreher

Zweitgutacher: Prof. Stephan Klasen, Ph.D.

Drittprüfer: Jun.Prof. Dr. Sebastian Vollmer

Tag der Abgabe: 21 September 2015

Tag der Disputation: 08 December 2015 


\section{Acknowledgements}

I am deeply grateful to Axel Dreher for believing in my potential and inviting me to Goettingen to commence my doctoral studies under his exemplary supervision in scope of the research training group "Globalization and Development". His consistent and thorough feedback on my work as well as his support and encouragement contributed to my academic achievements and helped me to efficiently finish my dissertation at the University of Goettingen. I am also immensely thankful to Stephan Klasen for being very supportive upon my arrival and providing me with the opportunities for teaching and involvement in the academic life. The openness and resourcefulness of both Axel Dreher and Stephan Klasen granted me the freedom and independence to utilize diverse learning opportunities in Germany and abroad. I also thank my co-author Peter Nunnenkamp for his support and a great teamwork.

I greatly appreciate being part of the "Globalization and Development" research training group during my doctoral studies as not only my dissertation greatly benefited from the comments and feedback of the group members and professors but also my academic life was not "a lone journey" but rather "an amusing ride.” Thanks to my office mate Juliane, I found out that sharing an office can actually be better than having one on one's own. Thanks to Marica for her openness, kindness and understanding, Bumi and Nil for being fine with my random "walk-ins" and ready to discuss and share ideas as well as good laughs in Blue Tower. Also thanks to Steffen, Nathalie, Merle, Atika, Ana, Simon and Kai as well as the colleagues in Heidelberg for the discussions, help and advice. I am also thankful to Thomas Stratmann and Viktor Brech for helping me with my research stay at the George Mason University and Siyu Wang from the ICES for her friendliness and great company during my stay in Arlington.

The generosity of German Academic Exchange Service (DAAD) and Open Society Institute enabled me to focus on my research by supporting me financially for which I am extremely thankful. In addition, I deeply appreciate the crucial support from my friends, Oleksandra (Sasha) and Philip, which facilitated my arrival and smooth start in Germany as a doctoral student. I also thank my friends, teachers and professors from Kapan and Konstanz as well as Hillary and Phil for contributing to the "deep roots" of my academic potential and personal development.

I thank Christian for his implicit support in the last three years and for making sure I stay critical: those numerous discussions on politics, feminism, media, art, history, culture, and comedy, among others, kept my "curious mind" satisfied and excited about new knowledge.

And...My dearest family that wishes to have me close-by but luckily also wants me to be happy: Thank you for trusting me in pursuing my own path. 


\section{Contents}

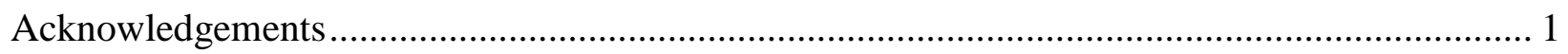

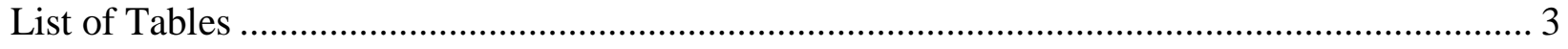

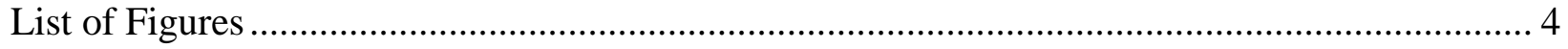

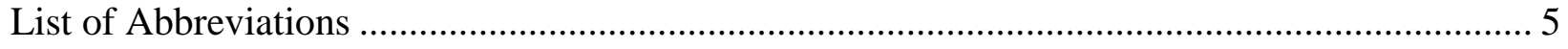

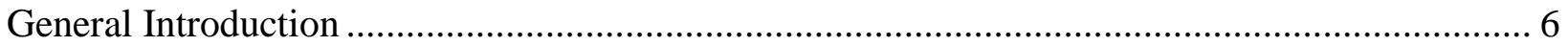

Chapter 1 Government ideology in donor and recipient countries: Does ideological proximity

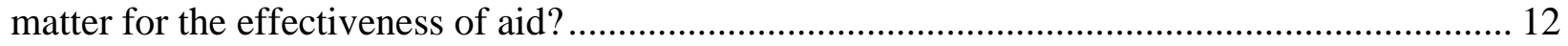

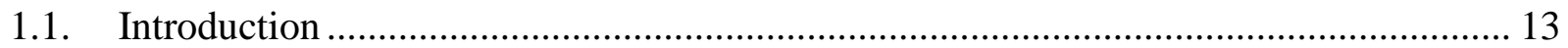

1.2. A theory of ideological proximity and aid effectiveness ........................................... 14

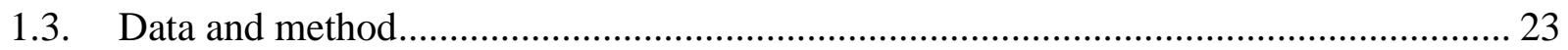

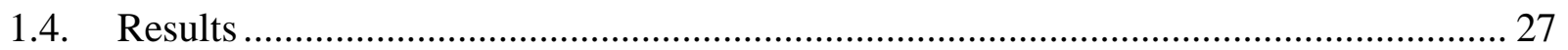

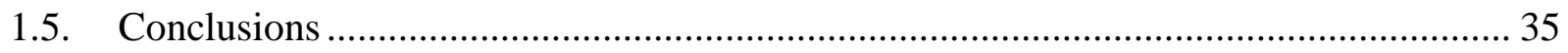

Chapter 2 Your development or mine? Effects of donor-recipient cultural differences on the aid-

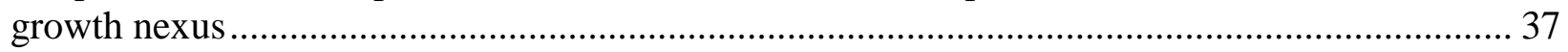

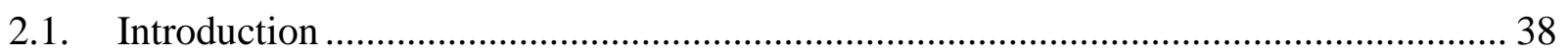

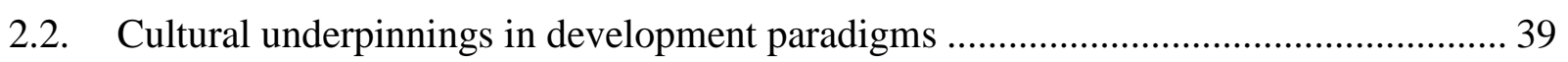

2.3. Anecdotal evidence on cultural differences in development paradigms ........................ 41

2.4. Proxy variables for cultural differences and transmission ............................................. 43

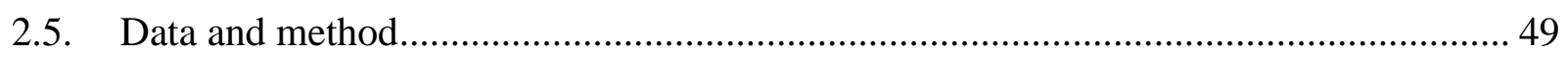

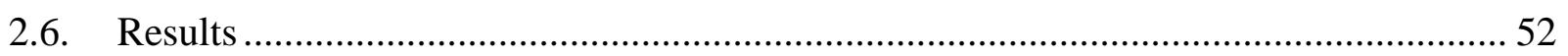

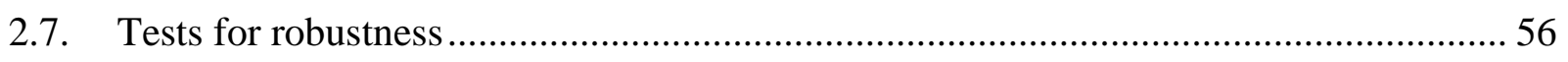

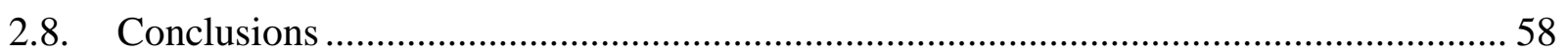

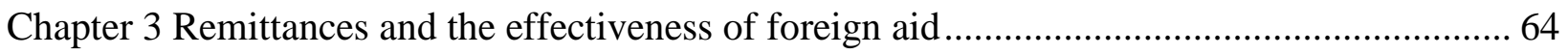

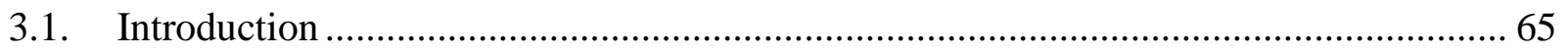

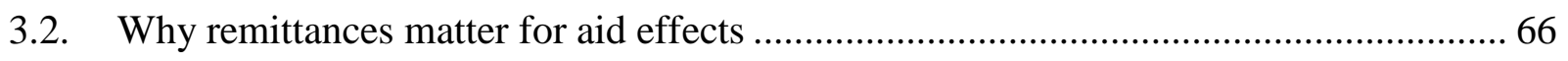

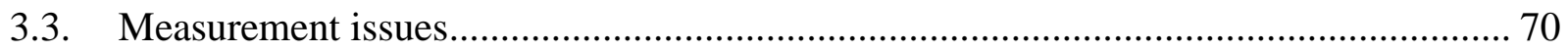

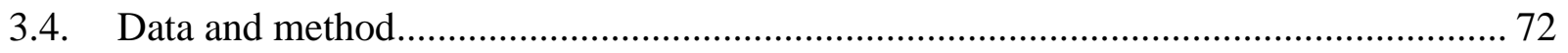

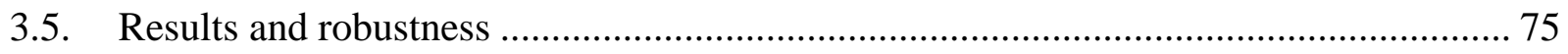

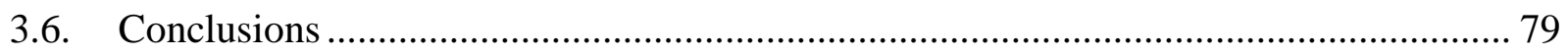

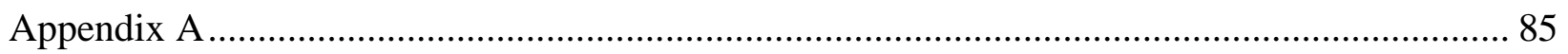

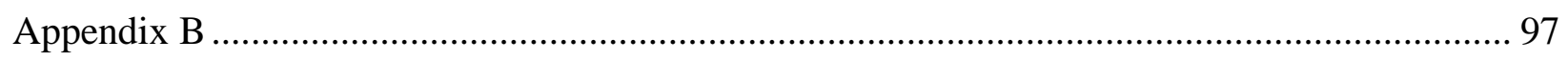

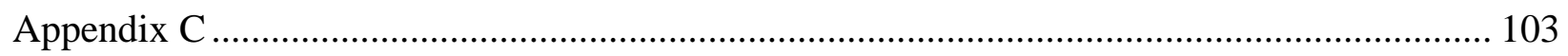

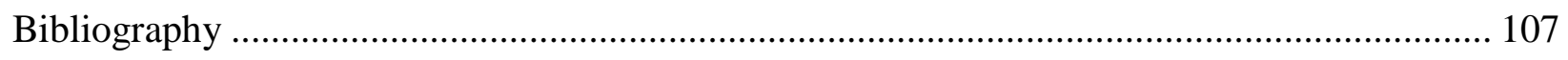




\section{List of Tables}

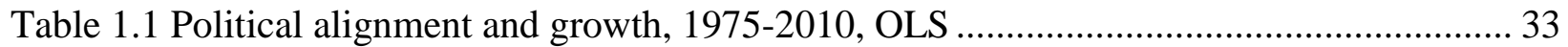

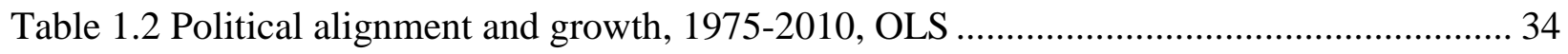

Table 2.1 The effect of aid-adjusted genetic distance on the aid-growth nexus ........................ 59

Table 2.2 The effect of leaders' western education on the aid-growth nexus ............................ 60

Table 2.3 Lagged effects of leaders' western education the on aid-growth nexus...................... 61

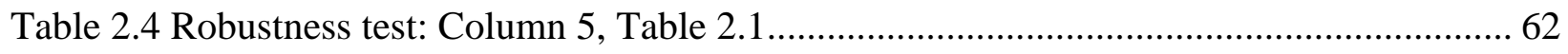

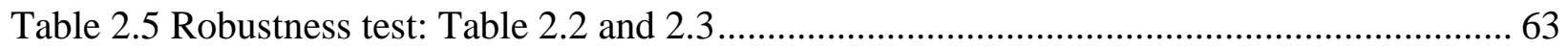

Table 3.1 DAC and non-DAC donors: Remittances and aid in percent of GDP ...................... 81

Table 3.2 Baseline estimation results, all donors, 1985-2010, Rajan and Subramanian (2008)

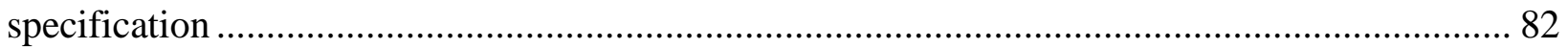

Table 3.3 Robustness tests for Column 2, Table 3.2, excluding control variables and lagging aid

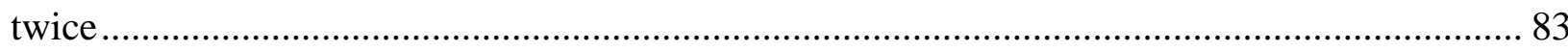

Table 3.4 Robustness tests for Column 2, Table 3.2, reduced donor or recipient samples .......... 84

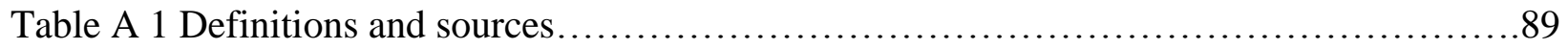

Table A 2 Descriptive Statistics (Table 1.1, column 3) ...................................................... 91

Table A 3 Regression in levels with country-fixed effects................................................. 92

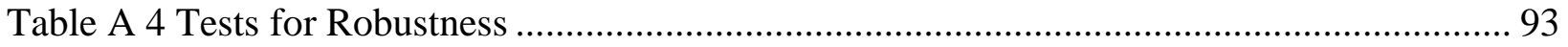

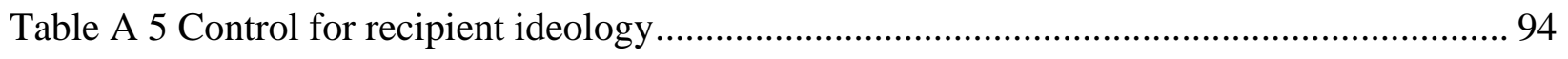

Table A 6 Comparison of means test in aid shares .......................................................... 95

Table A 7 Political alignment and growth controlled for tied aid, 1975-2010, OLS ................. 96

Table B 1 Alternative measures of differences: Column 5, Table 2.1 ......................97

Table B 2 WVS's well being cultural dimension and aid-adjusted genetic distance .................. 98

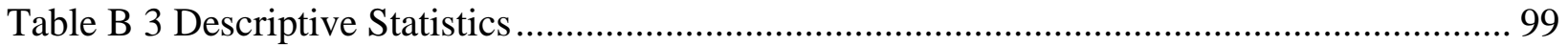

Table B 4 Variable Definition and Sources ..................................................................... 100 


\section{List of Figures}

Figure 1.1 Marginal effect of $\Delta$ aid on $\Delta$ growth as political alignment changes ........................ 28

Figure 2.1 Marginal effects of aid on growth as AwGD changes ........................................... 53

Figure 2.2 Marginal effects of aid on growth as leaders' western education change ................. 55

Figure 3.1 Marginal effects of aid on growth as DonQual changes ....................................... 80

Figure A1 How ideological proximity improves the effectiveness of aid....................88

Figure B1 Map of the (weighted) genetic distance to donors .............................101

Figure B2 Map of the standard deviation of (weighted) genetic distance to donors ................. 101

Figure B3 Map of the aid-adjusted (weighted) genetic distance to donors ............................. 102 


\section{List of Abbreviations}

AEL - Aid effectiveness literature

CDI - Commitment to Development Index

CGD - Center for Global Development

CRS - Common Reporting Standard

DAC - Development Assistance Committee

FDI - Foreign Direct Investment

GDP - Gross Domestic Product

GMM - Generalized Method of Moments

ICRG - International Country Risk Guide

IMF - International Monetary Fund

NGO - Non-Governmental Organization

ODA - Official Development Assistance

OECD - Organization for Economic Cooperation and Development

OLS - Ordinary Least Squares

p.c. - per capita

UCDP - Uppsala Conflict Data Program

PRIO - Peace Research Institute in Oslo

UK - United Kingdom

UN - United Nations

UNCTAD - United Nations Conference on Trade and Development

US - United States

WVS - World Value Surveys 


\section{General Introduction}

In the last decades, debates on foreign aid have generated many controversies regarding the effectiveness of aid. While some may argue that giving aid is a moral and ethical obligation analogous to "saving a drowning child," others stress that it is an exceedingly complex issue, where technical solutions are doomed to failure. Research on the effectiveness of aid shows ambiguous results. Many authors find that foreign aid has generated growth in recipient countries, while others fail to come to the same conclusion. Another group of scholars show that the effectiveness of foreign aid is conditional on several factors such as local policies, institutions, colonial history and the geography of aid recipient countries. This dissertation contributes to this research on the conditions that help determine the effectiveness of aid by looking not only at recipient characteristics but also that of the donors in chorus. It evaluates the role of political and cultural differences between donors and recipients as well as quality of the donors in the aid transactions. This study focuses on the effectiveness of bilateral foreign aid, that is, the official capital flows from one government to another for development assistance purposes, excluding military aid.

Eighteenth century philosopher, David Hume, argued that globalization would increase people's identification as being global citizens, causing them to care more for the wellbeing of those distant to themselves (Hume, 1912). After World War II, globalization intensified as countries across the world became more integrated economically, socially and politically (Dreher et al. 2008). Together with intense globalization, foreign aid from wealthy countries to poorer ones intensified. In the 1950s and 1960s, the rich countries in the West (i.e., United States and its allies) became the traditional bilateral foreign aid providers (donors) for the rest that were left behind not only in terms of income levels and economic growth but also in terms of socioeconomic and political institutions. This difference in development levels became more salient especially after the era of decolonization and the collapse of the Soviet Union, when more than 150 states with diverse cultures, political systems and histories were largely classified into two groups: developed and developing countries.

Developing countries are characterized with low levels of income and economic growth and different combinations of the following: civil or interstate conflicts and wars, corrupt governments, dysfunctional rule of law, lacking infrastructure, poor macroeconomic management, low standards of living, low life expectancy, deprivation of education and health, 
limited social, civil, political and economic rights and constrained personal freedom, among others. While the developed countries escaped most of these conditions and are characterized by high income levels, positive growth rates on average and well established political, socioeconomic institutions and welfare systems, among others.

In much of the literature, the effectiveness of foreign aid is measured in terms of changes in the recipient country's economic growth. The original rationale for foreign aid emerged from a Harod-Domar type of economic growth model according to which more capital investment "guarantees" more economic growth. Therefore, foreign aid's general purpose was seen as filling the "financing gap" in developing countries and assisting them in getting on the path to economic growth. Later on, poverty alleviation arguably became the key rationale for foreign aid. Nevertheless, the focus on the growth effect of aid has remained important because studies suggest that economic growth is the fastest and most sustainable way to escape poverty (Ravallion and Chen 1997, Dollar and Kraay, 2000), but one needs to keep in mind that not all growth is equally beneficial for the poor (Klasen, 2013). Furthermore, recent studies show that foreign aid is also politically motivated as it is at times given to fulfill strategic interests of particular donors. Moreover, anecdotal evidence suggests that growth models and development paradigms supplied by the donors' expertise fail due to the neglect of diverse cultures and institutions in the recipient countries. Thus, in this dissertation, I focus on the aid-growth nexus and its interplay with politics and culture of donor and recipient countries.

There are certainly many ways to evaluate conditions for the effectiveness of aid, especially when it comes to microeconomic projects and programs for specific purposes, such as vaccination initiatives, monetary encouragements for school attendance, building hospitals and roads, promoting capacity building, women empowerment etc. While it could be the case that a specific project or a program is evaluated as being successful in reaching its targets on the micro level in the short run, it does not necessarily guarantee lasting solutions for social and economic progress in the recipient country as a whole in the longer run. This phenomenon is also known as the micro-macro paradox. Meanwhile, at the macroeconomic level it remains unclear whether foreign aid has been effective in bringing growth and development to recipient countries, or conversely, whether it has undermined it. The paradigms of foreign aid, as official development assistance, have changed from one decade to the next as most efforts have failed as panaceas for growth (Easterly, 2001). While the majority of aid effectiveness literature has extensively explored conditions for aid effectiveness based on recipient characteristics only, scant attention 
has been paid to how differences between donors and recipients in terms of politics and culture affect aid's impact on growth. At the same time, donor policies that can complement foreign aid and increase growth in aid-recipient countries, such as those promoting freer movement of people, have not been examined sufficiently in the aid effectiveness literature. In the following three chapters, I seek to close this gap and contribute to the literature by empirically analyzing how the following factors influence the aid-growth relationship: 1) differences in donor-recipient political ideology 2) differences in culture between donors and recipients and 3) donors' openness to immigration and temporary work as a complimentary non-aid policy.

It is not an easy task to establish a causal relationship between aid and growth since lower growth and income levels attract more aid. This fact leads to problems of reverse causality and endogeneity of the aid variable in the econometric models of aid and growth. In the past decades scholars have attempted to overcome these problems by using instrumentation strategies in the aid-growth estimations. A variable can be qualified as an instrument for aid and help to estimate its causal effect on growth if it satisfies two conditions: 1) it is highly correlated with aid, and 2) it affects growth only through aid. However, recent research shows that the instruments for aid in the literature fail to satisfy the second condition (Bazzi and Clemens, 2012). Instead of using instruments that would more likely lead to misleading outcomes, Clemens et al. (2012) suggest an identification strategy that estimates the aid-growth equation using first differences and lagging aid by one period. By first differencing they control for time-invariant omitted variables and by lagging aid they eliminate the reverse causality issue. In this dissertation, I follow the estimation strategy of Clemens et al. (2012) and use the aid-growth model of Rajan and Subramanian (2008) from Clemens et al. (2012) as my baseline growth model. I then augment the growth model with my variables of interest and make use of panel data for almost 70 countries and forty years, on average. The causal identification strategy in all three chapters follows the intuition of difference-in-difference analysis, where the differential effect of aid on growth in aligned and non-aligned (political and culturally) recipients as well as from open and less open donors is unlikely to rise via channels other than aid. Possible weaknesses of this methodology are addressed in each chapter, respectively, via robustness tests on the main findings. The period of observation and country samples vary for each chapter depending on the availability of data for the variable of interest. At the same time, additional control variables (and their sources) differ, depending on the context of the chapter. In the next paragraphs, I summarize my main hypotheses, methods, findings and policy implications of each chapter. 


\section{Road Map}

Chapter one, co-authored with Axel Dreher and Peter Nunnenkamp and published in the European Economic Review, looks at how differences in political ideology between aid donors and recipients influence the effectiveness of aid. Greater ideological distance between donor and recipient governments may add to transaction costs and distort trust between the respective parties. For example, if a donor believes in the merits of a redistributive economic system and government intervention in reducing poverty then it would prefer to see aid being used to promote welfare systems. However, if the recipient government holds the opposite belief, then it would prefer to use aid for private sector investment instead. This divergence in political ideologies may increase negotiation and monitoring costs in aid transactions. It could also lead to lower trust levels between donors and recipients and, as an end result, render aid less effective. This hypothesis is further conceptualized and tested empirically by taking account of the political ideology of both governments along the left-right spectrum in an augmented model of economic growth and aid. The model used is based on Clemens et al.'s (2012) study of Rajan and Subramanian (2008) and is augmented with a new variable that measures the aid-weighted ideological distance between a recipient and its donors. Thereafter, this new variable is interacted with total bilateral aid received, which constitutes the variable of interest. All variables in the model are averaged over 5-year periods from 1975-2010 for 67 countries. After following the estimation strategy of Clemens et al. (2012) and testing for the results' robustness, it is concluded that aid becomes less effective with misaligned political ideology between donors and recipients. This outcome suggests that donors should not only focus on the need and merit of recipient countries but also make sure that the ideology of a recipient country government matches its own political ideology. This also supports the case for better donor coordination in delivering bilateral aid: donors should avoid directing much of their foreign aid towards those countries with which they are not politically aligned. This can then help to maximize aid's positive effect on growth.

In recent decades a number of studies on economic growth have started to empirically explore the deep roots of economic development thanks to the availability of new knowledge and data. The deep roots of development are those influential factors that have a long history of persistence and continue to exist due to ancestral knowledge transmission from one generation to the next. One of such factor is culture - a complex set of beliefs, values, attitudes and norms that is transferred via parental teaching and/or through resources. In chapter two, published in the Journal of Comparative Economics, I argue that culture influences how experts design 
development strategies. Most of development strategies are initiated and designed by economists who either come from the West or are highly influenced by it. Moreover, the economics discipline itself is mainly based on the growth and development processes that took place in the West. Therefore, the development strategies that are premised upon the western culture might easily fail when applied in non-western societies. I measure cultural differences using two proxy variables. First, I use aid-weighted genetic distance data, i.e. differences of frequencies of blood types between populations, as a proxy for cultural transmission through the parent-offspring channel. Second, I use western education of the recipient country leader to capture cultural transmission through resources and societal learning. The hypothesis is tested empirically using the baseline growth model as in chapter one and follows the same estimation strategy: OLS in first differences and bilateral aid lagged once. I use the interaction term of these proxy variables with aid, in separate estimation equations, to analyze how a change in aid affects the (change in) growth of recipients with larger cultural differences. Results of OLS panel estimation in first differences over the 1961-2010 period for 66 countries show that larger donor-recipient genetic distance reduces the overall effect of aid on growth. This implies that if parental teaching on beliefs, values, norms and values greatly varies between donor and recipient countries then aid is less effective. In turn, findings show that western education of a recipient country leader can facilitate the positive effect of aid on growth in a long run. These findings suggest that development strategies need to be thoroughly revised and adjusted for local cultures. Donors need to engage in very long-term commitments with a recipient country and respect local cultures by designing locally compatible projects and programs. On the other hand, more liberal policies that promote freer movement of people, as well as educational and temporary work opportunities between donor and recipient countries can help relax barriers for resistance through communication and cultural adaptation. In fact, chapter three investigates how donors' openness to immigration and temporary work of migrants influences the effectiveness of aid in general.

Free movement of people, just like free movements of goods, can be beneficial for poverty alleviation and development in recipient countries thanks to spillover effects, reduced transaction costs and lessened information asymmetries. Nevertheless, it has been harder to introduce policies for the freer movement of people in comparison to those for the movement of goods. Chapter three, co-authored with Peter Nunnenkamp and forthcoming in the Review of Development Economics, is an attempt to evaluate how such socially liberal policies could influence the effectiveness of aid. The main hypothesis here is that donors could improve the 
effectiveness of foreign aid by pursuing complementary and coherent non-aid policies simultaneously. In particular, aid can have stronger growth effects if recipients receive more aid from donors that allow for (temporary) worker mobility and (more permanent) migration. Remittances sent from the donor countries are used as a proxy for worker mobility and migration because bilateral remittance data - which would be preferable - are available only from 2010. Hence, the aid-growth baseline model used in the previous two chapters is augmented with aidweighted remittances paid by donors. Results from OLS panel estimation in first differences over the 1985-2010 period for 70 countries indicate that higher remittances paid by donor countries strengthen foreign aid's effect on growth. This implies that socially liberal policies for immigration and temporary work can benefit both the donor and the recipient in terms of aid effectiveness and should therefore be promoted in donor countries coupled with other complimentary policies for successful integration in the donor countries and lasting spillover effects in the recipient countries.

Overall, the findings of this dissertation suggest that aid effectiveness can be enhanced if the development strategies would be designed and delivered in a way that addresses political and cultural differences between donors and recipients, and if donors implement more socially liberal policies for the freer movement of people, i.e., human capital. 


\title{
1. Government ideology in donor and recipient countries: Does ideological proximity matter for the effectiveness of aid?
}

\begin{abstract}
Political misalignment and greater ideological distance between donor and recipient governments may render foreign aid less effective by adding to transaction costs and eroding trust. We test this hypothesis empirically by considering the political ideology of both governments along the left-right spectrum in augmented models on the economic growth effects of aid. Following the estimation approach of Clemens et al. (2012), we find that aid tends to be less effective when political ideology differs between the donor and the recipient.
\end{abstract}

Keywords: aid effectiveness, economic growth, politics and aid, government ideology

JEL codes: O19, O11, F35, F53

Acknowledgements: This chapter is a joint work with Axel Dreher and Peter Nunnenkamp. A similar version of this essay is published in the European Economic Review (doi:10.1016/..euroecorev.2015.07.004). I thank seminar participants of Globalization and Development research training group at the University of Goettingen and University of Hannover, participants of European Public Choice Conference in Cambridge 2014, CESIfo Political Economy Workshop in Dresden 2014 and the anonymous reviewers of the European Economic Review for useful comments and feedback. I also thank Jamie Parsons for proofreading. 


\subsection{Introduction}

The effect of a government's political ideology on its generosity in granting foreign aid has received considerable attention. Regarding aid effort, left-wing donor governments are generally perceived as being more generous; regarding aid allocation, they are expected to be more

altruistic in choosing their recipients. ${ }^{1}$ Also at the donor level, ideology has been shown to play a role in determining whether US legislators and their voters support or oppose foreign aid (Milner and Tingley 2010).

In contrast, scant attention has been paid to the political ideology of recipient governments. With the exception of Smets et al. (2013), who find that government ideology in recipient countries determines the success or failure of World Bank projects, the role of recipient governments' ideology for the effectiveness of aid has been neglected. What is more, the literature has ignored the ideological distance between donors and recipients along the left-right spectrum and its consequences for the effectiveness of aid.

We argue that this neglect represents an important gap in the aid effectiveness literature. In particular, we present a theory according to which the ideological proximity of a donor to a recipient government along the left-right spectrum improves the effectiveness of aid in promoting economic growth. We outline this theory in Section 2, where we argue that political proximity improves the effect of aid on growth because it increases trust within the donor-recipient pair and reduces transaction costs in bilateral aid relations. As we describe in Section 3, our empirical analysis follows the estimation approach of Clemens et al. (2012), augmenting the prominent aidgrowth study of Rajan and Subramanian (2008) with our indicators of ideological proximity between the governments of donor and recipient countries. Our estimation results in Section 4 show that aid tends to be less effective when the political ideology of the donor and the recipient differs. Section 5 concludes.

\footnotetext{
${ }^{1}$ The available evidence however is ambiguous in both regards. On the determinants of overall aid effort see Fuchs et al. (2014) and the literature given there. The role of the political ideology of donor governments in the allocation of aid is analyzed, inter alia, in Fleck and Kilby (2006), Dreher et al. (2015a), and Lskavyan (2014).
} 


\subsection{A theory of ideological proximity and aid effectiveness}

\section{Ideological proximity in the foreign aid literature}

According to Milner and Tingley (2010: 227), "Interests matter, but so does ideology" when explaining the votes of (US) legislators in favor of or against aid. In other words, legislators supporting aid do not only respond to the material interests of their constituencies or national strategic interests, but also to the ideological predisposition of their voters. In this paper, we argue that ideology is an important determinant of the effectiveness of aid. More specifically, we hypothesize that the ideological proximity of donor and recipient governments increases the chance that aid will affect growth in the recipient country positively.

Previous literature on the effectiveness of aid focuses on the recipient countries' quality of governance, institutions, and economic policies to explain differences in effectiveness between countries (e.g., Burnside and Dollar 2000, Rajan and Subramanian 2008). A fairly extensive literature addresses the question of whether and how donors use aid as a means of rewarding political allies and buying political support from recipient countries. Thacker (1999) introduces the 'political proximity' hypothesis according to which political friends of major shareholders of international financial institutions are more likely to receive financial support than political enemies. At the same time, Thacker (1999) proposes a more dynamic 'political movement' hypothesis according to which less closely aligned recipient countries are still rewarded if they move towards the major shareholders' political position. Political proximity or movement in Thacker's reasoning relates to foreign policy affinity as revealed by UNGA voting patterns. Financial support between politically allied donors and recipients is also the focus of recent studies such as Stone (2004), Carter and Stone (2015) and Vreeland and Dreher (2014). Bueno de Mesquita and Smith (2009: 315) model the interplay of donors and recipients as "the granting of policy concessions by the recipient in exchange for cash (or in-kind) transfers by the donor." Dreher et al. (2014) show that aid granted to strategic allies is less effective in raising growth than other aid. ${ }^{2}$

In contrast, ideological proximity along the left-right axis of the governments of the donor and recipient country has received scant attention in the literature on aid effectiveness. Smets et al. (2013) show that government ideology in recipient countries determines the success or failure

\footnotetext{
${ }^{2}$ See also Headey (2008) and Bearce and Tirone (2010).
} 
of World Bank projects. They find that the quality of loans from the Bank is higher when the recipient country has a left-wing government, and that left-wing governments comply more fully with World Bank conditions. The World Bank is widely considered to be a 'conservative' bastion of the so-called Washington Consensus of business-friendly reforms. At other times, however, the Bank pushed issues that are more associated with the left - such as poverty reduction, better provision of social services, gender equality, and environmental conservation. Hence, it is hard to position the Bank along the ideological left-right axis of national governments. What is more, Smets et al. (2013) do not assess the growth effects of aid. To the best of our knowledge, our paper is the first to address ideological proximity within donor-recipient pairs, in terms of ideological orientation of the two governments, and to assess its effects on aid-induced growth in the recipient country.

The simple model depicted in Figure A1 in Appendix A portrays our theory on how ideological proximity within a donor-recipient pair changes the effectiveness of foreign aid. First, we argue that ideological proximity improves aid effectiveness by increasing trust within the donor-recipient pair. Second, we hypothesize that ideological proximity improves aid effectiveness by reducing transaction costs in bilateral aid relations. We discuss both transmission mechanisms in the following.

\section{Ideological proximity, trust, and aid effectiveness}

Before turning to the question of how ideological proximity increases trust between governments within a donor-recipient pair, we draw on the extensive literature revealing the effects of trust of various outcome variables. This literature offers relevant insights, even though it has rarely addressed aid effectiveness and the exact meaning and measurement of trust is clearly contextual. $^{3}$ In business economics, trust has repeatedly been identified as an important determinant of firm performance. For instance, Costa e Silva et al. (2012: 293) analyze the trustperformance relationship in international firm alliances and find "a strong and positive effect." Focusing on firms in India, Pakistan, Poland, and the United Kingdom, Jiang et al. (2011) conclude that trust helps build relationships with long-term perspectives in international business

\footnotetext{
3 It should be stressed at this point already that trust between governments, as introduced in Figure A1, is unobservable in our subsequent empirical analysis. Consequently, we do not aim at identifying and separating the effects of trust between governments on aid effectiveness, relative to other transmission channels such as transaction costs in our empirical analysis.
} 
markets. Firm-level studies also find positive indirect effects of trust, working via transaction costs, on information sharing and information quality among supply chain partners (e.g., Dyer and Chu 2003).

More closely related to the present macroeconomic context, it has been shown that "lower bilateral trust leads to less trade between two countries, less portfolio investment, and less direct investment" (Guiso et al. 2009: 1095). According to several studies, trust has positive effects on investment, growth and productivity (Zak and Knack 2001, Algan and Cahuc 2010, Bjørnskov and Méon 2013). Finally, Rathbun (2011) argues that trust encourages international cooperation. More precisely, Rathbun (2011: 243 and 268) refers to generalized trust as "an ideological belief about the trustworthiness of others" which allows for "cooperation in situations about which rationalists would be pessimistic and without the price that rationalists would expect."

In regards to aid effectiveness, mistrust between governments in a donor-recipient pair has adverse effects in an indirect way by increasing transaction costs (Figure A1). A lack of trust appears to be associated with dysfunctional bureaucratic and political behavior (see also Bigsten 2006). As indicated in Figure A1, the effect of trust on transaction costs can also work through the composition of aid. As shown in Bermeo (2010), the composition of aid indeed depends on the strengths of existing ties between donors and recipients. She also shows that the amount of aid given depends on the recipient's capacity to use the aid. Unless donors are confident that recipients use aid productively, they tend to prefer a hands-on approach and disburse aid "in the form of hundreds of separate donor-managed projects" (Knack and Rahman 2007: 177), rather than in the form of general budget support and program-based approaches. In other words, a lower degree of trust would be associated with a higher share of project-specific support in the total aid received. ${ }^{4}$ Aid divided into many packets involves considerable transaction costs related to intensive negotiation and distinct management and reporting requirements (Acharya et al. 2006: 6). It also adds to poaching, i.e., donors absorbing talented local staff to improve their own project-related management and control - even though this often crowds out more productive local development activities (Knack and Rahman 2007). In contrast to project-specific aid, general budget support is widely believed to reduce transaction costs. According to Koeberle and

\footnotetext{
${ }^{4}$ The analysis of different aid allocation channels by Dietrich (2013) suggests that the share of government-togovernment transfers of aid generally declines under such conditions, in favor of aid channeled through nongovernmental organizations (NGOs). However, such a shift could also result in relatively high transaction costs (Acharya et al. 2006).
} 
Stavreski (2006: 21), "reduction of transaction costs is one of the key objectives of providing budget support. Compared to other aid modalities, the expectation is that budget support reduces the need for separate audits, project management, or implementation planning."

A lack of trust and disparate views on how to use aid are also likely to impair aid effectiveness by giving rise to incentive problems with regard to conditionality. Donors feel compelled to impose detailed conditions to justify aid to their political constituency at home, even though conditionality often fails to work (e.g., Collier 1997, Vreeland 2006). Recipients are particularly tempted under such conditions to evade conditionality by diverting aid. As a result, the effectiveness of aid is reduced by time-consuming and resource-absorbing negotiations over reform programs and control mechanisms to ensure better compliance. Conversely, greater trust encourages the decentralization of responsibility for aid programming to the recipient country level. According to Clay et al. (2008), such a decentralization of responsibility is closely linked with the untying of aid. Tied aid is generally seen as less effective and efficient. ${ }^{6}$ To the extent that trusting donors untie their aid, such changes in the composition of aid would increase its effect on growth.

Compared to the effects of trust on aid effectiveness, it may be less obvious how ideological proximity increases trust within a donor-recipient pair. All the same, it can be plausibly argued that ideological proximity renders it easier to trust a partner country as common ideological beliefs narrow the range of possible contingencies and limit the scope of opportunistic behavior. Cheating is less likely in pairs of ideologically closer countries than in pairs of ideologically distant ones. ${ }^{7}$ Borrowing from Rathbun (2011: 244), ideological proximity can be considered to be "part of a belief system, a particular way of looking at the world," which makes partner countries believe "that others are largely trustworthy." Ideological proximity thereby reduces problems of asymmetric information and the associated problems of writing complete and enforceable contracts, i.e., problems that are widely perceived to hinder mutually beneficial

\footnotetext{
${ }^{5}$ Lawson et al. (2003: 11) note: "Countries with a large number of projects and multiple donors each with their own reporting and accounting requirements face high transaction costs in the delivery of aid. In contrast, GBS [general budget support] can be managed and monitored through a single multi-donor process, allowing senior government officials to devote time to policy making, instead of dealing with large number of individual project missions." Extensive evaluation reports tend to support this view (Lawson et al. 2003, Lister and Carter 2006). Importantly, however, for general budget support to reduce transaction costs, governance and institutions in the recipient country would have to be sufficiently developed (Cordella and Dell'Ariccia 2007, Dietrich 2013).

${ }^{6}$ See Clay et al. (2008) and the literature cited there.

${ }^{7}$ See also Zak and Knack (2001: 317) who show in a principal-agent model that "cheating is more likely (and trust is therefore lower) when the social distance between agents is larger."
} 
economic transactions (see Spring and Grossmann 2013 and the literature given there). International associations of like-minded political parties, including the Socialist International and the International Democrat Union, as well as political foundations engaged in development cooperation and aid, offer specific conduits through which such problems may be contained and trust can be built. ${ }^{8}$

The plausibility of our theoretical reasoning is underscored by previous empirical studies on the effects of trust on international trade and investment. In particular, Guiso et al. (2009) include a measure of religious proximity of partner countries to account for the endogenous nature of trust. The underlying argument, similar to the reasoning above, is that religious proximity shapes common beliefs and thereby increases trust. Religious beliefs of the people in a pair of partner countries may be particularly relevant for identifying the impact of trust on private sector transactions such as trade and investment. ${ }^{9}$ In contrast, beliefs related to the political ideology of governments are probably more relevant in the context of official transfers such as foreign aid. ${ }^{10}$

\section{Ideological proximity, transaction costs, and aid effectiveness}

Recent research as well as various political initiatives to reform the aid system clearly point to the adverse effects of higher transaction costs on aid effectiveness. In scholarly debate, high transaction costs related to the delivery and management of aid are widely viewed "as detracting from aid's value" (Knack and Rahman 2007: 178). As noted by Bigsten (2006), the view that the costs of transferring aid render it ineffective can be traced back to Bauer (1971: 99): "It is by no means unusual for projects to absorb domestic inputs of greater value than net output, especially when the cost of administering the projects ... is also considered." More recently, Kanbur (2006: 1579) observed that the mechanisms adopted by donors to track and monitor aid flows "are very intensive in terms of recipient capacity."

\footnotetext{
${ }^{8}$ For instance, the Socialist International "works intensively throughout the year to strengthen and develop social democratic policies in the world" (http://www.socialistinternational.org/). The International Democrat Union "provides a forum in which political parties holding similar beliefs ... act cooperatively, establish contacts, and present a unified voice toward the promotion of centre-right policies across the globe" (http://www.idu.org/).

${ }^{9}$ In the study of Costa e Silva et al. (2012: 293) on international business alliances, "shared values" in terms of common motives and objectives are among the "key antecedents identified as significant influencers on trust."

${ }^{10}$ In another strand of related literature, Fischer (2011) finds that personal trust in political institutions is higher if the government's ideology matches with personal political leanings.
} 
These insights have led to political initiatives such as the so-called Paris Declaration of 2005 in which donors and recipients committed themselves to render aid more effective. The Paris Declaration lists various aspects of misaligned donor-recipient relations giving rise to higher transaction costs. ${ }^{11}$ For instance, it states that donors have traditionally been reluctant to "respect partner country leadership" and "base their overall support on partner countries' national development strategies, institutions and procedures" (paragraphs 15 and 16). Furthermore, partner countries and donors have often failed to "work together to establish mutually agreed frameworks that provide reliable assessments of performance" (paragraph 19). The subsequent Accra Agenda for Action of 2008 reiterated previous commitments, including the call on donors to "work with developing countries to agree on a limited set of mutually agreed conditions based on national development strategies" (paragraph 25).

In light of scholarly insights and political commitments, one may wonder why high transaction costs continue to impair the effectiveness of aid. We are not aware of any comprehensive assessments of this question. The OECD's own monitoring of the Paris Declaration indicates that progress in implementing the proposals for reducing transaction costs has remained modest and partial at best, but the OECD's monitoring hardly addresses the reasons for persistent implementation deficits. ${ }^{12}$ In the following, we argue that diverging political ideology contributes to misaligned donor-recipient relationships and increases the associated transaction costs of the delivery and management of aid.

As noted by Milner and Tingley (2010), it is widely accepted that political ideology shapes aid policy. Focusing on the traditional left-right political divide, the left is commonly assumed to rely on government intervention in order to achieve a less unequal distribution of income and wealth and alleviate absolute poverty; the right is commonly assumed to rely on markets, individual effort and private business to promote economic growth. Accordingly, ideological distance within a donor-recipient pair implies that the left-wing member of the pair holds the belief that aid should primarily be used as a means of redistribution and poverty alleviation, while the right-wing member holds the belief that aid, if deemed necessary at all, should ultimately promote private sector development. Clearly, negotiating aid programs and projects is more difficult, time-consuming, and costly when the donor and the recipient hold such

\footnotetext{
${ }^{11}$ For details, see http://www.oecd.org/dac/effectiveness/34428351.pdf (accessed: June 2013).

12 For details, see the 2008 Survey on Monitoring the Paris Declaration (http://www.oecd.org/development/effectiveness/41202121.pdf; accessed: June 2013).
} 
diverging views on the major purposes of aid transfers. In contrast, transaction costs tend to be lower when ideologically closer donor-recipient pairs fundamentally agree ex ante on the major objectives aid might help achieve.

In addition, ideological proximity also helps reduce transaction costs ex post, i.e., after an aid transfer is made. If the donor and recipient agree beforehand on how aid should principally be used, the recipient has less reason to evade donor conditions ex post and enforce his own priorities by exploiting the fungibility of aid and redirecting local funds to preferred uses. The donor would then have less reason to spend resources on extensive monitoring in order to avoid being cheated by ideologically distant recipients after the aid transfer has been made. ${ }^{13}$ Less intrusive monitoring of aid relations between ideologically closer donors and recipients could reduce so-called 'phantom aid' (ActionAid International 2005: 17) and, correspondingly, increase the share of aid that can actually be used productively in the recipient country.

In both stages, before and after an aid transfer, ideological proximity within a pair renders it easier for the donor to meet the above-noted requirements that the Paris Declaration deems necessary to reduce aid-related transaction costs. Specifically, donors will find it easier to "respect partner country leadership" and "base their overall support on partner countries' national development strategies, institutions and procedures" (paragraphs 15 and 16 of the Paris Declaration) in pairs with ideologically closer recipients. Also, it becomes more likely in such pairs that donors will "work with developing countries to agree on a limited set of mutually agreed conditions based on national development strategies" (paragraph 25 of the Accra Agenda for Action). Note that the above reasoning on ideological proximity and aid-related transaction costs resembles the notion of (cultural) proximity commonly applied in gravity-type models on bilateral trade and foreign direct investment. These models routinely use manifestations of cultural proximity - e.g., in terms of common language, religion, and legal systems - to account for transaction costs within pairs of trading or investment partners (e.g., Elkins et al. 2006). The ideological proximity of governments may play a minor role in capturing transaction costs in private-sector exchanges related to trade and investment, but is likely to figure prominently in government-to-government transfers of official aid.

\footnotetext{
${ }^{13}$ For a similar line of reasoning see Bjørnskov and Méon (2013).
} 


\section{Refinement and qualifications}

The theoretical framework outlined so far applies to different manifestations of ideological distance between donor and recipient governments. Lack of trust and high transaction costs impair the effectiveness of aid regardless of which government in a donor-recipient pair is on the left or right of the ideological spectrum. Nevertheless, one might suspect that incentive problems are particularly pronounced when the donor is left-wing while the recipient is right-wing. Azam and Laffont (2003) model aid as a contract where the donor government transfers aid in return for poverty reduction by the recipient government. In contrast to the donor who is assumed to be purely altruistic, the recipient government also cares for the welfare of the ruling elite. Likewise, Torsvik (2005) assumes donors to be 'poverty averse.' Governments in the recipient country can strategically exploit the altruism of donors by diverting funds from poverty alleviation efforts to the local elite. Arguably, the likelihood that the effectiveness of aid suffers from such diversion is particularly high with principal-agent problems between a left-wing donor and a right-wing recipient.

Furthermore, ideological proximity does not necessarily have the same effects on the growth-impact of aid when it comes to aligned left-wing pairs or, alternatively, aligned rightwing pairs. As noted above, left-wing governments are commonly assumed to aim at a fair distribution of income and wealth, while right-wing governments tend to favor private-sector development over redistribution. Consequently, proximity at opposite ends of the ideological spectrum can be expected to be associated with a different composition of aid (see Figure A1): Proximity at the left would imply a higher share of aid in social sectors such as education, health, and water and sanitation; proximity at the right would imply a higher share of aid in production sectors and business-related infrastructure. The different composition of aid may, in turn, influence the effectiveness of aid, e.g., if the growth effects of early-impact aid in the area of physical infrastructure are more immediate than the growth effects of aid aimed at improved social services delivery (Clemens et al. 2012). ${ }^{14}$

\footnotetext{
${ }^{14}$ However, other studies show that early-impact aid is not a robust predictor of growth (Rajan and Subramanian 2008, Bjørnskov 2013). A major drawback with this measure is that disaggregated aid disbursements are not available for the entire period, so that disbursements have to be estimated based on commitments. Data on commitments in the earlier periods suffer from severe underreporting, too, however, which is not addressed in Clemens et al. (2012). (see OECD/DAC CRS Guide, Coverage Ratios, accessed on March 3, 2014: http://www.oecd.org/dac/stats/crsguide.htm).
} 
Our main hypothesis that ideological proximity of donor and recipient governments improves the effectiveness of aid also needs to be qualified insofar as aid relations between ideologically close donor-recipient pairs may encourage favoritism. ${ }^{15}$ The effectiveness of aid in promoting economic development would be impaired to the extent that funds are diverted from more deserving recipients to ideologically favored ones. ${ }^{16}$ If donors systematically allocated more aid to recipients of the same ideological orientation, the effectiveness of aid would suffer from declining marginal returns, compared to a selection of aid projects that is not biased by ideological proximity and based on expected marginal returns exclusively. ${ }^{17}$ What is more, for any given amount of aid, ideologically close recipients may be able to extract projects that would otherwise not be granted because of quality concerns, further reducing the effectiveness of aid.

If ideologically motivated favoritism dominates the politicians' utility function, less effort might be spent on the ground to promote developmental objectives. Favoritism might thus allow projects to be pursued where important preconditions are not met or might reduce time and resources devoted to the preparation of a project (Kilby 2013, 2015). On the donor side, bureaucrats may not interfere with their political masters' preference for ideologically aligned recipient governments, as that might threaten the advancement of their careers in the aid agencies. From the recipients' perspective, aid inflows from ideologically aligned donor governments could be anticipated to persist even if important policy reforms to promote economic growth were delayed. In addition, ideologically aligned donor governments may continue to deliver aid through government-to-government transfers, even though bypassing recipient governments and delivering aid through NGOs could improve the effectiveness of aid under conditions of bad governance and weak institutions (Dietrich 2013).

Faye and Niehaus (2012) discuss another channel through which ideological proximity between the donor and the recipient could reduce the effectiveness of aid. They show that aid from donors to ideologically close recipients might fuel political business cycles by increasing aid transfers prior to an election. Aid thus allows incumbent governments to distort the economy,

\footnotetext{
${ }^{15}$ On the other hand, favoritism in terms of relaxing conditions which could have enhanced the growth effects of aid could prevail in looser aid relationships where donors use aid as a temporary bargaining chip to gain political or economic support from ideologically distant recipient countries, compared to more permanent aid relationships with ideologically closer recipients. Note that this argument resembles the above-noted 'political movement' hypothesis of Thacker (1999), rather than the 'political proximity' hypothesis.

${ }^{16}$ The previous literature shows that this might indeed be the case. For example, Bermeo (2010) finds that donors give more aid to countries with which they have strong existing ties.

${ }^{17}$ Note that we account for this possibility by including aid squared in our estimations.
} 
which might reduce growth rates in the medium and longer run (after the immediate stimulating effect of expansionary electoral policies evaporates).

Finally, donor inertia and the persistence of multi-year funding and allocation decisions work against finding significant effects of ideological proximity on the growth impact of foreign aid. Inertia and limited flexibility to adjust aid commitments for projects extending over several years weaken the link between ideological donor-recipient alignment and aid allocation. In particular, donor reactions to changes in the ideological orientation of the government in recipient countries, e.g., after elections, would be attenuated and delayed. On a more positive note, the moderating effect of multi-year funding and allocation decisions implies that we would err on the 'conservative' side; significant results on the growth impact of ideological proximity within donor-recipient pairs are unlikely to be biased upwards.

\subsection{Data and method}

A substantial amount of literature investigates the question of whether and to what extent aid affects growth. Many of the contributors to this literature are divided into different camps, with groups of supporters finding that aid is effective and skeptics pointing to the lack of robustness of these results to the choice of control variables, samples, and methods of estimation (Roodman 2007, Doucouliagos and Paldam 2009). Rather than propagating our own model, therefore, we closely follow the approach in Clemens et al. (2012) and add our variables of interest to some of their models. Clemens et al. show that the most prominent previous attempts to control for the potential endogeneity of aid rely on invalid instruments. Instead of suggesting more valid ones, Clemens et al. address the potential endogeneity of aid by differencing the regression equation and lagging aid so that it can reasonably be expected to cause growth rather than being its effect. We base our analysis on their permutations of Rajan and Subramanian (2008) - one of the studies that arguably gained most attention in the recent literature on aid and growth. We follow this prominent previous analysis, and add our measures for ideological proximity (and their interaction with aid) to its main equations. ${ }^{18}$ We rely on Clemens et al.'s specification following Burnside and Dollar (2000) to test robustness.

\footnotetext{
${ }^{18}$ A skeptical reader might argue that the setup of Clemens et al. (2012) suffers from endogeneity. For example, donors might grant more aid to a newly elected reform-oriented government. Higher growth resulting from these reforms could then spuriously be attributed to the increase in aid. On the other hand, donors might give more aid to countries where they anticipate shocks that will reduce future growth rates. However, even if the direct estimate of
} 
In terms of timing, we focus on ideological alignment at the time the aid is disbursed. We assume that disbursed aid takes one five-year period to become effective, in either increasing or decreasing economic growth, following Clemens et al. (2012). As in Clemens et al. our reducedform empirical model is at the country-period level:

$\Delta \operatorname{rrowth}_{\mathrm{i}, \mathrm{t}}=\alpha+\beta \Delta A i d_{\mathrm{i}, \mathrm{t}-1}+\gamma \Delta\left(\operatorname{Aid}_{\mathrm{i}, \mathrm{t}-1}^{2}\right)+\delta A L I G N_{\mathrm{i}, \mathrm{t}-1}+\zeta \Delta A i d_{\mathrm{i}, \mathrm{t}-1} * A L I G N_{\mathrm{i}, \mathrm{t}-1}+\eta \Delta \boldsymbol{X}_{\mathrm{i}, \mathrm{t}}+\varepsilon_{\mathrm{i}, \mathrm{t}}$

where Growth $h_{\mathrm{i}, \mathrm{t}}$ is recipient country $i$ 's average yearly growth of GDP per capita over period $t$. We denote the amount of aid (in percent of GDP) disbursed in the previous period as Aid $_{\mathrm{i}, \mathrm{t}-1}$. $A L I G N_{i, t-1}$ is defined as recipient $i$ 's ideological proximity to the average donor, with amounts of aid received from a donor forming this donor's weight. Specifically, we calculate it as:

$$
A L I G N_{i, t-1}=\sum_{j=1}^{n} s_{i j, t-1} * d_{i j, t-1}
$$

where $s_{i j, t-1}$ is the aid share of donor $j$ in recipient country $i$ 's total bilateral aid from the $n$ members of the Development Assistance Committee (DAC) in period $t-1$; and $d_{i j, t-1}$ is ideological proximity of recipient country $i$ and donor $j$ at the time the aid is disbursed, measured as the absolute distance in political ideology between the recipient and the donor. ${ }^{19}$ We assign right-wing governments the value of one, center governments the value of two, and left-wing governments the value of three, based on the classification of Beck et al. (2001). Beck et al. code

aid is biased, we have no reason to expect a systematic bias for our variable of interest, the interaction of aid with ideological alignment for any given level of aid. As shown in Nizalova and Murtazashvili (2012: 2), "If all the regressors but the exogenous regressor and the interaction term between this exogenous regressor and an endogenous covariate are jointly independent of the exogenous regressor of interest, the OLS estimate of interaction term's coefficient is consistent." In the words of Nunn and Qian (2012), "interacting an arguably exogenous term [ideological distance between donors and recipients] with one that is potentially endogenous [foreign aid], can be interpreted as exogenous since we directly control for the main effect of the endogenous variable." The intuition follows that of a difference-in-difference estimation strategy. While aid can clearly be endogenous to growth, we argue that a differential effect of aid on growth in aligned and non-aligned recipient countries is unlikely to arise via channels other than aid. Below we control for foreign direct investment and trade (and also interact them with our alignment indicator), which are the most obvious channels that could threaten this identification strategy.

${ }^{19}$ Our approach of weighting with aid shares is similar to Spilimbergo's (2009) analysis of the role of individuals educated in democracies for democracy in their home country, where he weights the host country's level of democracy with the sending country's number of students there. 
political party orientation with respect to economic policies in these three categories. ${ }^{20}$ They assign a fourth category, "not applicable," when a party has no ideology with respect to economic policy. ${ }^{21}$ We assign these non-partisan governments the value of 2 , together with centrist governments. This is reasonable as governments in this category fall in between left-wing and right-wing ideologies (see also Aleman 2009).

Note that the Beck et al. (2001) data are unlikely to measure ideology in a way that makes governments' ideological positions perfectly comparable, in particular between countries that are substantially different, such as donors and recipients of foreign aid. Clearly, a social democratic government might be more closely aligned with a Christian-democratic government than with a communist one. In our coding, the former would however be more closely aligned with the latter. While we would like to use perfect data for our analysis, such data do not exist for the wide range of countries and years included in our sample. This explains why Beck et al.'s ideology data are widely used in the political science and economics literature (e.g., Dutt and Mitra 2005, 2006, Mukherjee et al. 2009, Ha 2012). ${ }^{22}$ Beck et al. compared their data with those in Huber and Inglehart (1995) and found the codings to be the same in the vast majority (see Keefer 2012). When we compare these data with Swank's (2009) Comparative Parties Data Set as well as with the Comparative Political Data Set from Armingeon et al. (2011), we find them to be significantly correlated at the one percent level. ${ }^{23}$ Most importantly, measurement error arising from blurred classifications of governments' ideology would render it less likely that we find significantly positive effects of ideological proximity on aid effectiveness. In other words, we err on the 'conservative' side given that wrong classifications (unless systematically biased) would work against us finding significant effects.

\footnotetext{
${ }^{20}$ According to Keefer (2012), right-wing parties are defined as "conservative, Christian democratic, or right-wing," left-wing parties are "communist, socialist, social democratic, or left-wing" and center refers to parties that are "centrist or when party position can best be described as centrist (e.g. party advocates strengthening private enterprise in a social-liberal context)."

${ }^{21}$ Specifically, "not applicable" is assigned when the party does not focus on economics, or there are competing ideological wings, or information about the party's program is not available. In almost half of these observations, the chief executive is either independent, the monarch, from the military, or parties do not exist at all. In our sample, this coding is applied to 116 countries in at least one period (36 percent of all observations).

${ }^{22}$ Some studies also use governments' ideology in a dyadic setting, as we do (e.g., Allee and Peinhardt 2010, Dreher and Jensen 2013, Carter and Stone 2014).

${ }^{23}$ Specifically, we rely on the indicator "Left party legislative seats as a percent of all legislative seats" from Swank's data and on Armingeon et al.'s indicator "Right-wing parties in percentage of total cabinet posts, weighted by days." We do not use these data in our regressions due to the limited samples they cover.
} 
Note also that our specification assumes that ideology can be treated as cardinal. Following Dutt and Mitra (2005), we tested this assumption using separate indicator variables for the three groups of ideology:

$\Delta$ Growth $_{\mathrm{i}, \mathrm{t}}=\alpha+\beta \Delta A i d_{\mathrm{i}, \mathrm{t}-1}+\delta_{1} \operatorname{LEFT}_{\mathrm{i}, \mathrm{t}-1}+\zeta_{1} \Delta A i d_{\mathrm{i}, \mathrm{t}-1} * \operatorname{LEFT}_{\mathrm{i}, \mathrm{t}-1}+\delta_{2} \operatorname{CENTER}_{\mathrm{i}, \mathrm{t}-1}+\zeta_{2} \Delta A i d_{\mathrm{i}, \mathrm{t}-1} * C E N T E R_{\mathrm{i}, \mathrm{t}-1}$ $+\varepsilon_{\mathrm{i}, \mathrm{t}}$

We test whether $\delta_{1}=2 \delta_{2}$ and $\zeta_{1}=2 \zeta_{2}$ holds simultaneously. At conventional levels of significance, we cannot reject this joint hypothesis, so that "there are efficiency gains from treating ideology as a cardinal measure, with equal distances between right and center and between center and left" (Dutt and Mitra 2005: 63). We therefore treat ideology as cardinal in all regressions below.

We calculate (mis-)alignment as the absolute difference between the value of ideology for the donor government and the value for the recipient government. The resulting measure thus ranges from zero when the donor and recipient governments are ideologically aligned to two indicating the maximum possible value of ideological misalignment. Multiplying bilateral differences with a donor's aid share results in the overall measure of aid-weighted ideological proximity for each year, which is then averaged over the respective period of time. All regressions include the control variables used in the original study, denoted $\boldsymbol{X}$, which we include contemporaneously. ${ }^{24}$ In some specifications we include aid squared to test for decreasing returns to aid, again following Clemens et al. (2012). Finally, $\varepsilon$ is an error term.

According to Clemens et al. (2012), the appropriate method to test for the effect of aid on economic growth has to account for the non-linear effect of aid, has to remove country fixedeffects through first-differencing, ${ }^{25}$ and has to lag aid by one period. As they argue, this specification minimizes potential misspecification due to reversed causality between aid and

\footnotetext{
${ }^{24}$ Following Rajan and Subramanian (2008), our regressions include: (log) initial GDP/capita, initial (Wacziarg and Welch's extension of Sachs and Warner's) trade policy index, (log) initial life expectancy, (log) inflation, initial M2/GDP, budget Balance/GDP, revolutions, and period dummies. The original study also includes time-invariant variables that are removed here (as in Clemens et al. 2012) through taking differences. Table A1 in the Appendix A reports the sources and definitions of all variables, while we show descriptive statistics in Table A2.

${ }^{25}$ Alternatively, one might want to estimate the regression in levels and control for country-fixed effects. When the variable of interest is an interacted variable, standard fixed effects estimation can imply spurious results when the coefficients of the interacted variables are heterogeneous across countries (Ozer-Balli and Sørensen 2013). In our case, the effect of aid on growth might well differ across recipient countries. When we estimate the regression with country-fixed effects we therefore demean the interacted variables within each country before interacting them. Our main results are unaffected, as can be seen in Appendix A, Table A3. We thank an anonymous reviewer for alerting us of this possibility.
} 
growth, and omitted variables bias. This is our preferred estimation strategy. We report the results in the next section.

\subsection{Results}

Table 1.1 shows the results for the Rajan and Subramanian (RS) regressions using the extended data of Clemens et al. (2012), which we updated to cover the 1975-2010 period. ${ }^{26}$ All data are averaged over five years. The dependent variable is the (change in the) average annual growth rate of real GDP per capita; we measure aid as (the change in) gross bilateral Official Development Assistance (ODA) as a percentage of GDP. ${ }^{27}$ We control for multilateral aid for which we cannot calculate ideological alignment but which might be used to substitute for ideologically motivated changes in bilateral aid and might thus bias our results if omitted. We also include repayments of bilateral and multilateral aid. ${ }^{28}$ However, none of them turns out to be robustly significant in our estimates below.

Column 1 of Table 1.1 does not include our ideological alignment measure. As can be seen, average bilateral aid increases economic growth at the ten percent level of significance. In column 2 we include the aid-weighted ideological alignment (ALIGN) and column 3 adds its interaction with aid. The results show an insignificant coefficient for ideological alignment itself, but a significant and negative interaction, at the one percent level. We are interested in the marginal effect of aid, which depends on the value of ideological alignment. In terms of the notation in equation (1), the marginal effect of $\triangle A i d$ amounts to $\beta+\zeta A L I G N_{\mathrm{i}, \mathrm{t}-1}$. We calculate it over the range of ideological distance in our sample, from zero to two, and show the result in Figure 1.1, together with the 90 percent confidence interval.

As is obvious from the negative coefficient of the interaction term $(\zeta)$, Figure 1.1 shows the marginal effect of changes in aid to decrease with ideological distance. Calculated at average distance (which is 0.94), the marginal effect implies that an increase in aid by one percentage point increases growth by 0.24 percentage points, at the ten percent level of significance. At the

\footnotetext{
${ }^{26}$ The sample is limited by the availability of political ideology in Beck et al. (2001), which is not available prior to 1975.

${ }^{27}$ Clemens et al. (2012) calculated the data for GDP per capita growth based on the Penn World Table up to 2004 and the World Development Indicators for the year 2005, as described in the technical appendix to Clemens et al. (2012). We updated GDP per capita growth until 2010 based on the Penn World Table 7.1.

${ }^{28}$ While we think it is superior to allow for separate coefficients on gross aid and repayments, we tested the robustness of our results to using net ODA (and omitting repayments) instead. As can be seen in Appendix A, Table A4, our results are not affected by this.
} 
lowest ideological distance of zero, a one percentage point increase of bilateral aid increases GDP per capita growth by 0.85 percentage points (which is statistically significant at the one percent level). By contrast, at the highest ideological distance of two, one percentage point increase in bilateral aid decreases GDP per capita growth by 0.44 percentage points, statistically significant at ten percent level.

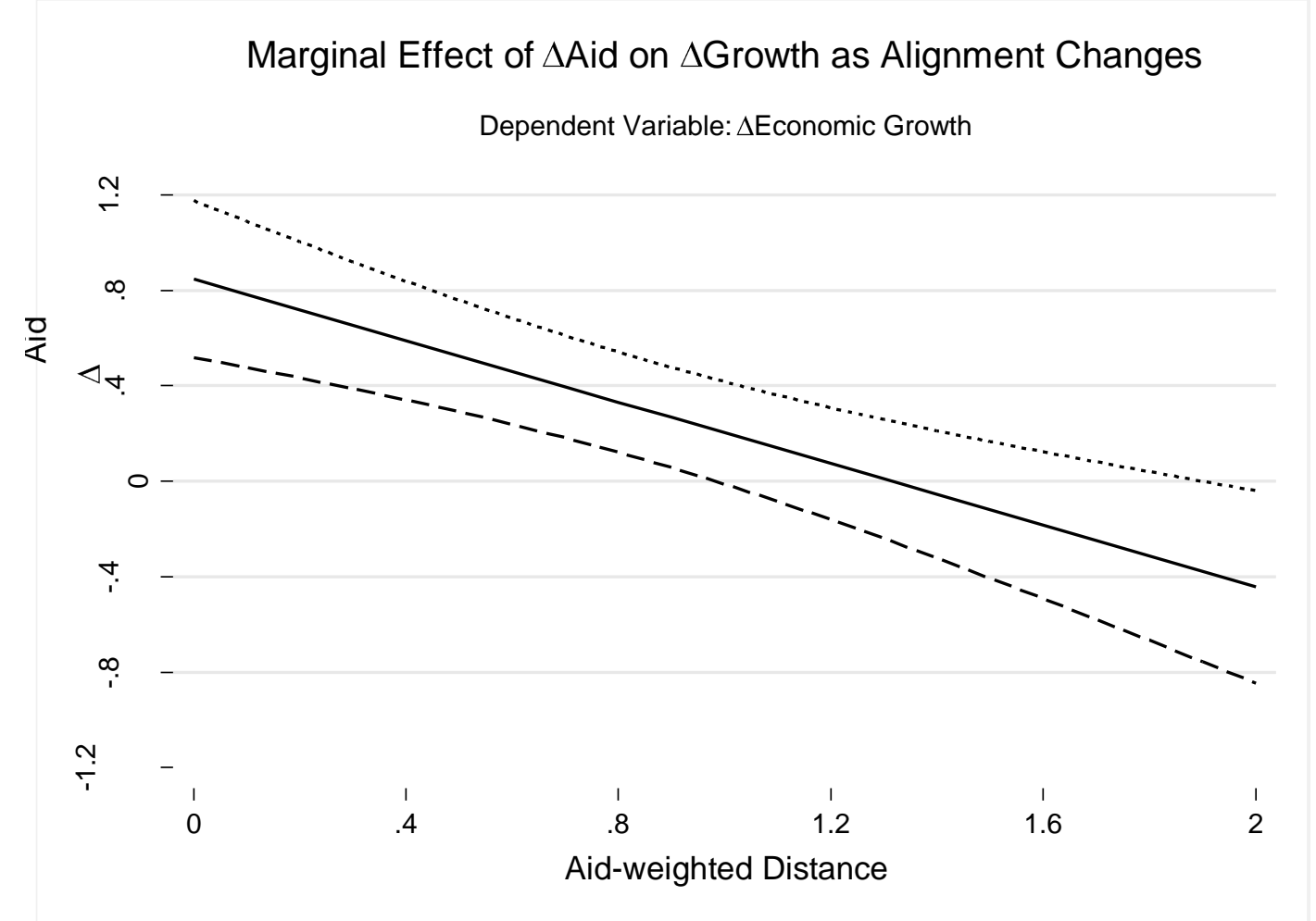

Figure 1.1 Marginal effect of $\Delta$ aid on $\Delta$ growth as political alignment changes

To put these results in perspective, consider the marginal effects of the control variables. The statistically significant variables include (log) initial GDP per capita, (log) inflation, and revolutions. According to column 3, the coefficient on initial GDP per capita implies that growth decreases by 0.74 percentage points when initial GDP per capita increases by ten percent. Our model also shows that each additional revolution decreases GDP per capita growth by 0.77 percentage points. When inflation increases by ten percent, GDP per capita growth decreases by 
0.12 percentage points. Overall, the effect of ideological distance on the marginal effect of aid on growth is clearly not negligible, compared to the other variables in the model. ${ }^{29}$

In column 4 we add squared terms for the aid variables and column 5 adds the interaction of bilateral aid squared with $A L I G N$. The results show that aid squared and its interaction with ALIGN are not significant at conventional levels. Decreasing returns to aid do not seem to play a role here, and neither does the impact of ideological distance depend on the amount of aid in a non-linear way. ${ }^{30}$

In Table 1.2 we replace total bilateral aid, aid-weighted ideological distance, and their interaction by two separate aid variables indicating the amount of aid received from aligned and non-aligned donors, respectively. Specifically, bilateral aid from aligned donors is the sum of aid disbursements to GDP in each year from donors with zero ideological distance to the particular recipient, averaged over the respective period of time. Bilateral aid from non-aligned donors is calculated in analogy for aid relationships in which the donor is left-wing and the recipient is right-wing, or vice versa. In other words, we contrast aid relations of donors and recipients at opposite ends of the ideological spectrum, omitting aid relations with an ideological distance of "one," i.e., where either the donor or the recipient is in the political center. We however also show regressions including such aid, and regressions including aid relations involving either a recipient or a donor in the center. ${ }^{31}$

Table 1.2 shows that aid in misaligned relationships hurts growth, while aid in ideologically aligned relationships does not affect growth at conventional levels of significance (column 1). When we include two separate squared terms for the two types of aid (in column 2), there do not seem to be decreasing (or increasing) returns to scale from aid donated by ideologically aligned donors. At the same time, the squared term is statistically significant at the

\footnotetext{
${ }^{29}$ One might argue that the effect of non-alignment could be driven by recipient country ideology alone, rather than by differences between the ideology of donors and recipients. As stressed by an anonymous reviewer, our aidweighted alignment variable is correlated with the ideology of recipients unless their aid inflows are balanced between donors of different ideology. However, the correlation proves to be modest, with a coefficient of 0.289. All the same, we included the recipient's ideology and its interaction with aid to the regression, so that variation in alignment reflects donor rather than recipient ideology. While the effectiveness of aid does depend on recipient ideology, the interaction between aid and political alignment is hardly affected by the inclusion of these additional variables (see Appendix A, Table A5). We also replicated the regression including aid from left donors, center donors and right donors separately, controlling for recipient ideology. As can be seen in Table A5, the coefficients and significances of these different types of aid differ to some extent. We reject the hypothesis of equal coefficients across the three types of aid at the one percent level of significance.

${ }^{30}$ Interestingly, the effect of multilateral aid repayments turns out to be significant in this specification. We find that multilateral aid repayments reduce growth when being low, but increase growth when being high.

${ }^{31} \mathrm{We}$ do not report the results for the control variables in the table to reduce clutter.
} 
five percent level for aid from donors of opposite ideology. Misaligned aid decreases growth once it exceeds 1.25 percent of GDP.

Columns 3 and 4 include an additional aid variable capturing "less mis-aligned" (or "less aligned") aid relationships, where either the donor or the recipient has a center government (but not both). As in the analysis above, we include "other" types of governments in the center category. However, we control for this category ("Aid undefined distance"). ${ }^{32}$ When squared terms are excluded (column 3), it seems that aid from less aligned donors increases growth, while aid from aligned and non-aligned donors has no significant effect. However, column 4 shows that the effect is again non-linear, with aid from non-aligned donors reducing the effectiveness of aid if given in abundance (the turning point being aid in the order of 4.6 percent of GDP), but aid from less aligned and aligned donors increasing growth.

As a next step, it is interesting to see whether all types of differences in the ideological orientation between the donor and recipient change the effectiveness of aid in the same way. Recall that we hypothesized incentive problems to loom particularly large when the donor is altruistic and poverty-averse, while the recipient government cares more for the welfare of the ruling elite and exploits the altruism of donors. This would imply that misalignment between a left-wing donor and a right-wing recipient would be more harmful for the effectiveness of aid than misalignment between a right-wing donor and a left-wing recipient.

We test this hypothesis in column 5 of Table 1.2. We introduce interactions between aligned and non-aligned donor-recipient pairs with variables measuring the share over a period that the recipient government was either left-wing or center (and right-wing recipients thus being the omitted category). As can be seen, aid in misaligned relationships is significantly negative when given by a right-wing donor to a center or left-wing recipient. ${ }^{33}$ The coefficient shows that the marginal effect of aid on growth is reduced by $0.70(0.76)$ percentage points when the donor is right-wing and the recipient is left-wing (center), compared to when the donor is left-wing and the recipient right-wing. The evidence is clearly in conflict with the hypothesis derived from the models of Azam and Laffont (2003) and Torsvik (2005). One may suspect that right-wing donor governments are more likely to use aid as a means of buying political support - not necessarily from traditional allies but also from left-wing recipient governments. Another possible

\footnotetext{
${ }^{32}$ When we exclude this variable results are qualitatively similar.

${ }^{33}$ When we include the squares of aligned and non-aligned aid these results are unchanged.
} 
explanation could be that right-wing donor governments are particularly intrusive in conditioning aid in their relations with left-wing recipients, thereby increasing transaction costs.

We next turn to potential explanations for the reduced effect of aid in non-aligned donorrecipient pairs. Recall that our theory attributes this effect to the lack of trust, higher transaction costs, and the composition of aid. While we lack the data to test for the role of trust and transaction costs, we can test the importance of the composition of aid. Given the availability of data on different modalities of aid delivery and the type of aid across recipient countries, it is possible to examine whether and to what extent the composition of aid differs between aligned and non-aligned donor-recipient pairs. While a detailed analysis is beyond the scope of this paper, Table A6 in Appendix A reports the share in a recipient's total aid that is tied, partially tied and untied according to alignment status as well as the shares of budget and project aid received. We find that ideologically aligned countries receive a lower share of their aid as tied aid, but a higher share as untied aid, significant at the one percent level, while there is no significant difference with respect to partially tied aid. This fits our theory well. To the contrary, aligned countries receive a lower share of their aid as budget aid, while the share in project aid does not differ significantly between aligned and non-aligned country pairs. There are no significant differences between the shares of aid in the social and private sector for aligned donor-recipient pairs on the right and left. Clearly, these bivariate correlations (and the levels of significances between them) could easily be driven by omitted variables. We leave a more detailed analysis of this question for future research.

Finally, we test to what extent the composition of aid is responsible for the effect of ideological distance on aid effectiveness. In Table A7 in the Appendix A we include the shares of tied and untied aid in our main regression (of column 3 in Table 1.1), with partially tied aid being the omitted category. These regressions therefore hold the influence of the composition of aid constant. If the effect of ideological distance on the effectiveness of aid we found above arises exclusively from changes in the composition of aid, the interaction between changes in the overall amount of aid and $A L I G N$ should no longer be significant once we hold changes in the composition constant. To the extent that aid composition is no relevant transmission channel for our result, we expect the above finding to be unchanged.

Table A7 includes the same control variables as the main regressions above (column 3 of Table 1.1) but does not show them. The results are almost identical to those excluding the shares 
of tied and untied aid. We therefore conclude that the composition of aid does not account for our results. $^{34}$

We tested the robustness of our results in a number of ways, as detailed in Appendix A. We replicate the analysis using Clemens et al.'s (2012) permutations of Burnside and Dollar (2000). We use net rather than gross disbursements as dependent variable, control for non-DAC aid, humanitarian aid, inflowing refugees, and civil wars, include an interaction of multilateral aid with alignment, and include $A L I G N$ in changes rather than levels. Ideological alignment could be correlated with trade and foreign direct investment (FDI) patterns that affect the impact of alignment on the effectiveness of aid on growth. We therefore control for trade and FDI as a share of GDP. We also construct alignment measures using bilateral trade and FDI as weights, in analogy to how we calculated aid-weighted alignment, and include them in our regression. Governments in certain world regions might be more likely to receive aid from donors of particular ideology and the aid they receive might differ in effectiveness for reasons other than ideology. We therefore interact aid with dummies for five regions (East Asia and Pacific, Latin America and the Caribbean, Middle East and North Africa, South Asia, and Sub-Saharan Africa). Our results are robust to all these changes. Our results are weaker when we focus on early-impact aid instead of total aid. Arguably, the larger noise due to missing information on sectoral aid commitments and disbursements can explain these differences. We split the sample in a number of ways (along the lines of democracy, corruption, good policy, and the Cold War period) but do not find significant differences between these samples.

\footnotetext{
${ }^{34}$ We also tried to control for budget aid and project aid. However, the number of non-zero observations was too low to run these regressions. When we include the shares of social and private sector aid, the results are unchanged.
} 
Table 1.1 Political alignment and growth, 1975-2010, OLS

\begin{tabular}{|c|c|c|c|c|c|}
\hline Dependant variable: $\Delta$ Growth & $(1)$ & $(2)$ & (3) & (4) & $(5)$ \\
\hline \multirow[t]{2}{*}{ Aid/GDP } & $0.256^{*}$ & $0.267 * *$ & $0.848 * * *$ & $0.780 * * *$ & $1.042 * * *$ \\
\hline & {$[0.138]$} & {$[0.135]$} & [0.199] & {$[0.214]$} & {$[0.345]$} \\
\hline \multirow[t]{2}{*}{ Alignment } & & -0.542 & -0.601 & -0.548 & -0.470 \\
\hline & & {$[0.565]$} & {$[0.526]$} & {$[0.533]$} & {$[0.550]$} \\
\hline \multirow[t]{2}{*}{ Aid*Alignment } & & & $-0.645^{* * *}$ & $-0.623 * * *$ & $-0.928 * *$ \\
\hline & & & {$[0.181]$} & [0.199] & {$[0.390]$} \\
\hline \multirow[t]{2}{*}{ Multilateral aid } & -0.112 & -0.114 & -0.050 & 0.018 & 0.063 \\
\hline & {$[0.133]$} & {$[0.132]$} & {$[0.123]$} & {$[0.265]$} & {$[0.277]$} \\
\hline \multirow[t]{2}{*}{ Bilateral repayments } & $-0.637 * *$ & $-0.621^{*}$ & -0.457 & -1.018 & -0.963 \\
\hline & {$[0.318]$} & {$[0.319]$} & {$[0.297]$} & {$[0.843]$} & {$[0.844]$} \\
\hline \multirow[t]{2}{*}{ Multilateral repayments } & -0.737 & -0.820 & -0.273 & $-3.262 *$ & $-3.400^{*}$ \\
\hline & {$[0.752]$} & {$[0.810]$} & {$[0.695]$} & {$[1.768]$} & {$[1.776]$} \\
\hline \multirow{2}{*}{ Aid squared } & & & & 0.002 & -0.008 \\
\hline & & & & {$[0.007]$} & {$[0.015]$} \\
\hline \multirow[t]{2}{*}{ Bilateral repayments squared } & & & & 0.172 & 0.149 \\
\hline & & & & {$[0.206]$} & {$[0.206]$} \\
\hline \multirow[t]{2}{*}{ Multilateral repayments squared } & & & & $1.316^{* *}$ & $1.333 * *$ \\
\hline & & & & {$[0.649]$} & {$[0.651]$} \\
\hline \multirow[t]{2}{*}{ Multilateral aid squared } & & & & -0.001 & -0.005 \\
\hline & & & & {$[0.014]$} & {$[0.015]$} \\
\hline \multirow[t]{2}{*}{ Aid squared*Alignment } & & & & & 0.012 \\
\hline & & & & & {$[0.015]$} \\
\hline \multirow[t]{2}{*}{ Initial GDP p.c. $(\log )$} & $-8.138 * * *$ & $-7.830 * * *$ & $-7.729 * * *$ & $-7.808 * * *$ & $-7.832 * * *$ \\
\hline & {$[1.242]$} & [1.217] & [1.215] & [1.207] & [1.205] \\
\hline \multirow[t]{2}{*}{ Initial life expectancy $(\log )$} & -0.050 & -0.025 & -0.035 & -0.041 & -0.043 \\
\hline & {$[0.074]$} & {$[0.069]$} & {$[0.064]$} & {$[0.062]$} & [0.062] \\
\hline \multirow[t]{2}{*}{ Openness } & $0.899 * *$ & 0.500 & 0.429 & 0.400 & 0.400 \\
\hline & {$[0.428]$} & {$[0.481]$} & {$[0.473]$} & {$[0.483]$} & [0.484] \\
\hline \multirow{2}{*}{ Inflation (log) } & $-1.154 * * *$ & $-1.266 * * *$ & $-1.292 * * *$ & $-1.270 * *$ & $-1.257 * *$ \\
\hline & {$[0.385]$} & {$[0.484]$} & {$[0.491]$} & {$[0.493]$} & [0.498] \\
\hline \multirow[t]{2}{*}{ Initial M2/GDP } & $0.024 *$ & -0.017 & -0.017 & -0.022 & -0.023 \\
\hline & {$[0.014]$} & {$[0.021]$} & {$[0.021]$} & {$[0.021]$} & {$[0.021]$} \\
\hline \multirow[t]{2}{*}{ Budget Balance/GDP } & 0.109 & 0.087 & 0.106 & 0.087 & 0.089 \\
\hline & {$[0.120]$} & {$[0.117]$} & {$[0.118]$} & {$[0.124]$} & {$[0.126]$} \\
\hline \multirow[t]{2}{*}{ Revolutions } & $-0.614^{*}$ & $-0.683 * *$ & $-0.769 * *$ & $-0.776 * *$ & $-0.793 * *$ \\
\hline & {$[0.352]$} & {$[0.330]$} & {$[0.326]$} & {$[0.327]$} & {$[0.328]$} \\
\hline \multirow[t]{2}{*}{ Constant } & 0.344 & $2.662 *$ & $2.903 * *$ & $3.069 * *$ & $3.017 * *$ \\
\hline & {$[0.272]$} & {$[1.376]$} & [1.351] & {$[1.321]$} & [1.340] \\
\hline Adj. R-Squared & 0.258 & 0.315 & 0.339 & 0.336 & 0.335 \\
\hline Number of Countries & 67 & 67 & 67 & 67 & 67 \\
\hline Number of Observations & 299 & 299 & 299 & 299 & 299 \\
\hline
\end{tabular}


Table 1.2 Political alignment and growth, 1975-2010, OLS

\begin{tabular}{|c|c|c|c|c|c|}
\hline Dependant variable: $\Delta$ growth & $(1)$ & $(2)$ & (3) & (4) & $(5)$ \\
\hline Aid aligned & $\begin{array}{l}0.112 \\
{[0.184]}\end{array}$ & $\begin{array}{l}-0.185 \\
{[0.241]}\end{array}$ & $\begin{array}{c}0.33 \\
{[0.236]}\end{array}$ & $\begin{array}{l}-0.076 \\
{[0.331]}\end{array}$ & $\begin{array}{l}0.071 \\
{[0.246]}\end{array}$ \\
\hline Aid not aligned (left vs. right) & $\begin{array}{l}-0.247 * * \\
{[0.115]}\end{array}$ & $\begin{array}{l}0.098 \\
{[0.206]}\end{array}$ & $\begin{array}{l}-0.018 \\
{[0.182]}\end{array}$ & $\begin{array}{l}0.369 \\
{[0.305]}\end{array}$ & $\begin{array}{l}0.291 \\
{[0.294]}\end{array}$ \\
\hline Aid less aligned (center vs. left or right) & & & $\begin{array}{c}0.486^{* *} \\
{[0.198]}\end{array}$ & $\begin{array}{l}0.183 \\
{[0.274]}\end{array}$ & \\
\hline Aid undefined distance & & & $\begin{array}{l}-0.215 \\
{[0.157]}\end{array}$ & $\begin{array}{l}0.007 \\
{[0.238]}\end{array}$ & \\
\hline Aid squared aligned & & $\begin{array}{l}0.033 \\
{[0.023]}\end{array}$ & & $\begin{array}{c}0.051^{*} \\
{[0.027]}\end{array}$ & \\
\hline Aid squared not aligned & & $\begin{array}{l}-0.033^{* *} \\
{[0.016]}\end{array}$ & & $\begin{array}{l}-0.040 * * \\
{[0.018]}\end{array}$ & \\
\hline Aid squared less aligned & & & & $\begin{array}{c}0.019^{*} \\
{[0.010]}\end{array}$ & \\
\hline Aid squared undefined distance & & & & $\begin{array}{l}-0.015 \\
{[0.010]}\end{array}$ & \\
\hline Aid aligned*Left & & & & & $\begin{array}{l}-0.077 \\
{[0.350]}\end{array}$ \\
\hline Aid not aligned*Left & & & & & $\begin{array}{l}-0.746^{* *} \\
{[0.332]}\end{array}$ \\
\hline Aid aligned*Center & & & & & $\begin{array}{l}0.243 \\
{[0.422]}\end{array}$ \\
\hline Aid not aligned*Center & & & & & $\begin{array}{l}-0.836^{* *} \\
{[0.416]}\end{array}$ \\
\hline Left & & & & & $\begin{array}{l}-0.138 \\
{[0.432]}\end{array}$ \\
\hline Center & & & & & $\begin{array}{l}-0.468 \\
{[0.459]}\end{array}$ \\
\hline Adj. R-Squared & 0.307 & 0.315 & 0.326 & 0.334 & 0.313 \\
\hline Number of Countries & 67 & 67 & 67 & 67 & 67 \\
\hline Number of Observations & 299 & 299 & 299 & 299 & 299 \\
\hline
\end{tabular}

OLS panel estimation in first differences: country fixed effects. All regressions include period dummies. All aid variables are in percent of recipient country's GDP. Aid denotes gross bilateral aid. Aid and Alignment variablea are lagged once. The regressions include the same controls as in Table 1.1. Significance levels $* p<0.10, * * p<0.05, * * * p<0.01$. 


\subsection{Conclusions}

Previous studies on the economic growth effects of foreign aid focused on factors such as the quality of governance, institutions and economic policies in recipient countries to explain differences in the effectiveness of aid. By contrast, the political ideology of governments and the ideological proximity between donors and recipients along the left-right spectrum have received scant attention. Theoretically, we argue that ideological proximity improves the effectiveness of aid by generating trust and reducing transaction costs.

We test this hypothesis empirically by considering the political ideology of donor and recipient governments along the left-right spectrum. We account for ideological proximity by augmenting the prominent aid-growth study of Rajan and Subramanian (2008), interacting the aid variable with our indicators of ideological proximity. We follow the approach of Clemens et al. (2012) and mitigate potential endogeneity problems by estimating the augmented models in first differences. Our identification strategy follows the intuition of a difference-in-difference approach, where we argue that a differential effect of aid on growth in aligned and non-aligned recipient countries is unlikely to arise via channels other than aid (even if the level of aid itself would be endogenous to growth).

We find that aid tends to be less effective when political ideology differs between the donor and the recipient. The interaction between aid and ideological distance is significantly negative. At the lowest ideological distance, a one percentage point increase of bilateral aid increases GDP per capita growth by 0.79 percentage points, while it decreases growth by 0.64 percentage points at the highest level of ideological distance. Furthermore, the negative effect of ideological distance between the governments of donor and recipient countries on the effectiveness of aid is corroborated when replacing the interaction terms by separate aid variables, indicating the amount of aid received by ideologically aligned and non-aligned donors, respectively. In contrast to aid from ideologically closer donors, aid from misaligned donors tends to be associated with significantly lower growth. We do not find evidence, however, that ideological misalignment is more harmful for growth if left-wing donors grant aid to right-wing recipients.

Further research could help disentangle the specific transmission mechanisms in our theory underlying our major finding that ideological misalignment between donors and recipients impairs the effectiveness of aid. Detailed country studies may reveal distinct characteristics of ideologically misaligned aid relationships, including transaction cost-increasing and growth- 
impairing intrusiveness on the part of donors and/or evasion of conditionality and monitoring on the part of recipients. A related question that could be analyzed in greater detail in country studies is whether ideologically misaligned donor-recipient relations erode trust and give rise to higher transaction costs by being associated with mission creep, fine-tuned aid and donor-managed projects.

In any case, our findings suggest that negative growth effects of aid were easier to avoid if donors focused on recipients with similar political ideology. This invites a new dimension of aid selectivity, in addition to targeting aid according to recipient need and merit. It also invites a new dimension of coordination among donors. It appears that it would be easier for donors to "respect partner country leadership," as the Paris Declaration has put it, and to reduce transaction costs if donors specialized not only according to comparative advantages they might have in certain countries or sectors, but also left ideologically misaligned recipients to donors with a closer fit in terms of political ideology. 


\title{
2. Your development or mine? Effects of donor-recipient cultural differences on the aid-growth nexus
}

\begin{abstract}
Development aid from the West may lead to adverse growth effects in the global South due to the neglected cultural differences between development aid (paradigm) providers and recipients. I test this hypothesis empirically by augmenting an aid-growth model with proxy variables for cultural differences between donors and recipients. First, I use donor-recipient genetic distance, i.e., blood types, to capture the traditional way of cultural transmission. Second, I use western education of recipient country leaders to capture resource-based transmission of culture. Results of the OLS panel estimation in first differences show that a one unit increase in donor-recipient genetic distance reduces the main effect of aid on growth by 0.2 percentage points when aid is increased by one percentage point. In turn, a one percentage point increase in aid yields on average a 0.3 percentage point increase in growth after a decade for countries with western educated leaders.
\end{abstract}

JEL classification: O11; O19

Keywords: aid effectiveness, cultural differences, genetic distance, western education

Acknowledgments: A similar version of this essay is published online in the Journal of Comparative Economics (doi:10.1016/i.jce.2015.07.002). This essay greatly benefited from feedback and comments from Axel Dreher and Stephan Klasen. In addition, I thank seminar participants at the University of Goettingen, the University of Hannover, the University of Heidelberg, Interdisciplinary Center of Economic Sciences at the George Mason University, participants at the 2014 Annual Conference on Economic Growth and Development in New Delhi, 2014 Annual Conference on Development Economics in Passau, 2013 Development Economics PhD workshop in Zurich and 2013 Summer School in Economic Growth at Warwick University as well as anonymous reviewers of the Journal of Comparative Economics for helpful comments and feedback. I also thank Jamie Parsons and Jennifer Phillips for proofreading. 


\subsection{Introduction}

It is a well-known fact that the raw data on development aid and economic growth are uncorrelated. For the last 50 years many authors have tried to overcome this fact by putting structure on the data. They have reached all results possible; see Doucouliagos and Paldam (2011, 2009) for a comprehensive bibliography. ${ }^{35}$ In particular, Doucouliagos and Paldam (2009) perform three meta-analyses for the unconditional, conditional and null strands of the aid effectiveness literature (AEL) and fail to find a statistically significant effect of aid on growth. ${ }^{36}$ They also note: "If there is an effect, it must be small" (2009, p. 457). This paper, therefore, explores one of the possible reasons for this negligible effect of aid on growth.

Aid is an intervention of a developed country into the society of the recipient country. When the two countries have very different belief systems and cultures this gives different preferences. This will easily lead to a mismatch between supply and demand in development transactions (Easterly, 2006) and diminish aid's effect on growth. ${ }^{37}$ This fact has been extensively documented through anecdotes (Bauer 1971, Escobar 1995, Easterly 2002, 2006, Moyo 2009, Altaf 2011, Coyne 2013), yet donor-recipient cultural differences have not been sufficiently addressed in the AEL. The literature rather focuses on recipient characteristics only when studying the aid-growth nexus. One exception is a study by Dreher et al. (2015a) that augments an aid-growth model with the donor-recipient differences in government ideology and its interaction with aid. They show that larger differences in donor-recipient political ideology reduce aid's effect on growth. This paper is closely related to that of Dreher et al. (2015a).

While the previous chapter explores the effect of donor-recipient differences in formal institutions (government ideology) on the aid-growth nexus, in this chapter, I examine that of the informal institutions (culture, beliefs and values). Hence, I argue that the theoretically expected positive effect of development aid on growth can be reduced or diminished due to the neglect of donor-recipient cultural differences in the development paradigms. Consequently, the contribution of this paper is the empirical test for the effect of donor-recipient cultural differences on the aid-growth nexus.

\footnotetext{
${ }^{35}$ Doucouliagos and Paldam (2011) update the meta-analysis from their 2009 study and find that some types of aid, such as program or project aid can be more effective than others.

36 See Burnside and Dollar (2000) and Dalgaard et al. (2004) for conditional, Hansen and Tarp (2001) for unconditional and Rajan and Subramanian (2008) for null effect of aid on growth.

${ }^{37}$ See Gibson et al. (2005) for a discussion of information asymmetry problems in aid transactions due to cultural differences.
} 
I conceptualize my hypothesis by analyzing relevant literature on the cultural underpinnings in development paradigms in Section 2. Anecdotal evidence in Section 3 shows how cultural differences can affect the aid-growth nexus. As described in Section 4, I use two proxy variables for cultural differences - genetic distance and western education of recipient country leaders - to measure their effect on the aid-growth nexus. Thereafter, following the technique in the previous chapter, I construct an aid-adjusted measure for the genetic distance between donors and recipients. I adopt the estimation method of Clemens et al. (2012) and augment an aid-growth model with proxy measures of donor-recipient cultural differences and their interactions with aid (Section 5), as in the previous chapter. The estimation results reported in Section 6 show that the effectiveness of aid is significantly reduced when a greater genetic distance exists between a recipient and western donors. In addition, results show that recipients with western educated leaders benefit from aid in the long run. The robustness tests presented in Section 7 reveal that donor-recipient differences in language and ethnicity do not have a statistically significant effect on the aid-growth nexus, and the main findings of this paper do not suffer from the inclusion of additional (omitted) variables. Section 8 concludes and provides policy implications.

\subsection{Cultural underpinnings in development paradigms}

Early development strategies evolved from modernization theories and practices in the West during the $20^{\text {th }}$ century (Bauer 1971, Escobar 1995, Gilman 2003, Radcliffe and Laurie 2006). Modernization, per se, is the transition from a traditional society into a modern one. It is characterized, on one hand, by cultural change (Inglehart and Baker 2000) and, on the other, by democracy, the development of a welfare state, egalitarianism, universal public education, income taxation and land reform (Gilman 2003). Modernity is premised upon rational technology and scientific knowledge: "It is the model of the West detached in some way from its geographical origins and locus" (Gilman 2003: 1).

Moreover, development discourses in the past century have been influenced by Talcott Parsons' functional sociology theory (1951), according to which certain types of thinking and behavior can benefit the modernization process (Gilman 2003, Turner 1999). A distinct characteristic of modernization is the change in beliefs and values that took place during the $20^{\text {th }}$ century in the West (Inglehart and Baker 2000). While changes in certain cultural beliefs and values accompanying modernization were internal to Western economies, in particular, to the United States (Rostow 1990) these were imposed externally on the diverse populations in the 
global South via the development processes (Escobar 1995). As Turner (1999) notes, in the 1950s and 1960s, policymakers in donor countries were encouraged to advocate modern cultural traits in aid recipient countries following Parsonian theory. Changing the beliefs, attitudes and behaviors of local people was seen as a way of "dragging them away from 'traditional' practices and introducing them to the modern Western culture" (Schech and Haggis 2000 cited in Radcliffe and Laurie 2006: 233). Academics and practitioners provide extensive anecdotal evidence, showing that the differences in preferences between donor and recipient countries can be part of the reason why development aid fails to generate long-term economic growth in recipient countries (Bauer 1971, Escobar 1995, Easterly 2002, Easterly 2006, Moyo 2009, Altaf 2011, Coyne 2013).

To illustrate, Moyo (2009) argues that foreign aid itself is largely responsible for Africa's underdevelopment. After examining how several aid projects have hindered the grassroots development, she concludes that foreign aid is destructive for African economies as it distorts incentives, perpetuates corruption and supports dysfunctional political elites. In relation to the aid paradigm for promoting democracy in African countries, Moyo writes: "In the early stages of development it matters little to a starving African family whether they can vote or not. Later they may care, but first of all they need food for today, and tomorrows to come, and that requires an economy that is growing" (Moyo 2009: 44).

Thus, applications of the conventional economic models of the West in the rest of the world can be largely responsible for development paradigm failures: in these models individual preferences are fixed in the assumptions of objective rationality. However, 'objective' rationality should not, and does not, always prevail when humans take actions in different times, places and contexts. Individuals may rather follow a subjective (bounded) rationality based on the existing options and alternatives available to them at a specific place and time (Kahneman 2003). Many prominent economic models for development arise from the rationality decisions available in Western societies but not necessarily in the rest. Therefore, development models that are taken to the aid recipient societies are rarely adjusted for such differences in culture. On that matter, Sen (2004) stresses the importance of studying how culture affects development in the presence of aid as it is highly influenced by the mainstream economists educated in the West.

On the other hand, Hodler and Dreher (2012) argue that development paradigms are unsuccessful because they are mainly pursued by those countries that are doomed to failure in the first place. But, at the same time, these paradigms fail to match with the country-specific 
circumstances. Clearly, differences in culture and belief systems can be part of the countryspecific circumstances. Culture is a type of local knowledge that is largely embedded in individuals, which makes it hard to measure (Gibson et al. 2005). How donor-recipient cultural differences can influence the aid-growth nexus is described through anecdotal evidence that follows. ${ }^{38}$

\subsection{Anecdotal evidence on cultural differences in development paradigms}

In the 1990s, Russia received thirteen structural adjustment loans to become a free-market economy after the collapse of the centrally-planned Soviet Union. The imposition of a market economy by donors onto the old Soviet enterprises was utopian: it was expected that, as in the West, the most competitive firms in Russia would drive out the inefficient ones based on the prices determined in the market. However, the opposite happened. Firms with influential managers were thriving with valuable inputs but worthless outputs. The networks and relationships with public officers and other firm managers outperformed supply and demand functions of the market and tax liabilities. The Soviet practice of doing business based on the informal rules, such as privileges and side-payments, carried on into the "imposed" market economy, and the efforts to transition failed. Such neglect of local practices of economic behavior in the western imposed structural adjustment programs was detrimental for the economic growth and progress in post-Soviet economies (Easterly 2006: 54). For example, Russia's economy recorded on average negative 5.7 percent growth rate from 1990-1999. During that decade, similar negative growth patterns were seen in Ukraine, Kazakhstan and the Kyrgyz Republic (Easterly 2006: 59). Meanwhile, Poland, Albania, Bulgaria, Romania, Hungry and Georgia experienced positive growth patterns.

In the 1950s and 1960s, the Ford Foundation spent millions of dollars with the purpose of training Indians on Western legal education and spreading ideas of democracy and rule of law. However, the American-style schools did not translate well to India due to the caste divisions, patronage politics, low respect for law as a subject, absenteeism, and bribing. All of these realities where not appropriately addressed in Ford's grant. An American law professor from

\footnotetext{
${ }^{38}$ The descriptive statistics in Table B3 in Appendix B based on the data in this paper do not reveal much information on cultural proximity and how it can affect growth in different countries at different periods since there is no direct correlation between genetic distance and economic growth. In this case, only through the regression analysis one is able to quantify the relation between cultural differences, measured by the genetic distance, and growth.
} 
Harvard stated that the Indian population did not embrace the legal system promoted by Ford because the laws in the books are Western rather than of local origin (Easterly 2006: 271). After observing Ford's failure, an Indian law professor educated in the West proposed a new law school model that imitated the structure of the highly respected engineering and medical schools in India. Later, the Ford Foundation and other locals supported the initiative and today it has become the well-respected National Law School of India. This case highlights the importance of local knowledge in bringing about desired structural and social changes.

In recent decades Ghana has continued to receive large amounts of foreign aid and the focus of the new paradigm has been good governance and the alleviation of poverty. Good governance also implies low levels of corruption in the country. However, foreign aid itself perpetuated corruption since the paradigm ignored how differently the practice of corruption is viewed in Ghana. Hasty (2005) specifies that corruption in Ghana is the use of public resources for social responsibility rather than for private gain as defined in the western lexicon. Premised upon power, privilege and responsibility, Ghanaian public officials have to satisfy so many social, cultural and material expectations of their extended family members and friends that it turns into an act of pleasure and intensifies the contacts. At the end of the day, the foreign aid money fails to serve its purpose and the economic growth in Ghana suffers from the increased levels of corruption, Ghana's average economic growth rate per capita over 1996-2000 was 2 percent while bilateral aid composed about 8 percent of its GDP. Ghana's corruption score in International Country Risk Guide decreased from 2.4 to 1.6 during the last decade. ${ }^{39}$

In the 2000s, the cultural changes implied by the well-intentioned development paradigms, such as women rights protection, secular education, mastery of state law over the customary law, have been controversial in Afghan society. The externally imposed social change created political opposition to the newly selected fragile government. The opponents argued that these policies were imported from the outside and aimed to destroy Afghan culture. Disconnections of Western experts from the realities of Afghanistan resulted in paradigm failure in reshaping the local economy (Coyne 2013:186). From 1996 to 2000, Afghanistan's average growth rate per capita was negative 9 percent, while in the following period it was on average 5 percent.

\footnotetext{
39 International Country Risk Guide measures corruption levels across countries and scales them from 1-6, where lower values indicate higher levels of corruption, see: ICRG (2012).
} 
Altaf (2011) presents a detailed account of the failure of the Social Action Program (SAP) in 1990s, which was developed by the government of Pakistan to fulfill the criteria of a donor organization without considering its appropriateness in the local setting. For instance, she describes a part of the program which carried out medical training for young women in rural areas. The project failed to be effective (women either emigrated for employment or were left unemployed) as it not only neglected gaps in the local healthcare system but also ignored certain circumstances related to local culture: adverse perceptions about women's education and their employment in remote areas, superstitious thinking about vaccination and 'irrational' preferences for large families. Despite the expensive SAP funding, the average economic growth rate per capita fell from 1.9 percent in 1990-95 to 0.4 percent in 1996-2000. In addition, a number of social indicators also fail to improve. As Altaf (2011) points out, the failure of the SAP is not only a story of one program in one country but it is the story of the majority of aid programs in many developing countries.

Anecdotal evidence can be motivating; however, it can also be non-representative and biased towards the extreme points of the distribution function. Therefore, it is important to test the reliability of the anecdotes and make use of the advantages of systematic statistical analysis. In the next section, I discuss existing measures for cultural differences and cultural transmission that can help in analyzing effects of cultural differences on the aid-growth nexus.

\subsection{Proxy variables for cultural differences and transmission}

\section{Measuring cultural differences}

The concept of culture is defined differently depending on the type of literature and context. In the economic literature, culture is mainly defined as beliefs, values, preferences and norms, transmitted from one generation to another in a fairly unchanged manner (Bisin and Verdier 2001, Guiso et al. 2009, Spolaore and Wacziarg 2009). Cavalli-Sforza (2001:175) defines it comprehensively as one's "ability to learn from the experience of others, [which] is a special phenomenon that relies on communication. [It] enables us to accumulate prior discoveries and helps us profit from [the] experience transmitted by our ancestors-knowledge that we would not have on our own." Fishbein and Ajzen (1975) show that values, attitudes, preferences and behavior emerge from the beliefs that one holds and a successful intervention targets the relevant beliefs. 
Hence, in this paper culture is understood as a set of beliefs about various aspects of life, which is shared by a group of people and is either communicated by parental teaching or learned from society at large. ${ }^{40}$

According to Inglehart and Welzel (2005) and the World Value Surveys, most of the aidrecipient countries are characterized with traditional and survival values while western donors are characterized by secular-rational and self-expression values. ${ }^{41}$ The most important values in a traditional society are religion, patriotism, respect for authority, obedience, and marriage, among others. On the contrary, in secular-rational societies these are the least important values. In regards to the second dimension, societies characterized with survival values prefer security to liberty and exhibit intolerance of homosexuality, political passivism, distrust in outsiders and a low level of life satisfaction, among others. On the contrary, in societies with self-expression values the opposite is true. The findings of Inglehart and Welzel (2005) also suggest that values can change with modernization and, depending on the transition mode (agrarian to industrial and industrial to knowledge-society), different sets of values may change (traditional to secular rational and survival to self-expression).

The cultural dimensions developed by Inglehart and Welzel (2005) are relevant to this study as they are closely associated with modernization and development processes. However, inconsistency of sample sizes throughout the waves of the World Value Surveys, especially for developing countries, as well as the endogeneity between cultural change and economic progress make them unsatisfactory for the identification strategy. ${ }^{42}$

Cavalli-Sforza (2001) establishes a conceptual framework on the relationship between genome and culture where both accumulate information to be passed from one generation to another. It is important to highlight that genes do not affect culture because in contrast to genomes, one has a choice whether to accept the culture and beliefs received from another person. Cavalli-Sforza (2001) mentions two modes of cultural transmission: traditional - through observation, teaching and communication - or through resources developed by modern

\footnotetext{
${ }^{40}$ Although the explanation for persistent belief systems is beyond the focus of this paper, research shows that it is most likely determined by the environmental, political and historical past of the society (Cosmides and Tooby 1994, Inglehart and Baker 2000).

${ }^{41}$ An exception is the US, which is characterized by self-expression and traditional values.

${ }^{42}$ Other cultural dimensions (Hofstede and Hofstede 2001, Schwartz 1994) are more limited in sample size and scope.
} 
technology - books, computers and other media. Therefore, a measure of genetic distance can be a good proxy for cultural differences rather than an instrument as genes are not necessarily correlated with beliefs but rather have similar accumulation and transmission processes. Moreover, to stress the ethical appropriateness of this measure, Cavalli-Sforza (2001) explains that most of the variation in genes is between individuals and not 'races': genetic differences between observable physical characteristics of populations constitute a very small percentage of DNA and are mainly attributable to climate changes over long periods of time.

In their model of the economics of cultural transmission and the dynamics of preferences, Bisin and Verdier (2001) show that globally stable heterogeneous preferences can exist among populations when children acquire beliefs, values and preferences from their parents (vertical) and/or adapt and imitate the beliefs, preferences and values most prevalent in a society (horizontal). That is, family and society are considered as substitutes in the socialization process. Bisin and Verdier's (2001) vertical cultural transmission can be related to the traditional way of cultural transmission, and their horizontal mode can be related to the resource-based cultural transmission discussed in Cavalli-Sforza (2001). In this study, I use both types of transmission channels as proxy variables for cultural differences.

\section{Proxy for Vertical Transmission of Culture}

Spolaore and Wacziarg (2009) develop an analytical framework linking genetic distance and income differences to explain long-term barriers to diffusion of development. Following CavalliSforza et al. (1994), Spolaore and Wacziarg (2009) consider a type of genetic distance, also known as "co-ancestor coefficient," which estimates the time passed since two populations shared common ancestors. More specifically, their measure of genetic distance represents the differences in the frequencies of blood types that prevail in different populations due to migration and isolation. This measure is based on neutral characteristics of genetic variations that resulted from the random drift rather than natural selection. ${ }^{43}$

\footnotetext{
${ }^{43}$ A gene is commonly defined as a DNA sequence that codes for a protein (protein polymorphism). The data on allele frequencies for different genes in different populations of the world can be found at http://alfred.med.yale.edu/ For more details on the specifics of genetic distance see Cavalli-Sforza et al. (1994), Cavalli-Sforza (2001) and Spolaore and Wacziarg (2009).
} 
Spolaore and Wacziarg (2009) claim that this genetic distance measure captures intergenerationally transmitted characteristics that include beliefs, preferences, values and social norms (vertical transmission of culture). According to them, similarity in such characteristics eases the communication and adaptation of practices conducive to socio-economic development such as rapid human capital accumulation, lower fertility and better political institutions. By extension, genetically distant populations face difficulties in interacting and communicating with one another that even language translation techniques cannot fully overcome, leading to resistance in adopting progressive practices (Spolaore and Wacziarg 2009: 513). In addition, Spolaore and Wacziarg (2009) point out that other proxy variables for cultural differences often used in the literature, such as religion, language and ethnicity, are also captured by the genetic distance because they are part of the intergenerationally transmitted characteristics. ${ }^{44}$

Desmet et al. (2011) use the genetic distance from Spolaore and Wacziarg (2009) as a proxy for cultural differences within Europe as they find that genetically closer Europeans give similar answers to the World Value Surveys' questions on perception of life, religion, family and morals. They show that the genetic distance is a preferred proxy for cultural differences by controlling for linguistic and geographic distances. In result, only the correlation between the genetic distance and cultural distance continues to be positive and statistically significant at the five percent level. Gorodnichenko and Roland (2010), on the other hand, instrument cultural differences with the genetic distance variable.

Based on this literature, I use the genetic distance from Spolaore and Wacziarg (2009) between aid recipients and western donors as a proxy for cultural differences. I further compute an aid-adjusted genetic distance measure, a technique adopted from Dreher et al. (2015a). According to Spolaore and Wacziarg (2009), genetic distance takes a value of zero in the case of identical allele distributions (frequency of blood types) across two populations, while it takes positive values where allele distributions differ. Large differences in allele distributions between two populations imply greater genetic distance between the two.

Using data from Alesina et al. (2003) and Cavalli-Sforza et al. (1994), Spolaore and Wacziarg (2009) compute a weighted genetic distance measure between countries, which accounts for recent immigration and populations that are composed of genetically distant subpopulations:

\footnotetext{
44 These conclusions are linked with those of Bisin and Verdier (2000) who show that ethnic and religious minorities persist in the USA, in contrast to the "melting pot" theory, due to parental preferences for transmission of certain cultural traits to their offspring, such as strong preferences for marriages within same religion and ethnicity.
} 


$$
G D_{i j}^{W}=\sum_{n=1}^{N} \sum_{a=1}^{A}\left(s_{\mathrm{in}} \times s_{j a} \times d_{n a}\right),
$$

where $G D_{i j}^{w}$ is the weighted genetic distance between country $i$ and country $j . s_{\text {in }}$ is the share of group $n$ in country $i, s_{j a}$ is the share of group $a$ in country $j$ and $d_{n a}$ is the genetic distance between groups $n$ and $a$. Equation (1) represents expected genetic distance between two randomly selected individuals from two different countries. ${ }^{45}$

In terms of development aid effectiveness, the weighted genetic distance (hereafter, genetic distance) between two populations may matter more or less depending on the magnitude (involvement and degree of intervention) of the aid received. To capture this influence, I compute an aid-adjusted genetic distance measure based on aid shares:

$$
A w G D_{i, t}=\sum_{j=1}^{n} s_{i j, t} * G D_{i j}^{w}
$$

where $s_{i j, t}$ is donor $j^{\prime} s$ share of total bilateral aid in country $i$, in year $t . G D_{i j}^{w}$ is the genetic distance between recipient $i$ and donor $j$ from equation (1). $A w G D_{i, t}$ is the aid-adjusted genetic distance to western donors for each recipient in period $t$. In line with the argument in the previous section, larger aid-adjusted genetic distance between a recipient and western donors indicates bigger differences in intergenerationally transmitted characteristics, including preferences, attitudes, values and beliefs. ${ }^{46}$

Vertical transmission of culture captures the traditional way of cultural adoption, which gives little weight to cross-cultural exposure and learning from alternative sources. Therefore, in this case, I expect aid's effect on growth to decrease as the genetic distance increases. In the next section, I present a proxy for horizontal cultural transmission to distinguish the effect of resourcebased cultural learning.

\footnotetext{
${ }^{45}$ Spolaore and Wacziarg (2009) also construct another genetic distance measure based on the dominant population groups in every country, which is highly correlated with the weighted genetic distance ( 94 percent). It should be noted that the weighted genetic distance is the current match between populations that does not change for a donorrecipient pair over the time period considered in this paper.

${ }^{46}$ Appendix B includes maps for aid-adjusted genetic distance to western donors.
} 


\section{Proxy for Horizontal Transmission of Culture}

I use recipient country leaders' education in the West to measure resource-based, horizontal, cultural transmission between aid recipients and western donors. Research shows that individuals who have studied in democratic states promote democracy in their home countries (Spilimbergo 2009). Gift and Krcmaric (2015) argue that leaders educated in the West are more likely to push for democratization due to their democratic socialization in western societies. In addition, leaders educated for a prolonged period in (western) donor countries may promote the culture of the respective host country back home and foster international transactions (Constant and Tien 2010). That is, the leader's (individual's) socialization in the West may lead to the transmission of beliefs and values that are different from that of the parental transmission at home.

I focus on the leaders and not on the share of individuals educated in the West because country leaders are responsible for internal and external policy at large, and development aid objectives need to be coordinated and negotiated with the recipient country's leadership as noted in Paris Declaration. Also, Jones and Olken (2005) study country leaders' performance in terms of economic growth and monetary policy, and find that leaders play a significant role in the growth processes of their country, especially in authoritarian regimes. In addition, a study by Dreher et al. (2009) shows that the professional background and education of the head of the government, in the context of developing economies, matters for reforms.

Following Gift and Krcmaric (2015), I code foreign education of a recipient country leader 'western', if he or she studied either in the US or the UK. Also, the US and the UK have the lion's share in total bilateral aid disbursements and a large share of recipient country leaders have been educated in these two donor countries. Moreover, development policies are largely influenced by economics (Sen 2004), which in turn is Americanized (Coats 1997). 


\subsection{Data and method}

In this paper, bilateral aid (hereafter, Aid) is defined as gross disbursements of Official Development Assistance (ODA) from Development Assistance Committee (DAC) traditional (western) donors, a statistic taken from the OECD's Aid Statistics database (2012).

Economic growth data is from the Penn World Table. The data on the genetic distance is from Spolaore and Wacziarg (2009) and the data on leaders' foreign education and education level is from Dreher et al. (2013). The panel data includes 66 recipient countries from 1961 to $2010{ }^{47}$

The aid-growth model of Rajan and Subramanian (2008), hereafter RS, is usually categorized as belonging to the "null strand" of AEL as no statistically significant effect of aid on growth is found. Like the original RS study, most of the aid-growth models in the AEL use instrumentation methods to tackle the endogeneity of aid. However, as Clemens et al. (2012) argue, based on Bazzi and Clemens (2013), the established results in the AEL suffer from the invalid instrumentation (mostly correlated with population) and weaknesses of GMM methodology (a "black-box"), which undermine their accuracy. Instead, Clemens et al. (2012) lag aid by one period to address the problem of reversed causality and use OLS estimator in first differences to capture country specific time-invariant omitted variables. I follow this strategy and distinguish the effect of donor-recipient cultural distance on the aid-growth nexus by augmenting the model of RS from Clemens et al. (2012) with the aid-adjusted genetic distance between recipients and donors and its interaction with aid. The reduced-form empirical model is as follows:

$$
\Delta G_{i, t}=\beta+\delta \Delta A i d_{i, t-1}+\gamma A w G D_{i, t-1}+\zeta \Delta A i d_{i, t-1} * A w G D_{i, t-1}+\theta \Delta X_{i, t}^{\prime}+\epsilon_{i, t},
$$

where, $\Delta G_{i, t}$ is (the change in) recipient country $i$ 's annual GDP per capita growth rate averaged over period $t$ (five years), $\Delta A i d_{i, t-1}$ denotes (the change in) total bilateral aid received by country $i$ in the period $t-1$ as a percentage of its GDP, $A w G D_{i, t-1}$ is the lagged aid-adjusted measure of genetic distance as described in the previous section. $\Delta X_{i, t}^{\prime}$ is (the change in) the vector of control variable from RS aid-growth model and $\epsilon_{i, t}$ is the error term. I am interested in the effect of $\zeta$, the interaction between Aid and AwGD, on growth. All variables are 5-year period averages as in RS.

\footnotetext{
${ }^{47}$ Detailed data sources and variable descriptions are provided in Appendix B, Table B3.
} 
Similarly, in terms of horizontal cultural transmission, I augment RS aid-growth model from Clemens et al. (2012) with leaders' education in the West and its interaction with Aid. The reduced form of the empirical model is:

$$
\Delta G_{i, t}=\beta+\delta \Delta A i d_{i, t-1}+\gamma \Delta F_{i, t}+\zeta \Delta A i d_{i, t-1} * \Delta F_{i, t}+\varphi \Delta E L_{i, t}+\theta \Delta X_{i, t}^{\prime}+\epsilon_{i, t}
$$

where $\Delta F_{i, t}$ indicates (the change in) a leader's education in the West. It is a continuous variable, since year dummies have been averaged over five year periods. $\Delta E L_{i, t}$ is an additional control variable for (the change in) leader's education, ranging from illiterate to advanced (doctoral) degree. The control variables $\left(\Delta X_{i, t}^{\prime}\right)$ are defined as in equation (3) and all variables are 5-year period averages.

In equation (3) and (4), in addition to the RS control variables, I also include the changes in multilateral aid as well as bilateral and multilateral repayments as there is no reason to assume that these variables do not affect growth (Clemens et al. 2012). In the next section, I discuss possible endogenity issues in the models and the methodology specified above.

\section{Endogeneity concerns}

Genetic distance between donors and recipients is generally considered exogenous to growth as it is independent of natural selection and physical fitness of individuals (Spolaore and Wacziarg 2009). As Gorodnichenko and Roland (2010: 3) point out "there are no identified genetic reasons as to why some countries became wealthier than others." However, the cultural transmission channel of the genetic distance variable might not be straightforward. One can argue that genetic distance measures differences in language or ethnicity instead. In the Appendix B, I present tests for these alternative measures. The results show that the donor-recipient distance in ethnic, linguistic and ethno-linguistic fractionalization do not affect aid's impact on growth and the effect of the key coefficient is hardly changed by this.

Although Clemens et al. (2012) claim that their estimation methodology takes care of the endogeneity of aid, the concern may still persist. Yet, the coefficient of interest in this paper, the interaction term between $A i d$ and $A w G D$, is consistent given that one of the interaction terms is exogenous, as shown in Nunn and Qian (2012). Namely, the interaction between an exogenous term (i.e., $A w G D$ ) and a potentially endogenous term (Aid) can be interpreted as exogenous as 
long as the main effect of the endogenous variable is directly controlled for in the estimation. ${ }^{48}$ Based on this, I argue that the differential effect of Aid on growth in culturally closer and distant recipients is most likely caused by Aid rather than other channels. Yet, when the aid shares are used as weights in the aid-adjusted genetic distance, this measure might not be fully exogenous after all. ${ }^{49}$ Therefore, in the robustness tests, I do not use the aid shares but instead take the average genetic distance between recipients and donors. ${ }^{50}$ The effect of the key coefficient is hardly affected by this change.

In terms of leaders' education abroad it may be the case that those individuals who choose western education already embrace the set of beliefs and preferences of the destination country. This would indicate a self-selection problem and introduce endogeneity. Interestingly, there is an empirical evidence showing that US educated leaders do not necessarily vote in-line with the US on key issues during United Nations General Assembly voting (Dreher et al. 2013). Additionally, reports show that future leaders choose to study abroad because it is prestigious to do so and not because of their unconditional acceptance of (liberal) Western culture and beliefs. For instance, autocrats in China, Russia and Africa have themselves studied in prestigious western universities or sent their children to the West without necessarily approving of western values (Braw 2014, Higgins and Fan 2012, Tschudi 2013). That is, the choice of western education does not essentially mean a preference for the western belief system over that of one's own country. Rather, the exposure to the western lifestyle can help one to improve cross-cultural communication skills and possibly update the set of beliefs and values that one holds.

\footnotetext{
${ }^{48}$ Nunn and Qian (2012) cite section 2.3.4 of Angrist and Krueger (1999) for technical details.

${ }^{49}$ I thank an anonymous reviewer for this point.

${ }^{50}$ This variable is constant over time as the variation in the AwGD was due to the changes in aid shares
} 


\subsection{Results}

\section{Effects of Vertical Transmission of Culture}

Table 2.1 displays the OLS estimation in first differences for a panel of 66 recipients over 19612000, averaged over 5-year periods, as in equation (3): Aid is also lagged once while aid-adjusted genetic distance is lagged once but not differenced. ${ }^{51}$

Column (1) displays the baseline growth regression without inclusion of the AwGD and Aid. $A w G D$ is added to the baseline in column (2). The AwGD is statistically significant at the one percent level and has a negative sign. Based on the study of Spolaore and Wacziarg (2009), the main effect of the $A w G D$ can be interpreted as cultural barriers to the knowledge diffusion from donor countries. The larger the genetic distance to the western donors the greater the cultural barriers to knowledge transfer.

Aid is added to the baseline in column (3): its coefficient is positive but does not have a statistically insignificant effect on growth. This result is in line with RS original findings as well as with that of Clemens et al. (2012) when 'long-impact' aid is considered. The next column includes both the $A w G D$ and Aid, which increases the adjusted $\mathrm{R}^{2}$ by 0.01 points compared to the baseline.

In column (5), Table 2.1, I include the variable of interest: the interaction between Aid and the $A w G D$. This increases the adjusted $\mathrm{R}^{2}$ further, and almost 30 percent of the variation in growth is explained by the model. The coefficient for the main effect of Aid is positive and statistically significant at the five percent level. However, its overall effect on growth is reduced by the coefficient of interest, the interaction term, which is negative and statistically significant at the five percent level. In column (6), I add additional controls, such as bilateral and multilateral repayments and multilateral aid, none of which have statistically significant effects on growth. In column (7), I include the squared terms of aid variables to capture any non-linear relationship between aid and growth. However, I do not find such a relationship, except in the case of multilateral repayments. Also, the adjusted $\mathrm{R}^{2}$ does not gain from the inclusion of the additional aid variables.

Overall, the results in columns (5) and (6) show that a one unit increase in $A w G D$ reduces the effect of Aid on growth by 0.2 percentage points. Values of $A w G D$ range from 0.06 to 2.2, a one

\footnotetext{
${ }^{51}$ In robustness tests aid-adjusted genetic distance is also differenced and lagged once.
} 
unit increase in donor-recipient genetic distance would mean switching between Uruguay (0.2) and India (1.2). ${ }^{52}$ Thus, depending on the regression, the overall affect of Aid on growth ranges from 0.1 to 0.2 percentage points on average instead of a possible 0.3 to 0.4 percentage points, ceteris paribus.

The marginal effects of the estimation results in column (5) are depicted in Figure 2.1, which shows that the overall effect of Aid remains positive to some extent, but once a country's AwGD is larger than 1.5, the overall effect of bilateral aid gradually becomes negative. Countries with a very large genetic distance to the western donors include Tanzania and Botswana among 18 other countries, mostly from sub-Saharan Africa. In the sample Poland has the smallest, 0.06, while The Republic of Congo has the largest $A w G D, 2.2$, to western donors.

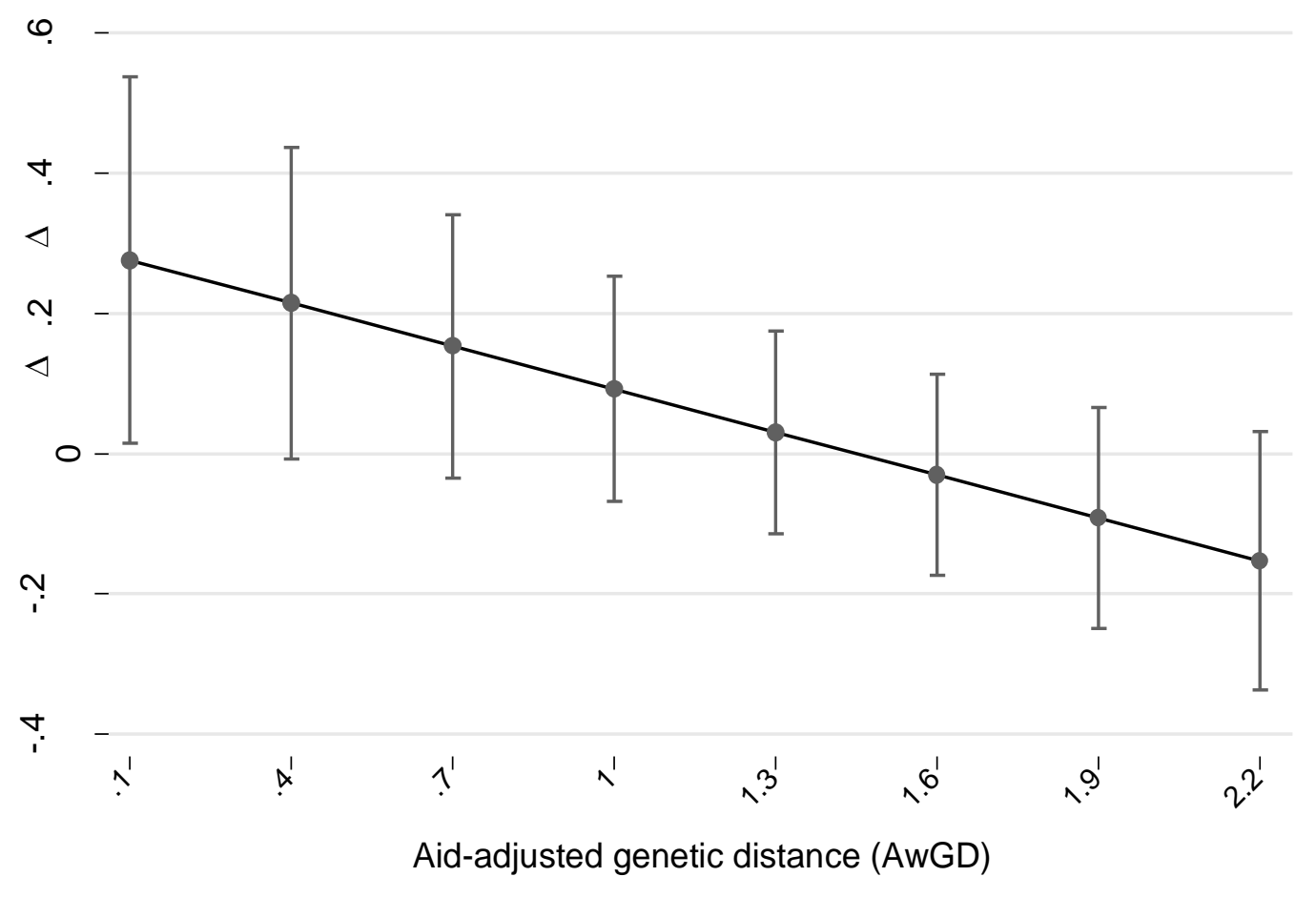

Figure 2.1 Marginal effects of aid on growth as AwGD changes

The results in Table 2.1 suggest that aid effectiveness is significantly reduced with larger genetic distance between the recipient and western donors. This also conforms with the notion

\footnotetext{
${ }^{52}$ The values of $A w G D$ are divided by 1000 so the coefficients in Table 2.1 are on a similar scale.
} 
that culturally (genetically) closer populations find it easier to communicate and understand each other, which leads to a faster adoption of growth-generating development practices.

\section{Effects of Horizontal Transmission of Culture}

In Table 2.2, I estimate equation (4) with OLS in first differences as in Table 2.1. The coefficient of interest is that of the interaction between Aid and the leader's western education. In this specification, the coefficient of Aid has mostly very weak or no statistically significant effect on growth while the interaction term is negative and statistically significant from columns (3) to (5).

The results in Table 2.2 imply that on average a recipient country leader with western education has an adverse influence on the aid-growth nexus contemporaneously. However, the sign of the coefficient turns positive when education is lagged twice as shown in Table 2.3. In column (4), Table 2.1, I add another control variable for leaders' education abroad in general. This helps to single out the effect of western education from that of overall education abroad. The coefficient of the main variable of interest is hardly affected by this change. The results also show that, in general, education abroad has a positive effect on the aid-growth nexus. ${ }^{53}$ In column (5), I include squared terms of the aid and repayment variables, which increase the magnitude of the coefficient of the variable of interest and strengthen its statistical significance to the one percent level.

Looking at the marginal effects of the estimation results from column (3), depicted in Figure 2.2, one can see that the effect of Aid on growth turns negative when a country's leadership transitions from a non-western educated to a western educated one (positive change). Assuming that leaders educated in the West also promote cultural change, mainly "westernization," then the negative sign of the coefficient can indicate initial resistance to the change from the public. This resistance may first increase the costs of public transactions (via reforms) and hurt growth, but then yield positive growth effects with the adoption of cultural change by new generations. If so,

\footnotetext{
${ }^{53}$ When leaders' education in the US or the UK is not controlled for, the main and the interaction effect of foreign education and Aid become negative and statistically insignificant at the conventional levels.
} 
one should expect the coefficient of the interaction term to switch the sign when the education variables are lagged.

In Table 2.3, I redo the analysis of column (3), Table 2.2, but lag leaders' education variables twice to allow for the effect of generational change. The coefficient of the interaction term in Table 2.3, column (2) becomes positive and statistically significant at the ten percent level. In column (3), I use the same sample from column (2) but without the education lags and confirm that the change in the sign is not due to the change in the sample size.

Hence, in the long-run, the education of recipient country leaders in the West benefits the effectiveness of aid as it, presumably, promotes cultural transformation together with economic reforms. In terms of economic significance, the results in column (2), Table 2.3, show that when a western educated leader is in power then a one percentage change in Aid leads to a 0.3 percentage change in growth in the same direction after a decade.

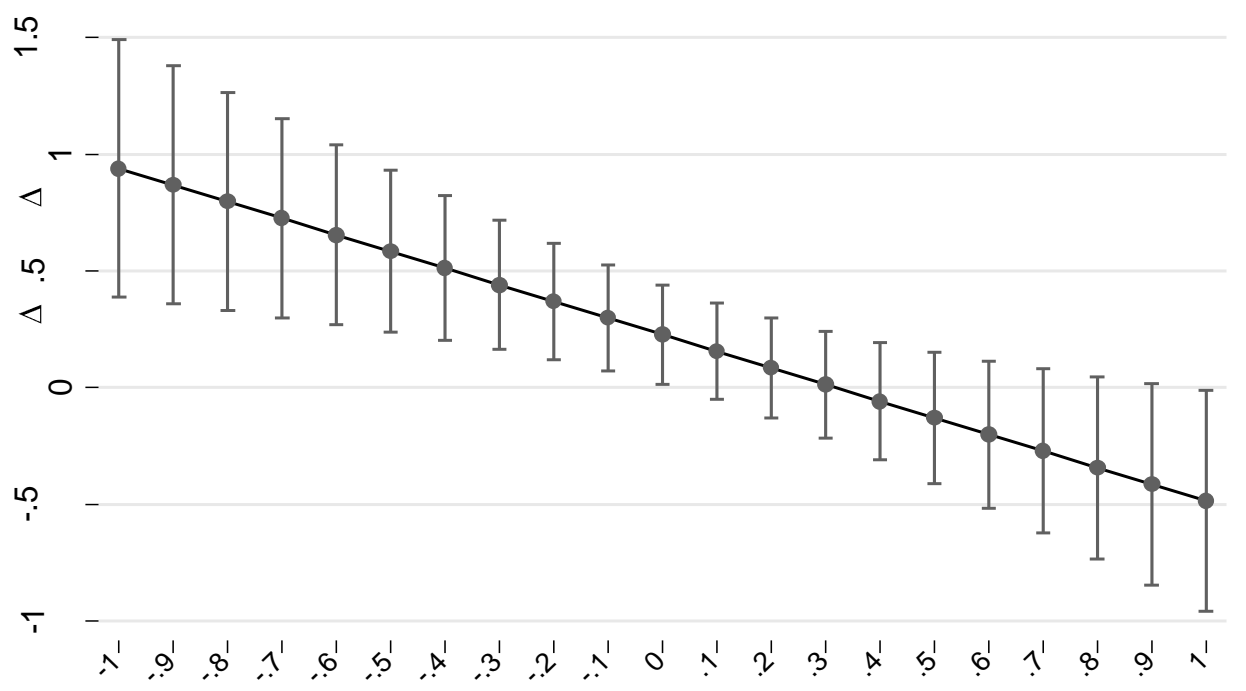

$\Delta$ Western education of leaders

Figure 2.2 Marginal effects of aid on growth as leaders' western education change 


\subsection{Tests for robustness}

In Table 2.3, I test the robustness of the regression results in column (5), Table 2.2. In column (1), Table 2.3, I use first differenced (and lagged) $A w G D$ rather than that in levels. The coefficient of the interaction term between Aid and the $\triangle A w G D$ is negative and statistically significant at the five percent level. As one can see, the key coefficient is much larger when the $A w G D$ is first differenced. This indicates that within country changes in the $A w G D$ lead to much larger effects. ${ }^{54}$ However, the adjusted R-squared does not gain from this specification of first differencing the $A w G D$, confirming that the specification in column (5), Table 2.1, is a better fit in terms of explained variance. In column (2), I remove the possible endogeneity of $A w G D$ introduced by the aid shares and instead use average genetic distance, $a G D$, to western donors is calculated as follows:

$$
a G D_{i}=\frac{1}{n} \sum_{j=1}^{n} G D_{i j}^{w}
$$

where $a G D_{i}$ is the average genetic distance to all donors for recipient $\mathrm{i}, \mathrm{GD}_{\mathrm{ij}}^{\mathrm{W}}$ is the genetic distance between donor $\mathrm{j}$ and recipient $\mathrm{i}$ and $\mathrm{n}$ is the number of western donors. The sign, statistical significance and the magnitude of the coefficient of the interaction term is hardly affected when aGD is used instead of the AwGD in column (2), Table 2.3. In column (3), I control for changes in humanitarian aid, while in column (4), I control for changes in bilateral aid from new DAC and non-DAC donors. The main findings are robust to the inclusion of these variables.

In Table 2.4, I test the robustness of the results in Table 2.2 by adding control variables related to the power constraints of the leader. Depending on the level of democracy, the power of the executive might vary, and more time may be required from policy changes to the implementation and the realization of results. I control for the country's democracy level, using unified democracy scores from Pemstein et al. (2010).

The form of governance, such as monarchy, presidential, parliamentarian, military or socialist, might also matter for growth. I control for it using the Effective Executive variable from Banks and Wilson (2012). This is a categorical variable ranging from 1 to 5, where higher values correspond to military and socialist dictatorships. The next control variable is the type of leader: Head of the State (monarch, president, premier, military and other - i.e., general secretary in

\footnotetext{
${ }^{54}$ This, however, is hard to observe in reality as genetic distance and culture change very slowly over long periods of time.
} 
communist regimes). The inclusion of these variables strengthens the statistical power of the interaction term up to the five percent level. In column (2), I test the robustness of the regression in column (4), Table 2.2 with the inclusion of the additional controls. In column (3), the leader's education variable is lagged twice. As can be seen, the interaction term is positive and statistically significant at the five percent level, which confirms the findings in column (2), Table 2.3. Column (4) shows that the change of the coefficient sign is not due to the sample size.

One can argue that genetic distance is capturing differences in language, ethnicity and religion instead of beliefs and norms transferred from one generation to another. In Table B1, Appendix B, I test this by including distance in ethno-linguistic fractionalization and religion between donors and recipients, using data from Kolo (2012). I do not find any statistically significant effect of donor-recipient differences in religion, language or ethnicity on the aidgrowth nexus and the statistical significance of the interaction term of the AwGD and Aid is hardly influenced by the inclusion of these variables. This implies that the intergenerationally transmitted characteristics are beyond ethnicity, religion and language.

Dreher et al. (2015a) show that differences in political ideology between donors and recipients (alignment) matter for the aid-growth nexus. Therefore, I control for these differences in column (5), Appendix B Table B2, by including the political alignment variable from Dreher et al. (2015a) in the main regression. ${ }^{55}$ However, since the data on political ideology are available only from 1975 onwards, it reduces the sample size by 81 observations. ${ }^{56}$ In result, the key coefficient becomes statistically insignificant due to the reduced sample size rather than by the inclusion of the political ideology variable as shown in column (6). ${ }^{57}$

Next, I test whether inclusion of the cultural dimensions developed by Inglehart and Welzel (2005) influences the coefficient of interest - the interaction between Aid and AwGD. I include the World Value Surveys' cultural dimension of well-being and authority (waves 1-5) in the main estimation equation. The number of observations is reduced to 152 in the panel setting, covering 42 countries only. Since some countries step in and out in different waves, the values for the years where observations are absent are replaced with those before and/or after the observations. The results in column (2), Appendix B, Table B2, show that the key coefficient is negative and

\footnotetext{
${ }^{55}$ I thank an anonymous reviewer for suggesting this test.

56 Source: Database of Political Institutions (Beck et al. 2001).

57 This result, however, does not fundamentally undermine the main findings of this study: in statistical analysis the true parameter is more likely to be found in larger rather than in smaller samples.
} 
statistically significant at the one percent level. The coefficient of the interaction term between Aid and well-being is also positive but has a weak statistical significance. This outcome tentatively suggests that certain cultural values measured by the WVS can be part of the intergenerationally transmitted characteristics. However, due to the data limitations and a very small sample size, no strong inference can be made.

\subsection{Conclusions}

The findings of this paper empirically support the anecdotal evidence on adverse effects of the donor-recipient cultural differences on the aid-growth nexus. I find these results by augmenting a prominent aid-growth model with two proxy variables for donor-recipient cultural differences: aid-adjusted genetic distance and western education of a recipient country leader. As in the previous chapter, I introduce an interaction term between the proxy variable(s) and bilateral aid to an aid-growth model to find how aid's effect on growth changes with different levels of donorrecipient cultural differences.

Using the estimation method of Clemens et al. (2012) for the panel data of 66 recipient countries from 1961-2010, averaged over 5-year periods, I find that the main effect of bilateral aid on growth is reduced by 0.2 percentage points when aid is increased by one percentage point and the aid-adjusted genetic distance by one unit. However, when an aid recipient country has a western educated leader it results in a positive and statistically significant effect of aid on growth in a long run. Robustness tests show that alternative proxy variables for donor-recipient cultural differences such as distance in language and ethnicity do not have statistically significant effects on the aid-growth nexus.

These findings imply that the effectiveness of aid can be enhanced if donors focus on culturally closer regions and/or engage in long-term commitments at the local level. Moreover, development paradigms should be designed with greater involvement and input from local scholars and political leaders, who possess a deep understanding of both western and local culture. In addition, the movement of people between (western) donor countries and recipient countries and/or intense intercultural communication can relax cultural barriers to knowledge transfer and help the localization of ‘western' development paradigms. 
Table 2.1 The effect of aid-adjusted genetic distance on the aid-growth nexus

\begin{tabular}{|c|c|c|c|c|c|c|c|}
\hline Dependant variable: $\Delta$ Growth & $(1)$ & (2) & (3) & (4) & $(5)$ & $(6)$ & $(7)$ \\
\hline \multirow[t]{2}{*}{ Aid } & & & 0.012 & 0.018 & $0.296^{* *}$ & $0.399 * *$ & 0.404 \\
\hline & & & {$[0.084]$} & {$[0.082]$} & {$[0.140]$} & {$[0.186]$} & {$[0.287]$} \\
\hline \multirow[t]{2}{*}{ Aid-adjusted genetic distance (AwGD) } & & $-0.969^{* *}$ & & $-0.972 * *$ & $-1.015^{* *}$ & $-0.950 * *$ & $-0.900 * *$ \\
\hline & & {$[0.436]$} & & [0.435] & {$[0.438]$} & {$[0.460]$} & {$[0.452]$} \\
\hline \multirow[t]{2}{*}{ Aid *AwGD } & & & & & $-0.204 * *$ & $-0.213 * *$ & $-0.183^{* *}$ \\
\hline & & & & & {$[0.081]$} & {$[0.087]$} & {$[0.085]$} \\
\hline \multirow[t]{2}{*}{ Bilateral repayments } & & & & & & -0.446 & $-1.472 *$ \\
\hline & & & & & & {$[0.293]$} & {$[0.870]$} \\
\hline \multirow[t]{2}{*}{ Multilateral aid } & & & & & & -0.026 & 0.049 \\
\hline & & & & & & {$[0.139]$} & {$[0.355]$} \\
\hline \multirow[t]{2}{*}{ Multilateral repayments } & & & & & & -0.866 & $-4.231 * *$ \\
\hline & & & & & & {$[0.922]$} & {$[2.136]$} \\
\hline \multirow[t]{2}{*}{ Aid squared } & & & & & & & -0.001 \\
\hline & & & & & & & {$[0.006]$} \\
\hline \multirow[t]{2}{*}{ Bilateral repayments squared } & & & & & & & 0.303 \\
\hline & & & & & & & {$[0.211]$} \\
\hline \multirow[t]{2}{*}{ Multilateral aid squared } & & & & & & & -0.002 \\
\hline & & & & & & & {$[0.017]$} \\
\hline \multirow[t]{2}{*}{ Multilateral repayments squared } & & & & & & & $1.622 *$ \\
\hline & & & & & & & {$[0.905]$} \\
\hline \multirow[t]{2}{*}{ Initial GDP p.c. (log) } & $-9.129 * * *$ & $-9.659 * * *$ & $-9.098^{* * *}$ & $-9.613^{* * *}$ & $-9.757 * * *$ & $-9.624 * * *$ & $-9.568 * * *$ \\
\hline & [1.387] & [1.453] & {$[1.458]$} & [1.519] & {$[1.532]$} & {$[1.554]$} & {$[1.546]$} \\
\hline \multirow[t]{2}{*}{ Initial life expectancy (log) } & -0.001 & -0.074 & -0.001 & -0.074 & -0.088 & -0.085 & -0.09 \\
\hline & {$[0.070]$} & {$[0.071]$} & {$[0.070]$} & {$[0.071]$} & {$[0.068]$} & {$[0.067]$} & {$[0.067]$} \\
\hline \multirow[t]{2}{*}{ Openness } & 0.652 & 0.622 & 0.651 & 0.621 & 0.568 & 0.558 & 0.444 \\
\hline & {$[0.441]$} & {$[0.452]$} & {$[0.442]$} & {$[0.453]$} & {$[0.455]$} & {$[0.476]$} & {$[0.497]$} \\
\hline \multirow[t]{2}{*}{ Inflation (log) } & $-1.364 * * *$ & $-1.315^{* * *}$ & $-1.368^{* * *}$ & $-1.322 * * *$ & $-1.182^{* * * *}$ & $-1.195^{* * *}$ & $-1.223 * * *$ \\
\hline & {$[0.448]$} & [0.427] & {$[0.450]$} & [0.430] & {$[0.433]$} & {$[0.440]$} & {$[0.447]$} \\
\hline \multirow[t]{2}{*}{ Initial M2/GDP } & -0.011 & -0.03 & -0.01 & -0.029 & -0.031 & -0.029 & -0.031 \\
\hline & {$[0.022]$} & {$[0.024]$} & {$[0.022]$} & {$[0.024]$} & {$[0.023]$} & {$[0.023]$} & {$[0.023]$} \\
\hline \multirow[t]{2}{*}{ Revolutions } & $-0.800 * *$ & $-0.783^{* *}$ & $-0.796^{* *}$ & $-0.776^{* *}$ & $-0.759^{* *}$ & $-0.751 * *$ & $-0.759 * *$ \\
\hline & {$[0.335]$} & {$[0.336]$} & {$[0.332]$} & {$[0.333]$} & {$[0.330]$} & {$[0.327]$} & {$[0.329]$} \\
\hline \multirow[t]{2}{*}{ Budget Balance/GDP } & 0.141 & 0.091 & 0.14 & 0.089 & 0.057 & 0.032 & 0.015 \\
\hline & {$[0.122]$} & {$[0.136]$} & {$[0.122]$} & [0.136] & [0.142] & {$[0.140]$} & {$[0.148]$} \\
\hline Adj. R-Squared & 0.278 & 0.29 & 0.276 & 0.288 & 0.294 & 0.293 & 0.292 \\
\hline Aid variables squared & No & No & No & No & No & No & Yes \\
\hline Number of Countries & 66 & 66 & 66 & 66 & 66 & 66 & 66 \\
\hline Number of Observations & 378 & 378 & 378 & 378 & 378 & 378 & 378 \\
\hline
\end{tabular}

OLS panel estimation in first differences: country fixed effects. All regressions include period dummies. All aid variables and repayments are in percent of recipient country's GDP. Aid denotes gross bilateral aid. Aid variables and AwGD are lagged once. Significance levels * p<0.10, ** $\mathrm{p}<0.05, * * * \mathrm{p}<0.01$. 
Table 2.2 The effect of leaders' western education on the aid-growth nexus

\begin{tabular}{lccccc}
\hline Dependant variable: $\Delta$ Growth & $(1)$ & $(2)$ & $(3)$ & $(4)$ & $(5)$ \\
\hline Aid & 0.17 & 0.174 & 0.193 & $0.211^{*}$ & 0.286 \\
& {$[0.137]$} & {$[0.140]$} & {$[0.133]$} & {$[0.128]$} & {$[0.254]$} \\
Ed US UK & & 0.472 & 0.551 & 0.374 & 0.261 \\
& & {$[0.471]$} & {$[0.455]$} & {$[0.632]$} & {$[0.636]$} \\
Education Level & & 0.035 & -0.009 & -0.026 & -0.007 \\
& & {$[0.197]$} & {$[0.198]$} & {$[0.207]$} & {$[0.202]$} \\
Aid* $\Delta$ Ed US UK & & $-0.290^{*}$ & $-0.713^{* *}$ & $-0.811^{* * *}$ \\
& & & {$[0.167]$} & {$[0.284]$} & {$[0.312]$} \\
Education abroad (incl. US/UK) & & & 0.206 & 0.331 \\
& & & & {$[0.667]$} & {$[0.703]$} \\
Aid* $\Delta$ Education abroad (incl. US/UK) & & & & $0.548^{*}$ & $0.623^{*}$ \\
& & & & {$[0.302]$} & {$[0.323]$} \\
\hline \hline Adj. R-Squared & 0.28 & 0.277 & 0.281 & 0.283 & 0.288 \\
Aid variables squared & No & No & No & No & Yes \\
Number of Countries & 66 & 66 & 66 & 66 & 66 \\
Number of Observations & 378 & 378 & 378 & 378 & 378 \\
\hline \hline
\end{tabular}

OLS panel estimation in first differences: country fixed effects. All regressions include period dummies. Aid denotes gross bilateral aid as percent of recipient's GDP and is lagged once. Control include initial GDP p.c. (log), initial life expectancy (log), openness, inflation (log), initial M2/GDP, budget balance/GDP, revolutions, multilateral aid, multilateral and bilateral repayments. All aid variables and repayments are in percent of recipient's GDP. Significance levels $* \mathrm{p}<0.10, * * \mathrm{p}<0.05, * * * \mathrm{p}<0.01$. 
Table 2.3 Lagged effects of leaders' western education on the aid-growth nexus

\begin{tabular}{lccc}
\hline Dependant variable: $\Delta$ Growth & $(1)$ & $(2)$ & $(3)$ \\
\hline Aid & 0.193 & 0.07 & 0.135 \\
& {$[0.133]$} & {$[0.132]$} & {$[0.129]$} \\
$\Delta$ Ed US UK & 0.551 & 0.437 & 0.42 \\
& {$[0.455]$} & {$[0.503]$} & {$[0.484]$} \\
Education Level & -0.009 & -0.074 & -0.058 \\
Aid* $\Delta$ Ed US UK & {$[0.198]$} & {$[0.206]$} & {$[0.199]$} \\
& $-0.290^{*}$ & $0.320^{*}$ & $-0.269^{*}$ \\
\hline Education twice lagged & {$[0.167]$} & {$[0.185]$} & {$[0.159]$} \\
Adj. R-Squared & No & Yes & No \\
Aid variables squared & 0.281 & 0.306 & 0.304 \\
Number of Countries & No & No & No \\
Number of Observations & 66 & 66 & 66 \\
\hline
\end{tabular}

OLS panel estimation in first differences: country fixed effects. All regressions include period dummies. Aid denotes gross bilateral aid as percent of recipient's GDP. Control variables are: initial GDP p.c. (log), initial life expectancy (log), openness, inflation (log), initial M2/GDP, budget balance/GDP, revolutions, multilateral aid, bilateral and multilateral repayments. All aid variables and repayments are in percent of recipient's GDP. Significance levels $* \mathrm{p}<0.10, * * \mathrm{p}<0.05, * * * \mathrm{p}<0.01$. 
Table 2.4 Robustness test: Column 5, Table 2.1

\begin{tabular}{|c|c|c|c|c|}
\hline Dependant variable: $\Delta$ Growth & $(1)$ & $(2)$ & (3) & (4) \\
\hline \multirow[t]{2}{*}{ Aid } & 0.056 & $0.290 * *$ & $0.300 * *$ & $0.285^{* *}$ \\
\hline & {$[0.079]$} & {$[0.134]$} & {$[0.140]$} & [0.129] \\
\hline \multirow[t]{2}{*}{ Aid-adjusted genetic distance (AwGD) } & $-6.340 * *$ & & $-1.013 * *$ & $-1.010 * *$ \\
\hline & [2.664] & & {$[0.438]$} & [0.432] \\
\hline \multirow[t]{2}{*}{ Aid*AwGD } & $-2.287 * *$ & & $-0.205^{* *}$ & $-0.198 * * *$ \\
\hline & [0.901] & & {$[0.081]$} & {$[0.076]$} \\
\hline \multirow[t]{2}{*}{ Mean Genetic Distance (GD) } & & $-0.718 *$ & & \\
\hline & & {$[0.405]$} & & \\
\hline \multirow[t]{2}{*}{ Aid*GD } & & $-0.199 * *$ & & \\
\hline & & {$[0.078]$} & & \\
\hline \multirow[t]{2}{*}{ Humanitarian Aid } & & & -0.357 & \\
\hline & & & [2.088] & \\
\hline \multirow[t]{2}{*}{ Rest Bilateral Aid } & & & & $1.237 * *$ \\
\hline & & & & [0.604] \\
\hline AwGD/GD first differenced $(\Delta)$ & Yes & No & No & No \\
\hline Adj. R-Squared & 0.284 & 0.288 & 0.292 & 0.307 \\
\hline Number of Countries & 66 & 66 & 66 & 66 \\
\hline Number of Observations & 378 & 378 & 378 & 378 \\
\hline
\end{tabular}

OLS panel estimation in first differences: country fixed effects. All regressions include period dummies. Aid denotes gross bilateral aid as percent of recipient's GDP. Controls are: initial GDP p.c. (log), initial life expectancy $(\log )$, openness, inflation (log), initial M2/GDP, budget balance/GDP, revolutions. Significance levels $* \mathrm{p}<0.10,{ }^{* *} \mathrm{p}<0.05, * * * \mathrm{p}<0.01$. 
Table 2.5 Robustness test: Table 2.2 and 2.3

\begin{tabular}{lcccc}
\hline Dependant variable: $\Delta$ Growth & $(1)$ & $(2)$ & $(3)$ & $(4)$ \\
\hline Aid & 0.203 & $0.223^{*}$ & 0.12 & 0.188 \\
& {$[0.138]$} & {$[0.134]$} & {$[0.147]$} & {$[0.133]$} \\
$\Delta$ Ed US UK & 0.69 & 0.568 & $1.013^{*}$ & 0.424 \\
$\Delta$ Education Level & {$[0.453]$} & {$[0.619]$} & {$[0.604]$} & {$[0.621]$} \\
& -0.04 & -0.041 & -0.055 & -0.086 \\
Aid* $\Delta$ Ed US UK & {$[0.204]$} & {$[0.210]$} & {$[0.228]$} & {$[0.222]$} \\
& $-0.327^{* *}$ & $-0.769^{* * *}$ & $0.358^{* *}$ & $-0.699^{* *}$ \\
$\Delta$ Education abroad & {$[0.164]$} & {$[0.255]$} & {$[0.176]$} & {$[0.273]$} \\
& & 0.123 & -0.74 & 0.083 \\
Aid * $\Delta$ Education abroad (incl. US/UK) & & {$[0.680]$} & {$[0.585]$} & {$[0.708]$} \\
& & $0.573^{* *}$ & -0.114 & $0.493^{*}$ \\
Democracy & & {$[0.283]$} & {$[0.160]$} & {$[0.295]$} \\
& $-1.025^{*}$ & $-1.033^{*}$ & $-1.086^{*}$ & $-1.161^{*}$ \\
Effective Executive & {$[0.530]$} & {$[0.530]$} & {$[0.596]$} & {$[0.607]$} \\
& $-1.882^{* * *}$ & $-1.863^{* * *}$ & $-1.706^{* * *}$ & $-1.576^{* * *}$ \\
Head of State & {$[0.515]$} & {$[0.500]$} & {$[0.515]$} & {$[0.510]$} \\
& $3.005^{* *}$ & $3.016^{* *}$ & $2.687^{* *}$ & $2.472^{*}$ \\
\hline Education lagged (2 periods) & {$[1.342]$} & {$[1.336]$} & {$[1.266]$} & {$[1.269]$} \\
Adj. R-Squared & No & No & Yes & No \\
Aid variables squared & 0.306 & 0.309 & 0.327 & 0.329 \\
Number of Countries & No & No & No & No \\
Number of Observations & 64 & 64 & 64 & 64 \\
\hline OL & 357 & 357 & 320 & 320 \\
\hline
\end{tabular}

OLS panel estimation in first differences: country fixed effects. All regressions include period dummies. Aid denotes gross bilateral aid as percent of recipient's GDP. Control variables are: initial GDP p.c. (log), initial life expectancy (log), openness, inflation (log), initial M2/GDP, budget balance/GDP, revolutions as well as multilateral aid, multilateral and bilateral repayments. All aid variables and repayments are in percent of recipient's GDP and are lagged once. Education variables are lagged and differenced. Significance levels $* \mathrm{p}<0.10, * * \mathrm{p}<0.05, * * * \mathrm{p}<0.01$. 


\title{
3. Remittances and the effectiveness of foreign aid
}

\begin{abstract}
We argue that donors could improve the effectiveness of foreign aid by pursuing complementary and coherent non-aid policies. In particular, we hypothesize that aid has stronger growth effects if recipients receive more aid from donors that allow for (temporary) worker mobility and (more permanent) migration. We focus on overall remittances paid by the donor countries to proxy for worker mobility and migration. Our empirical results support the hypothesis that higher remittances paid by donor countries strengthen the growth effects of foreign aid.
\end{abstract}

JEL code: F35, F24, O11

Keywords: aid effectiveness, remittances, economic growth

Acknowledgments: This essay is a joint work with Peter Nunnenkamp. A similar version of this essay is accepted for publication in the Review of Development Economics. I thank the seminar participants at the University of Heidelberg, Globalization and Development research training group, participants of the AEL Development Economics Conference in Kiel 2015 and the Globalization and Development Conference in Goettingen 2015 as well as anonymous reviewers of the Review of Development Economics for useful comments. 


\subsection{Introduction}

The World Bank's study “Assessing Aid: What Works, What Doesn't, and Why?” (World Bank 1998) and the underlying contribution of Burnside and Dollar (2000) have triggered a lively and ongoing debate on the role of sound economic policies in the recipient countries for foreign aid to have the desired effects on poverty alleviation and economic growth. It has received considerably less attention how donor countries could enhance the effectiveness of their aid.

Berthélemy (2006) concluded from his analysis of selfish and altruistic motives of aid allocation that donors do not behave the same. Concerning donor motives and aid effectiveness, Bearce and Tirone (2010), Kilby and Dreher (2010) and Dreher et al. (2014) found that the growth impact is insignificant or even negative for politically or strategically motivated aid which typically provides favors to political allies, while the growth impact tends to be positive if aid is motivated by the need of recipients. ${ }^{58}$

However, it remains open to question whether donors could improve the effectiveness of aid by pursuing complementary and coherent policies. As argued by Fuchs et al. (2014), foreign aid may be complemented or substituted by donor policies related to private financial flows, imports and exports of goods and services, and international migration. Here, we focus on the overall remittances paid by donor countries, as a proxy of (temporary) worker mobility and (more permanent) immigration, since the interaction between aid and remittances has received scant attention so far. Specifically, we hypothesize that aid has stronger growth effects if recipients receive more aid from donor countries with higher outflows of remittances than from donor countries with lower outflows of remittances.

Section 2 sketches the analytical background of our hypothesis. Section 3 discusses measurement issues and justifies our focus on remittances, while Section 4 describes the method and data used. We present our estimation results in Section 5, and conclude in Section 6.

\footnotetext{
${ }^{58}$ More specifically, it has been discussed whether donors could render aid more effective by: (i) selecting sectors where aid is more likely to have short-term effects (Clemens et al. 2012); (ii) offering appropriate aid modalities, e.g., by untying aid (Clay et al. 2008), replacing loans by grants (Odedokun 2004), and providing general budget support instead of project-specific support (Koeberle et al. 2006); (iii) optimizing aid delivery, e.g., through nongovernmental organizations (NGOs) (Dietrich 2013, Acht et al. 2015) and so-called performance based aid (Svensson 2003); (iv) reducing the volatility and unpredictability of aid disbursements (Lensink and Morrissey 2000, Kodama 2012); and (v) improving donor coordination (Easterly 2007, Knack and Rahman 2007).
} 


\subsection{Why remittances matter for aid effects}

According to the OECD Development Centre, donor countries "must also make intelligent use of non-aid policies," including migration policies, to render aid more effective; the relevant question for OECD policy makers is how to combine aid and non-aid policies to achieve the desired results most effectively (Dayton-Johnson and Katseli 2006: 1). Likewise, the view that "foreign aid is only one aspect of the relationship between rich and poor countries" is underlying the Commitment to Development Index (CDI) of the Center for Global Development (Birdsall and Roodman 2003: 2). This index, which has been compiled annually since 2003, includes migration as a major component to assess the policy coherence of donor countries. ${ }^{59}$

In actual practice, however, the required policy coherence often appears to be violated by donor countries. For instance, some large donor countries, notably France and Japan, ranked at the bottom of the CDI's 2003 scorecard on migration policies (Birdsall and Roodman 2003). De Haas (2005: 1269) observes that "migration and development policies generally constitute separate policy domains" in the donor countries, which hampers more positive links between migration and development in the recipient countries. It even appears that some donors regard foreign aid as a 'remedy' against migration from recipient countries. ${ }^{60}$

As noted by the Center for Global Development and Foreign Policy magazine when launching the CDI in 2003, "at first glance, it may seem odd to include immigration policy in the CDI. How is the process of development advanced if thousands of Turks exit their native country for Germany or if millions of Mexicans cross the border into the United States? Clearly, migration flows hurt in some ways and help in others. On balance, however, the freer movement

\footnotetext{
${ }^{59}$ As noted by Birdsall and Roodman (2003: 20), "migration is one of the thorniest topics covered in the index. The effects of migration and migration policy on development have not been as extensively studied as those of aid and trade policies." We return to the Center for Global Development's index when discussing measurement issues in Section 3.

${ }^{60}$ De Haas (2005) considers it a myth that foreign aid is an effective remedy against migration. See also Berthélemy et al. (2009) on the complex relationship between aid inflows and emigration from recipient countries. FernándezHuertas Moraga and Rapoport (2013) argue that existing international migration regimes are generally too restrictive and inefficient as they ignore important externalities. The public good nature of poverty alleviation encourages freeriding on immigration, while restrictions are justified by apparently unbearable social and political costs.
} 
of people-like the freer movement of goods - generally enhances development."61 The evidence on positive developmental effects of migration in the sending countries has mounted since then. ${ }^{62}$

According to Fernández-Huertas Moraga and Rapoport (2013: 1), “international migration is maybe the single most effective way to alleviate global poverty." In quantitative terms, the remittances of migrants and temporary foreign workers are a much more important source of external financing for many developing countries than aid inflows (Gammeltoft 2002). However, in addition to directly contributing to external financing and poverty alleviation, donor countries allowing for temporary worker mobility and more permanent immigration could also enhance economic growth in aid recipient countries indirectly by increasing the effectiveness of foreign aid.

Empirical evidence on whether liberal policies with respect to worker mobility and migration and higher remittances improve the effectiveness of official development aid hardly exists. By contrast, there is a fairly large literature on the links between migration and private international transactions. Various studies address the effects of migration on international trade relations. Starting with the pioneering work of Gould (1994), Head and Ries (1998) and Rauch (2001), "evidence of a positive relationship between trade and migration has been around for almost two decades" (Hatzigeorgiou and Lodefalk 2015). ${ }^{63}$ This is typically attributed to the immigrants' familiarity with business conditions and market opportunities in their country of birth. In addition to disseminating trade-related information and generating trust, immigrants are widely perceived to reduce transaction and communication costs, inter alia, through scarce language skills and access to local networks (see, e.g., Gould 1994, Parsons 2012, Hatzigeorgiou and Lodefalk 2015). Likewise, it is argued that immigrants help promote private cross-border financial flows, offshoring, and foreign direct investment (FDI) by providing relevant information, reducing uncertainty and building trust (see, e.g., Leblang 2010, Javorcik et al. 2011, Kugler et al. 2013).

61 See Foreign Policy, Ranking the rich. May/ June 2003, page 64 (http://terpconnect.umd.edu/ dcrocker/Courses/Docs/Aid\%20Effectiveness.htm; accessed: January 2015).

${ }^{62}$ For instance, Adams and Page (2005: 1645) find that "both international migration and remittances significantly reduce the level, depth, and severity of poverty in the developing world." Anyanwu and Erhijakpor (2010) report similar results for a sample of 33 African countries. See also various contributions on the brain drain/ gain and remittances to the volume edited by Czaika and Vargas-Silva (2012: Part III). Ratha et al. (2011) review the relevant literature.

${ }^{63}$ However, Parsons (2012) finds that the positive impact of migration on trade vanishes in a dyadic setting when including country-pair fixed effects to account for unobserved bilateral factors. 
In a similar vein, one might argue that immigrants help improve the effectiveness of official development aid by reducing "information and trust friction" (Hatzigeorgiou and Lodefalk 2015). Donors could make use of the immigrants' familiarity with local conditions and specific needs for aid in their home countries. Better information on specific needs could render aid more effective if donors adjusted the composition of aid accordingly and, thus, provided welltargeted aid. ${ }^{64}$ Conversely, immigrants and possibly even temporary foreign workers tend to acquire skills when working in the more advanced donor countries. The poorer sending countries may tap into superior knowledge acquired by the diaspora abroad, especially when migrants and workers return home: “Access to information through the diaspora and the skills learned by returning migrants can improve technology, management and institutions in the sending country" (Ratha et al. 2011: 6) and, thereby, improve the aid recipient country's absorptive capacity for a productive use of aid inflows.

Furthermore, lobbying by foreign ethnic groups in the donor countries may render aid more effective and strengthen complementarities between aid and remittances. Lahiri and Raimondos-Møller (2000) present a theoretical model to explain the striking relationship between the presence of ethnic groups in the donor countries and the allocation of aid across the countries of origin of these groups. The authors argue that foreign ethnic groups "often lobby the (host) government for the benefit of the countries of their origin." Specifically, potential investors among migrants living in the donor countries may lobby for particular types of aid, namely those which help remove critical bottlenecks and, thereby, promote the productivity of their own remittances. Finally, by encouraging "continuous and expanding economic relations between sending and receiving countries" (Grieco and Hamilton 2004: 5; emphasis added), immigrants may help reduce the typical volatility of aid disbursements, which have been shown to erode the growth effects of aid (Lensink and Morrissey 2000, Kodama 2012).

It is questionable, however, whether immigrants and foreign workers have sufficient political clout to influence the aid policies of donor countries. ${ }^{65}$ Furthermore, compared to the effects of migration on international trade and private financial flows, it appears to be more

\footnotetext{
${ }^{64}$ The role of trust for more effective aid has been stressed by Dreher et al. (2015a).

${ }^{65} \mathrm{We}$ are grateful to an anonymous reviewer for having stressed this point. As discussed in more detail in Section 3 , the proportion of illegal migration included in the available datasets is often unknown (Parsons 2012). The political clout of foreign ethnic groups would diminish further in donor countries whose statistical reporting does not distinguish between temporary workers and immigrants in the strict sense, and where temporary workers play a major role.
} 
difficult to reduce "information and trust friction" when it comes to the effectiveness of official development aid. According to the literature on trade and FDI, it is mainly skilled migrants who play a significant role in fostering private international flows (Head and Ries 1998, Javorcik et al. 2011, Kugler et al. 2013). However, migrants and temporary workers from strongly aiddependent countries are often unskilled and may lack the knowledge and contacts needed for reducing transaction costs. Moreover, the dissemination of relevant information and the generation of trust tend to take place at the firm-level through employment of foreign workers and immigrants (Hatzgeorgiou and Lodefalk 2015). A comparable transmission mechanism is largely lacking at the level of official bureaucracies administering foreign aid.

Consequently, one might suspect that it is mainly through the remittances of temporary foreign workers and migrants residing more permanently in donor countries that aid may become more effective. ${ }^{66}$ Approximating the developing world of aid recipients to include all countries outside the donor community, the available evidence suggests that about two thirds of donors' overall outflows of remittances are transferred to aid recipients. ${ }^{67}$ An increase in donors' overall outflows of remittances can, thus, be reasonably assumed to render complementarities between aid and remittances more likely, even though bilateral data on remittances are not available for most of our period of observation so that complementarities cannot be assessed at the bilateral level for specific pairs of donors and recipients. ${ }^{68}$

The literature offers several arguments that the interaction of aid with remittances might have positive growth effects in the aid recipient countries. Aid and remittances can be complementary means of financing. While remittances are private flows and primarily benefit the families of migrants in the sending country, "philanthropic remittances" are not uncommon (Ratha et al. 2011: 5). In other words, the diaspora contributes to social and economic development at home by co-financing projects in education, health, and community infrastructure (e.g., Goldring 2004). Complementarities between aid and remittances may even exist if projects

\footnotetext{
${ }^{66}$ It should be noted that temporary workers, e.g., in the construction sector of Arab donor countries and in agriculture of some European donor countries, often contribute considerably to the outflows of overall remittances from donor countries.

${ }^{67}$ According to recent World Bank data on bilateral remittances (http://go.worldbank.org/092X1CHHD0), non-donor countries received 63 percent of the overall outflows of remittances from DAC donors included in our sample in 2010, i.e., the latest year of our period of observation. The corresponding share was still higher (about 80 percent) for non-DAC donors included in our sample. Even though we miss some 'new' donors in our sample (see Section 4 for details), the above approximation appears to be reasonable since new donors such as China and India were important aid recipients throughout most of our period of observation.

${ }^{68}$ As we discuss in Section 3, bilateral data on remittances are available only since 2010.
} 
in education and health are purely aid-financed. According to Ratha et al. (2011), a growing body of evidence suggests that the private income from remittances is largely spent on education and health, rather than conspicuous consumption. In other words, remittances tend to fuel higher demand for productivity enhancing social services that aid helped to provide. ${ }^{69}$

Similar complementarities between aid and remittances have been suggested in other fields. De Haas (2005) reports that migrant households often tend to have a higher propensity to invest in agriculture and other private enterprises than non-migrant households. According to McKenzy and Yang (2014: 21), "a large variety of initiatives are ongoing to channel migrant remittances towards longer-run household investments." Aid and invested remittances could then mutually reinforce each other in promoting economic growth. Aid may help remove critical bottlenecks to a more productive use of invested remittances, e.g., by improving the recipient country's infrastructure and institutions. Conversely, higher local investments financed by remittances could boost the growth effects of aid-financed infrastructure and institutions by making better use of facilities and business opportunities. ${ }^{70}$

\subsection{Measurement issues}

As stressed by Roodman (2013: 40), "there are data problems, including the lack of comprehensive information on remittances and illegal immigration, and a paucity of internationally comparable information on rich countries' migration policies." The above noted sub-index on migration policies, which is part of the Center for Global Development's overall Commitment to Development Index, has much to recommend from a conceptual point of view. The index combines several indicators supposed to capture important aspects of the migration policies of donor countries and their relevance for aid-recipient countries. The 2013 edition of the index is based on the following indicators: gross migrant inflows, weighted by poverty of sending countries, in percent of the donor country's population; students from developing countries, in percent of all foreign students in the donor country; refugee population and asylum applications per billion US\$ of donor country's GDP (Roodman 2013).

\footnotetext{
${ }^{69}$ This reasoning implies that higher remittances could improve the effectiveness of aid from any donor (not only the donor with higher remittances).

${ }^{70}$ In a similar vein, Dayton-Johnson and Katseli (2006: 21) argue that aid could diffuse the benefits of migration better: "Remittances might expand economic opportunities in migrants' home regions, but with bad roads or telephone service, it might be difficult for workers elsewhere in the country to move to those regions and benefit from expanded opportunities."
} 
For several reasons, however, the CGD's index of migration cannot be used in our empirical analysis below. It is available only since 2003. Furthermore, within this rather short period, the construction of the index has been modified repeatedly - in terms of coverage and exact definition of indicators included. For instance, the 2013 edition of the index removed two indicators previously used, including the change in the stock of non-native residents without tertiary education (Roodman 2013). These modifications often resulted in significant changes in the ranking of donors countries. The United States provides an example: it appears to be largely due to changes in index construction that the US ranking fluctuated heavily between position 14 (among 21 donor countries) in 2003, position 2 in 2004, and position 12 in $2005 .^{71}$

Given the problems of constructing an index of migration in a consistent way over a sufficiently long period of time, one has to revert to simpler proxies in empirical panel analyses. While the stock or flow of migrants is widely used in the literature on the determinants of international trade and FDI, ${ }^{72}$ we focus on the remittances paid by donor countries in the present context of donor quality and aid effectiveness.

Importantly, using remittances as a proxy of donor quality has a limitation in common with the CGD's index: This measure does not vary across recipient countries. Bilateral data on the remittances paid by donor countries to specific recipient countries are not available for a sufficiently long period of time. ${ }^{73}$ In contrast, origin-destination matrices are principally available on migration. ${ }^{74}$ However, these matrices are typically based on census data collected in ten-year intervals. ${ }^{75}$ Consequently, extensive interpolation would be required to allow for a meaningful panel analysis on aid effectiveness. Furthermore, while "every effort has been made to remove refugees" from the data on migration provided by Özden et al. (2011), "it is still likely that a fairly large proportion of illegal migrants are captured in national censuses" (Parsons 2012: 13).

\footnotetext{
71 For details see the annual briefs and the related technical papers available from the CGD's website: http://www.cgdev.org/initiative/commitment-development-index/index (accessed: June 2015).

${ }^{72}$ See the references given to this literature ion Section 2 above.

${ }^{73}$ The World Bank publishes bilateral remittance matrices only since recently; matrices for the years 2010-2014 are available from: http://go.worldbank.org/092X1CHHD0 (accessed: June 2015). The World Bank's estimates of bilateral remittances use migrant stocks, host-country incomes and origin-country incomes, based on the methodology of Ratha and Shaw (2007). See also Roodman (2004: 33) on the inflows and outflows of worker remittances reported in the IMF's Balance of Payments Statistics: "The inflow numbers are not disaggregated by source, and the outflow numbers are not disaggregated by destination."

74 For details, see Özden et al. (2011) and the OECD database available from: http://stats.oecd.org/Index.aspx?DataSetCode=MIG\# (accessed: June 2015).

${ }^{75}$ Note that Kugler et al. (2013) use bilateral data on migration for just two points in time, 1990 and 2000 . Parsons (2012) uses data with ten-year intervals since 1960. Annual OECD data on bilateral migration are available only since 2004.
} 
Data on international migrant stocks reported in the World Bank's World Development Indicators, with the United Nations Population Division given as the ultimate source, include refugees. ${ }^{76}$ Data from the same source on remittances paid by donor countries comprise personal transfers and compensation of employees. ${ }^{77}$ While this measure is also far from perfect as a proxy of donor quality, its major advantage is the availability of sufficiently long and consistent time series on an annual basis.

Against this backdrop, we focus on remittances as our preferred proxy of donor quality in our empirical analysis below. As shown in Table 3.1, the donors with the highest remittances in our sample are Luxembourg, Kuwait, Switzerland, Israel and Belgium. In particular, the first three of these donors are outliers in terms of average remittances paid throughout the period of observation, in percent of the donors' GDP, considering that remittances typically accounted for less than one percent of GDP. ${ }^{78}$ For some donor countries in Central Europe and the Baltics, but also for Japan and Turkey, remittances did not even reach 0.1 percent of GDP. At the same time these countries often had small overall aid budgets, but small overall aid budgets are also observed for several donor countries with relatively high remittances (e.g., the Czech Republic, Korea, and some non-DAC donors in Table 3.1). Conversely, larger aid budgets go along with relatively low remittances in Sweden. Taken together, we observe considerable heterogeneity within our sample when comparing remittances and aid in percent of donors' GDP.

\subsection{Data and method}

It has proven notoriously difficult to identify the impact of foreign aid on economic growth in the recipient countries. While the endogeneity of foreign aid is generally accepted, the instrumentation strategies of empirical analyses appear to be inappropriate to mitigate endogeneity concerns. Dreher et al. (2014) argue that widely used instrumentation strategies relying on the recipient countries' population size or on internal (GMM-style) instruments typically violate the exclusion restriction. Another strategy relying on bilateral political relations, e.g., as reflected in voting coincidence in the United Nations General Assembly, can be regarded

\footnotetext{
${ }^{76}$ For details see: http://data.worldbank.org/indicator/SM.POP.TOTL.ZS (accessed: June 2015).

${ }^{77}$ For details see: http://data.worldbank.org/indicator/BM.TRF.PWKR.CD.DT (accessed: June 2015).

${ }^{78}$ Hence, we test the robustness of our baseline results to the exclusion of donors with particularly high remittances in percent of GDP in Section 5 below.
} 
as problematic when the donors' motive to grant aid influences the effectiveness of aid. ${ }^{79}$ Likewise, Bazzi and Clemens (2013) conclude that previous studies on aid effectiveness employ weak instruments.

Clemens et al. (2012: 591) deliberately "avoid poor-quality instrumental variables and instead address potential biases from reverse and simultaneous causation by the more transparent methods of lagging and differencing." They suggest first-differencing in order to eliminate omitted variable bias due to unobserved time-invariant heterogeneity. By lagging aid by one period, Clemens et al. (2012) assess whether economic growth follows aid inflows. In other words, they assess whether aid Granger-causes growth.

We follow the approach of Clemens et al. (2012) in our empirical analysis below even though it has been criticized for several reasons by Roodman (2015), notably for failing to remove contemporaneous endogeneity. First-differencing removes omitted-variable bias from time-invariant factors. In contrast, first-differencing does not address omitted-variable bias from time-variant characteristics of recipient countries. For instance, donors may grant more aid to a newly elected government that initiates growth promoting reforms. Higher growth induced by local reforms could then be spuriously attributed to foreign aid (see also Dreher et al. 2015b). Generally speaking, Granger causality would not necessarily reflect causal effects of aid on growth in the strict sense. ${ }^{80}$ While Roodman (2015: 269) agrees that "instrumenting aid is difficult," he recommends reducing "endogeneity by twice-lagging aid when regressing in differences."

Arguably, the problems of identifying the growth effects of aid per se are less serious in the present context of assessing whether the growth effects depend on complementary donor policies, as reflected in overall remittances. Even if the direct effect of aid on growth is biased, this does not automatically imply a systematic bias for our variable of principal interest, i.e., the

\footnotetext{
${ }^{79}$ Brückner (2013) uses variations in rainfall and international commodity price shocks as instruments for growth in a two-step procedure in order to assess the causal effects of aid on growth for a relatively small sample of least developed recipient countries. In the first step, he estimates the effect of growth on aid using rainfalls and international commodity price shocks as instruments to generate exogenous variation in GDP per capita growth. In the second step, the residual variation in aid that is not driven by GDP per capita growth is used as an instrument for aid to estimate by 2SLS the effect of aid on economic growth. The suitability of variations in rainfall and international commodity price shocks as instruments is open to debate, however, once the sample is extended to include the whole spectrum of low- and middle-income aid recipients.

${ }^{80}$ It should be noted that Clemens et al. (2012: 600) explicitly acknowledge this limitation.
} 
interaction between aid and the donors' outflows of remittances. ${ }^{81}$ All the same, we perform an additional estimation with an extended lag of two periods for the aid variable to account for Roodman's (2015) above noted critique of the approach of Clemens et al. (2012).

Specifically, we base our analysis on Clemens et al.'s (2012) permutations of the study of Rajan and Subramanian (2008) which figures most prominently in the recent literature on aid and growth. We then extend the specification by adding our variable of principal interest, the quality of recipient country $i$ 's donors in terms of overall remittances paid by the donors to all countries (DonQual), and the interaction of this measure with the aid variable. This results in the following reduced-form empirical model at the country-period level:

$\Delta$ Growth $_{\mathrm{i}, \mathrm{t}}=\alpha+\beta \Delta \operatorname{Aid}_{\mathrm{i}, \mathrm{t}-1}+\gamma \Delta \operatorname{DonQual}_{\mathrm{i}, \mathrm{t}-1}+\delta \Delta \operatorname{Aid}_{\mathrm{i}, \mathrm{t}-1} * \Delta \operatorname{DonQual}_{\mathrm{i}, \mathrm{t}-1}+\zeta \Delta \boldsymbol{X}_{\mathrm{i}, \mathrm{t}}+\varepsilon_{\mathrm{i}, \mathrm{t}}$

where Growth $h_{\mathrm{i}, \mathrm{t}}$ is recipient country $i$ 's average yearly growth of GDP per capita over the fiveyear period $t$. $A i d_{\mathrm{i}, \mathrm{t}-1}$ denotes the amount of bilateral aid, in percent of the recipient country's GDP, disbursed in the previous five-year period. ${ }^{82}$

DonQual $_{\mathrm{i}, \mathrm{t}-1}$ reflects the quality of the average donor in recipient country $i$ at time $t-1$, by weighting the amount of aid a country receives from donor $j$ with $j$ 's overall remittances paid:

$$
\text { DonQual }_{\mathrm{i}, \mathrm{t}-1}=\sum_{j=1}^{n} s_{\mathrm{ij}, \mathrm{t}-1} * \text { Remit }_{\mathrm{j}, \mathrm{t}-1} \text {, }
$$

where $S_{\mathrm{ij}, \mathrm{t}-1}$ is the aid share of donor $j$ in recipient country $i$ 's total bilateral aid in period $t$ - 1 ; Remit $_{\mathrm{j}, \mathrm{t}-1}$ represents the amount of remittances, paid by the donor country in percent of its GDP. ${ }^{83}$ As mentioned in Section 3 above, Remit varies only across donor countries $j$ as bilateral data on remittances paid to specific recipient countries $i$ are not available for our sample of donor countries for a sufficiently long period of time. The variation of DonQual by recipient country stems exclusively from the varying aid shares of $i$ 's different donors. This implies that the

\footnotetext{
${ }^{81}$ According to Nunn and Qian (2012), "interacting an arguably exogenous term [here: donors' remittances paid to all countries, rather than bilateral flows] with one that is potentially endogenous [here: bilateral aid], can be interpreted as exogenous since we directly control for the main effect of the endogenous variable." This reasoning resembles the logic of a difference-in-differences estimation (Nunn and Qian 2014). In a similar vein, Kugler et al. (2013:4) argue that focusing on the differential impact of a potentially endogenous variable renders omitted variable bias less likely since a possible confounder would have to "explain not just the main effect but also the differential effects." Dreher et al. (2014: 3) follow this logic by distinguishing the growth effects of politically motivated aid from the effects of all aid, without offering "recipes to estimate a causal effect of all aid on growth."

${ }^{82}$ Note that we account for multilateral aid as a control variable.

${ }^{83} \mathrm{We}$ are most grateful to Andreas Fuchs for sharing his data with us.
} 
interaction between Aid and DonQual in equation (1) captures whether aid is more effective in promoting growth when donors with higher outflows of (overall) remittances contribute more to recipient country $i$ 's total aid receipts.

All regressions are in first differences and account for the control variables used in the original study of Rajan and Subramanian (2008), denoted $\boldsymbol{X}$, which we include contemporaneously (as in Clemens et al. 2012): (log) initial GDP per capita, initial trade policy index (the well-known Sachs-Warner index, extended by Wacziarg and Welch), initial life expectancy, (log) inflation, initial M2/GDP, budget balance/GDP, revolutions, and period dummies. ${ }^{84}$ In some specifications we additionally include aid squared to test for decreasing returns to aid, following Clemens et al. (2012). ${ }^{85}$ Finally, $\varepsilon$ is the error term. The standard errors in all our estimations are heteroskedasticity-robust and clustered by recipient country.

Equation (1) is estimated for a sample of 70 aid recipient countries. The sample includes all countries with sufficient data availability listed by the OECD's Development Assistance Committee (DAC) as recipient countries at the beginning of our period of observation. Appendix $\mathrm{C}$, Table $\mathrm{C} 3$, lists the recipient countries included in our baseline estimation. The calculation of donor quality according to equation (2) is based on a sample of 38 donor countries. As can be seen from the list in Table 3.1, the donor sample includes all 29 member countries of the OECD's DAC (as of 2015) and nine non-DAC donors with sufficient data availability.

\subsection{Results and robustness}

Table 3.2 presents our baseline regression results covering the $1985-2010$ period. ${ }^{86}$ It should be recalled that all data are averaged over five years. Our dependent variable is the (change in the) growth rate of real GDP per capita. The explanatory variables of major interest are: (the change in) gross bilateral official development assistance as a percentage of the recipient country's GDP

\footnotetext{
${ }^{84}$ Rajan and Subramanian (2008) also include time-invariant variables which are dropped here by taking differences. See Appendix C, Table C1 and Table C2, for summary statistics as well as detailed variables descriptions and data sources.

${ }^{85}$ At the same time, we perform additional estimations with a reduced set of control variables; see below for details.

${ }^{86}$ The time dimension of our sample is limited by data availability, notably the availability of consistent data on remittances from World Development Indicators (2013).
} 
(Aid), (the change) in the aid-weighted remittances paid by the donor countries of a particular recipient country (DonQual), and the interaction between these two variables. ${ }^{87}$

For a start, column (1) of Table 3.2 does not account for DonQual. As can be seen, Aid enters with a negative sign, but proves to be statistically insignificant at conventional levels. This is in line with the original finding of Rajan and Subramanian (2008), according to whom aid per se is not effective in stimulating growth in the recipient countries. The results on the control variables taken from Rajan and Subramanian (2008) are similar to those in Dreher et al. (2015a), who also employ the approach of Clemens et al. (2012) by taking first differences and lagging aid. While several variables are insignificant at conventional levels, the coefficients on Initial GDP p.c. (log), Inflation (log) and Revolutions have negative signs as expected and are significant at the five percent level or better.

In column (2) we include DonQual and the interaction of Aid with DonQual. The estimation in column (3) includes the aid variables in squared terms to account for decreasing returns to aid, while the estimation in column (4) also accounts for the interaction of Aid in squared terms with DonQual. The results on the control variables used by Rajan and Subramanian (2008) are hardly affected by these modifications, compared to the basic specification in column (1).

As concerns our variables of principal interest, the coefficients on both Aid per se and DonQual per se are statistically insignificant at conventional levels. However, we find significant and positive interactions between aid and DonQual in terms of aid-weighted remittances paid by donors, at least at the five percent level. This supports our hypothesis that bilateral aid is more likely to have positive growth effects when recipient countries receive aid mainly from donor countries with higher outflows of remittances.

We are particularly interested in the marginal effect of aid on growth over the whole range of DonQual. We calculate the marginal effect of $\Delta A i d$ which is equal to $\beta+\delta \Delta$ DonQual $_{\mathrm{i},-1}$ (according to equation 1), based on the regression results in column (2) of Table 3.2. Figure 3.1 portrays the marginal effect, together with the 95 percent confidence interval. The figure clearly reveals that the growth impact of aid improves with higher remittances - or, more precisely, the

\footnotetext{
${ }^{87}$ In addition to the control variables taken from Rajan and Subramanian (2008), we also control for gross multilateral aid as well as repayments of (bilateral and multilateral) aid in Table 2. However, these additional control variables typically enter statistically insignificant (except for multilateral repayments when accounting for squared aid inflows and repayments).
} 
more aid inflows recipients receive from donor countries with higher remittances - as evident from the positive and statistically significant coefficient of the corresponding interaction term $(\delta)$.

Specifically, assume that aid is increased by one percentage point. This increase in aid raises the growth rate by 0.7 percentage points if DonQual, i.e., aid-weighted remittances, increases by one percentage point, compared to no change in DonQual. As can be seen in Figure 3.1, the confidence intervals widen to the left from the point of zero on the $\mathrm{x}$-axis. This implies that the effect of aid on growth becomes insignificant with negative changes in DonQual.

We conclude from column (2) of Table 3.2 that the effectiveness of aid in promoting growth in the recipient countries depends considerably on the donors' outflows of remittances. This finding also holds when accounting for aid in squared terms (column 3) plus the interaction between squared aid and DonQual (column 4). Interestingly, these extensions do not point to decreasing returns to aid; neither do they suggest that the impact of DonQual on the effectiveness of aid depends in a non-linear way on the amount of aid.

We test the robustness of our major results in several ways. First, we employ the specification of Burnside and Dollar (2000), instead of the specification of Rajan and Subramanian (2008). In other words, we replace all control variables $\boldsymbol{X}$ in equation (1) taken from Rajan and Subramanian by the control variables used by Burnside and Dollar, whereas all other characteristics of equation (1) are left unchanged. For the sake of brevity, we do not show the results with the alternative specification of Burnside and Dollar (2000). However, the marginal effects of aid on growth over the range of DonQual closely correspond to the pattern shown in Figure 3.1. ${ }^{88}$

Second, we report two estimations based on parsimonious specifications of equation (1) in Table 3.3. ${ }^{89}$ In column (2), we drop all control variables that proved to be statistically insignificant in Table 3.2. In column (1), we even drop the three statistically significant control variables from Table 3.2 (Initial GDP p.c., Inflation and Revolutions). Not surprisingly, the adjusted $\mathrm{R}^{2}$ declines considerably when excluding all control variables. Importantly, however, our major results hold in columns (1) and (2) of Table 3.3. In particular, the interaction between Aid and DonQual is hardly affected and continues to be statistically significant at the one percent level.

\footnotetext{
${ }^{88}$ See the working paper version of this article for details and additional figures.

${ }^{89}$ As noted by an anonymous reviewer, some of the control variables may be endogenous so that including them may be problematic.
} 
Third, we address the above noted concern that first differencing, as suggested by Clemens et al. (2012), is insufficient to account for the endogeneity of aid. Specifically, we follow Roodman's (2014) advice to lag the aid variable by two periods, rather than just one period, in column (3) of Table 3.3. Employing the specification of equation (1) as in column (2) of Table 3.2, there are two notable changes when lagging aid twice. First, the effect of Aid per se becomes significantly negative at the five percent level. Second, the size of the coefficient on the interaction of Aid and DonQual is somewhat smaller compared to the estimation with aid lagged just once. Importantly, however, the interaction continues to be statistically significant at the one percent level. In other words, we still find that aid is more likely to have positive growth effects when recipients receive aid mainly from donors with higher outflows of remittances.

Fourth, we exclude non-DAC and non-traditional DAC donors from the sample of donor countries. As shown in Section 3, some of these donors are major sources of workers' remittances. Thus, one might suspect that our results are mainly driven by these donor countries. This is not the case, however. The results from column (2) of Table 3.2 hold when DonQual is based on remittances only from traditional DAC members. As can be seen in column (1) of Table 3.4, the interaction of Aid and DonQual is statistically significant at the one percent level and the coefficient of the interaction term is of similar size when non-DAC and non-traditional DAC donors are excluded from our sample.

Fifth, we assess whether our basic results are driven by traditional DAC donors with relatively high remittances as percentage of their GDP. ${ }^{90}$ In column (2) of Table 3.4, we exclude Luxembourg with outstandingly high remittances, followed by those traditional DAC donors that rank next in terms of remittances (columns 3-6). Independent of the DAC donor excluded, the interaction of Aid and DonQual is statistically significant at the one percent level and the size of the coefficient of the interaction term is hardly affected compared to column (2) in Table 3.2.

Finally, we exclude either the quartile of recipient countries with the lowest growth or the quartile with the highest growth from our sample to test whether the complementarity between aid and the donors' outflows of remittances is restricted to a particular sub-group of aid recipients. As shown in Table 3.4, the statistical significance of the interaction of Aid and DonQual weakens to the ten percent level when excluding the recipients with the lowest growth

\footnotetext{
90 Note that new DAC donors such as Israel and the Czech Republic, which joined the DAC after 2009, were excluded together with non-DAC donors in column (1) of Table 3.4.
} 
(column 7). The results are hardly affected, compared to the full sample of recipients, when excluding the recipients with the highest growth (column 8). Taken together, this could be taken as an indication that it is mainly the slow growing recipient countries that benefit from the complementarity of aid and donors' outflows of remittances.

\subsection{Conclusions}

We argue that donors could improve the effectiveness of foreign aid by pursuing complementary and coherent non-aid policies. In particular, we hypothesize that aid has stronger growth effects if recipients receive more aid from donors that allow for (temporary) worker mobility and are open to immigration. We focus on overall remittances paid by the donor countries to proxy for worker mobility and immigration. We follow Clemens et al. (2012) and estimate the aid-growth nexus in first differences. At the same time, we account for Roodman's (2015) critique of this approach by performing an additional estimation with longer lags of the aid variable in order to reduce endogeneity concerns. Our empirical results support the hypothesis that the donors' outflows of remittances strengthen the growth effects of foreign aid.

Our findings have important implications for both the donors and recipients of foreign aid, even though it has to be kept in mind that remittances are far from perfect in capturing the donors' policies with respect to (temporary) worker mobility and (more permanent) immigration. Political resistance in various donor countries against more worker mobility and immigration not only involves costs for the donors themselves (e.g., in terms of access to foreign skills and improving the age structure of the workforce) but also for the recipients of development aid. In particular, the effectiveness of aid is eroded if official financial generosity is misconceived as an alternative to offering better employment opportunities for foreign workers and migrants, resulting in higher remittances, which should be of concern at least for altruistic donors. From the perspective of aid recipients, it appears that maximizing aid inflows is unlikely to have the desired effects on economic growth and poverty alleviation unless development cooperation with donors is broadened to cover complementary (non-aid) policies such as international worker mobility and migration.

Our analysis of the complementarity of aid and donors' outflows of remittances suggests two avenues of future research. On the one hand, taking a broader perspective by accounting for various non-aid policies may help identify further complementarities. This research direction would be closely related to the Commitment to Development Index (CDI) of the Center for 
Global Development, which covers various policy areas that could complement aid and, thereby, result in a coherent approach of helping the poor. On the other hand, further research may take the opposite direction to identify the driving forces underlying the complementarity between aid and remittances. Refined analyses, including micro-level surveys, could offer important insights on the role of remittances, the acquisition of superior skills and knowledge by (returning) workers and migrants, and lobbying by foreign ethnic groups in the donor countries for improving the effectiveness of aid. Furthermore, once sufficiently long time series of bilateral data on remittances become available, one might consider the interaction between aid and remittances from the same donor and, alternatively, the interaction with remittances from other donors. This would help overcome a limitation of our analysis above, by making it possible to assess whether or not the complementarity between aid and remittances is mainly bilateral for a specific donorrecipient pair.

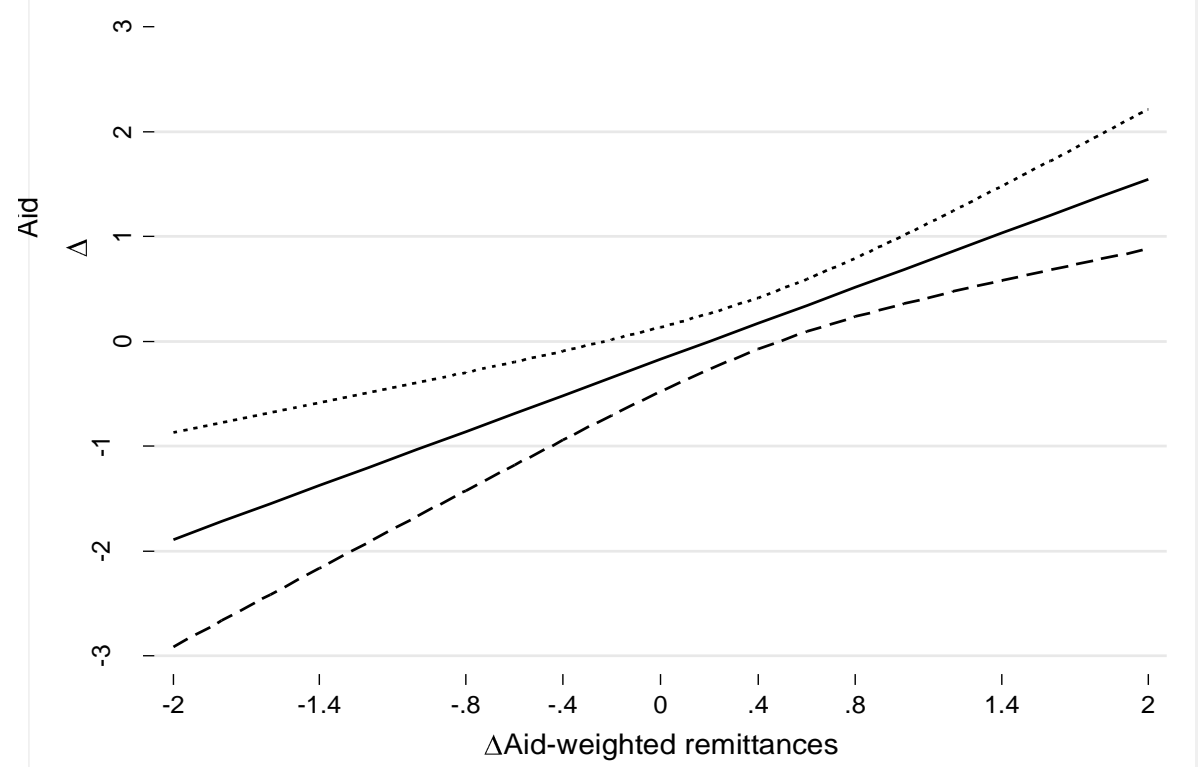

Figure 3.1 Marginal effects of aid on growth as DonQual changes

Note: Based on the regression results in column 2 of Table 3.2. Solid line in the graph shows the marginal effect of $\Delta A i d$ which is equal to $\beta+\delta \Delta D o n Q u a l_{\mathrm{i}, \mathrm{t}-1}$ (according to equation 1 ), based on the regression results in column (2) of Table 3.2. Dotted lines portray the 95 percent confidence interval. 
Table 3.1 DAC and non-DAC donors: Remittances and aid in percent of GDP

\begin{tabular}{|c|c|c|}
\hline DAC & Remit/GDP & Aid/GDP \\
\hline Australia & 0.236 & 0.253 \\
\hline Austria & 0.428 & 0.190 \\
\hline Belgium & 1.013 & 0.254 \\
\hline Canada & 0.308 & 0.187 \\
\hline Czech Republic & 0.869 & 0.034 \\
\hline Denmark & 0.470 & 0.384 \\
\hline Finland & 0.062 & 0.168 \\
\hline France & 0.483 & 0.344 \\
\hline Germany & 0.536 & 0.260 \\
\hline Great Britain & 0.156 & 0.195 \\
\hline Greece & 0.237 & 0.059 \\
\hline Ireland & 0.458 & 0.094 \\
\hline Island & 0.274 & 0.072 \\
\hline Israel & 1.326 & 0.132 \\
\hline Italy & 0.216 & 0.097 \\
\hline Japan & 0.050 & 0.226 \\
\hline Korea & 0.400 & 0.030 \\
\hline Luxembourg & 15.623 & 0.330 \\
\hline Netherlands & 0.625 & 0.458 \\
\hline New Zealand & 0.674 & 0.105 \\
\hline Norway & 0.428 & 0.398 \\
\hline Poland & 0.206 & 0.019 \\
\hline Portugal & 0.269 & 0.161 \\
\hline Slovakia & 0.053 & 0.022 \\
\hline Slovenia & 0.270 & 0.029 \\
\hline Spain & 0.261 & 0.139 \\
\hline Sweden & 0.149 & 0.366 \\
\hline Switzerland & 2.926 & 0.151 \\
\hline United States & 0.211 & 0.133 \\
\hline \multicolumn{3}{|l|}{ Non-DAC } \\
\hline Cyprus & 0.702 & 0.018 \\
\hline Estonia & 0.213 & 0.009 \\
\hline Hungary & 0.496 & 0.029 \\
\hline Kuwait & 4.784 & 2.744 \\
\hline Latvia & 0.095 & 0.004 \\
\hline Lithuania & 0.604 & 0.019 \\
\hline Romania & 0.066 & 0.007 \\
\hline Thailand & 0.194 & 0.027 \\
\hline Turkey & 0.020 & 0.047 \\
\hline
\end{tabular}

Source: Authors' calculation based on World Bank Development Indicators and the OECD-DAC Aid Statistics Database. 
Table 3.2 Baseline estimation results, all donors, 1985-2010, Rajan and Subramanian (2008) specification

\begin{tabular}{|c|c|c|c|c|}
\hline Dependent variable: $\Delta$ Growth & $(1)$ & $(2)$ & (3) & (4) \\
\hline \multirow{2}{*}{ Aid } & -0.100 & -0.171 & -0.337 & -0.369 \\
\hline & {$[0.155]$} & {$[0.154]$} & {$[0.280]$} & {$[0.306]$} \\
\hline \multirow[t]{2}{*}{ DonQual (Remittances/GDP) } & & 0.356 & 0.251 & 0.638 \\
\hline & & {$[1.372]$} & {$[1.372]$} & {$[1.538]$} \\
\hline \multirow[t]{2}{*}{ Aid*DonQual } & & $0.860 * * *$ & $0.834 * * *$ & $1.248^{* *}$ \\
\hline & & {$[0.197]$} & {$[0.190]$} & {$[0.606]$} \\
\hline \multirow[t]{2}{*}{ Aid squared*DonQual } & & & & -0.016 \\
\hline & & & & {$[0.019]$} \\
\hline \multirow[t]{2}{*}{ Aid squared } & & & 0.007 & 0.008 \\
\hline & & & {$[0.006]$} & {$[0.007]$} \\
\hline \multirow[t]{2}{*}{ Bilateral repayments squared } & & & 0.217 & 0.216 \\
\hline & & & {$[0.247]$} & {$[0.249]$} \\
\hline \multirow[t]{2}{*}{ Multilateral aid squared } & & & -0.018 & -0.020 \\
\hline & & & {$[0.015]$} & {$[0.016]$} \\
\hline \multirow[t]{2}{*}{ Multilateral repayments squared } & & & $1.857^{* *}$ & $1.858^{* *}$ \\
\hline & & & {$[0.730]$} & {$[0.741]$} \\
\hline \multirow[t]{2}{*}{ Multilateral aid } & 0.069 & 0.201 & 0.559 & 0.581 \\
\hline & {$[0.151]$} & {$[0.158]$} & {$[0.382]$} & {$[0.399]$} \\
\hline \multirow[t]{2}{*}{ Bilateral repayments } & 0.092 & 0.066 & -0.674 & -0.671 \\
\hline & {$[0.394]$} & {$[0.370]$} & {$[1.095]$} & {$[1.096]$} \\
\hline \multirow[t]{2}{*}{ Multilateral repayments } & -0.623 & 0.304 & $-3.673 *$ & $-3.774 *$ \\
\hline & {$[0.922]$} & {$[0.890]$} & {$[1.968]$} & {$[1.973]$} \\
\hline \multirow[t]{2}{*}{ Initial GDP p.c. (log) } & $-8.680 * * *$ & $-8.528 * * *$ & $-8.588 * * *$ & $-8.642 * * *$ \\
\hline & {$[1.098]$} & {$[1.222]$} & {$[1.206]$} & {$[1.224]$} \\
\hline \multirow[t]{2}{*}{ Initial life expectancy } & 0.008 & -0.003 & -0.015 & -0.020 \\
\hline & {$[0.075]$} & {$[0.072]$} & {$[0.067]$} & {$[0.066]$} \\
\hline \multirow[t]{2}{*}{ Openness } & 0.834 & 0.737 & 0.679 & 0.694 \\
\hline & {$[0.589]$} & {$[0.582]$} & {$[0.596]$} & {$[0.600]$} \\
\hline \multirow[t]{2}{*}{ Inflation $(\log )$} & $-1.127 * * *$ & $-1.251 * * *$ & $-1.228 * * *$ & $-1.219 * * *$ \\
\hline & {$[0.376]$} & {$[0.453]$} & {$[0.437]$} & {$[0.440]$} \\
\hline \multirow[t]{2}{*}{ Initial M2/GDP } & 0.005 & -0.021 & -0.025 & -0.024 \\
\hline & {$[0.013]$} & {$[0.024]$} & {$[0.024]$} & {$[0.024]$} \\
\hline \multirow[t]{2}{*}{ Budget balance/GDP } & 0.145 & 0.138 & 0.135 & 0.134 \\
\hline & {$[0.123]$} & {$[0.136]$} & {$[0.140]$} & {$[0.139]$} \\
\hline \multirow[t]{2}{*}{ Revolutions } & $-0.855^{* *}$ & $-0.920 * *$ & $-0.901 * *$ & $-0.894 * *$ \\
\hline & {$[0.389]$} & {$[0.366]$} & {$[0.369]$} & {$[0.370]$} \\
\hline Adj. R-Squared & 0.224 & 0.262 & 0.264 & 0.262 \\
\hline Number of Countries & 70 & 70 & 70 & 70 \\
\hline Number of Observations & 257 & 257 & 257 & 257 \\
\hline
\end{tabular}

OLS panel estimation in first differences following the specification of Rajan and Subramanian (2008) as in Clemens et al. (2012). All aid and repayment variables are calculated as \% of GDP and are lagged. All regressions include period (5-year) dummies. Significance levels $* \mathrm{p}<0.10, * * \mathrm{p}<0.05 * * * \mathrm{p}<0.01$. Standard errors are heteroskedasticity-robust and clustered by recipient country. 
Table 3.3 Robustness tests for Column 2, Table 3.2, excluding control variables and lagging aid twice

\begin{tabular}{|c|c|c|c|}
\hline Dependent variable: $\Delta$ Growth & (1) & (2) & (3) \\
\hline \multirow[t]{2}{*}{ Aid } & 0.043 & -0.081 & $-0.159 * *$ \\
\hline & {$[0.073]$} & {$[0.076]$} & [0.071] \\
\hline \multirow[t]{2}{*}{ DonQual (Remittances/GDP) } & 0.059 & 0.309 & 1.219 \\
\hline & {$[1.465]$} & [1.347] & [1.294] \\
\hline \multirow[t]{2}{*}{ Aid*DonQual } & $0.728 * * *$ & $0.786 * * *$ & $0.661 * * *$ \\
\hline & [0.196] & {$[0.172]$} & {$[0.210]$} \\
\hline \multirow[t]{2}{*}{ Multilateral aid } & & & 0.097 \\
\hline & & & [0.092] \\
\hline \multirow[t]{2}{*}{ Bilateral repayments } & & & -0.202 \\
\hline & & & {$[0.237]$} \\
\hline \multirow[t]{2}{*}{ Multilateral repayments } & & & -0.395 \\
\hline & & & [0.709] \\
\hline \multirow[t]{2}{*}{ Initial GDP p.c. (log) } & & $-8.879 * * *$ & $-7.669 * * *$ \\
\hline & & [1.214] & [1.376] \\
\hline \multirow[t]{2}{*}{ Initial life expectancy } & & & 0.022 \\
\hline & & & {$[0.080]$} \\
\hline \multirow[t]{2}{*}{ Openness } & & & 0.813 \\
\hline & & & {$[0.575]$} \\
\hline \multirow[t]{2}{*}{ Inflation $(\log )$} & & $-1.304 * * *$ & $-1.798 * * *$ \\
\hline & & {$[0.404]$} & [0.613] \\
\hline \multirow{2}{*}{ Initial M2/GDP } & & & -0.011 \\
\hline & & & {$[0.022]$} \\
\hline \multirow[t]{2}{*}{ Budget balance/GDP } & & & 0.106 \\
\hline & & & [0.121] \\
\hline \multirow[t]{2}{*}{ Revolutions } & & $-0.940 * *$ & $-0.925 * *$ \\
\hline & & {$[0.387]$} & {$[0.354]$} \\
\hline Adj. R-Squared & 0.021 & 0.269 & 0.347 \\
\hline Number of Countries & 70 & 70 & 67 \\
\hline Number of Observations & 257 & 257 & 192 \\
\hline First differenced & Yes & Yes & Yes \\
\hline Aid twice lagged & No & No & Yes \\
\hline
\end{tabular}

OLS panel estimation in first differences following the specification of Rajan and Subramanian (2008) as in Clemens et al. (2012). All aid and repayment variables are calculated as \% of GDP and are lagged. All regressions include period (5-year) dummies. Significance levels $* p<0.10, * * p<0.05 * * * p<0.01$. Standard errors are heteroskedasticity-robust and clustered by recipient country. 
Table 3.4 Robustness tests for Column 2, Table 3.2, reduced donor or recipient samples

Traditional DAC

Only

w/o Luxembourg w/o Switzerland

w/o Belgium w/o Netherlands w/o New Zealand

w/o lowest

w/o highest

Dependent variable: $\Delta$ Growth

$-0.151$

(2)

$-0.151 \quad-0.156$

$-0.156-0.188$

(4)

[0.150] [0.157]

0.486

DonQual (Remittances/GDP)

0.178

0.696

[2.497]

[1.487]

Aid*DonQual

$1.064 * *$

$0.910 * * *$

[1.405]

[0.207]

Adj. R-Squared

[0.369]

Number of Countries

70

0.259

$0.910 * * *$

$-0.220$

[0.169]

0.670

[1.476]

[0.207]

Number of Observations

257

70

257

$\begin{array}{cc}0.265 & 0.265 \\ 70 & 70\end{array}$

$[0.237]$
0.265
70

257

$\begin{array}{lc}(5) & (6) \\ -0.173 & -0.17 \\ {[0.161]} & {[0 .} \\ 0.451 & 0.368 \\ {[1.375]} & {[1 .} \\ 0.875^{* * *} & 0 . \\ {[0.205]} & {[0 .} \\ 0.261 & 0.262 \\ 70 & \\ 257 & \end{array}$

$-0.171$

[0.154]

0.368

$[1.375]$

[0.198]

0.262

70
257

growth $(<25 \%)$ growth $(>75 \%)$

(2012). All regressions include period (5-year) dummies. Significance levels $* \mathrm{p}<0.10, * * \mathrm{p}<0.05 * * * \mathrm{p}<0.01$. All control variables from Table 2 are included in the regressions. Traditional DAC donors are defined as DAC members as of 2009. Lowest/highest quartiles (below 25\% and above 75\%) are defined according to the growth rates for each period. Standard errors are heteroskedasticity-robust and clustered by recipient country. 


\section{Appendix A}

This section reports results for a number of extensions and tests for robustness. We replicate the main results focusing on Clemens et al.'s (2012) permutation of the regressions of Burnside and Dollar (2000). These data are averages over four rather than five years, and we extended them to cover the 1975-2009 period before differencing and lagging. ${ }^{91}$

We modify the way how we deal with repayments of aid. In the main regressions, we focused on gross ODA, controlling for repayments. Here, we replace the explanatory variable to be net rather than gross disbursements of ODA.

Our results might be affected by the omission of aid from non-traditional donors. Unfortunately, data for non-DAC donors are only available for recent years and, unlike multilateral aid, are therefore not included in our main regressions. We test robustness to including data from the arguably largest emerging donor, China, for the 2000-2010 period (available for African recipient countries exclusively, taken from Strange et al. 2013) as well as available bilateral aid data from other emerging donors such as India (for the 2009-2010 period), Saudi Arabia (starting in the 1980s), South Africa (for 2009) and Taiwan (starting in the 1980s). We set missing data to zero for periods and countries where they are unavailable, to be able to include these data in our regressions. While thus not providing a reasonable estimate of the effect of emerging donor aid, this provides an important robustness test for the stability of our variable of interest.

We further control for the amount of humanitarian aid a country receives, taken from the OECD's DAC aid statistics. Humanitarian aid is arguably less effective in raising growth compared to other forms of aid. In fact, it is not given to promote growth, but to alleviate humanitarian disaster. Controlling for humanitarian aid might thus increase the precision of our estimates. We code this variable to include food aid also, coded as the percentage of the total (bilateral and multilateral) humanitarian aid in the recipient country's GDP.

We control for a number of additional variables. First, we account for the estimated costs from natural disasters in a country and period as an additional indicator of need, taken from the International Disaster Database. Second, we control for (log) refugee inflows (with data taken

\footnotetext{
91 The year 2010 is not covered here due to averaging over four-year-periods. Therefore, 2006-2009 represents the latest period, while 2006-2010 is the latest period for Rajan and Subramanian (2008).
} 
from the United Nations High Commissioner for Refugees) and, third, for civil wars (taken from UCDP/PRIO). Fourth, we control for bilateral trade (exports plus imports) with a recipient country's donors and FDI from the donors (both as a share of recipient country GDP, based on bilateral trade and FDI data taken from Barbieri et al. 2009 and UNCTAD, respectively). Alternatively, fifth, we account for trade-weighted and FDI-weighted ideological alignment, calculated in analogy to our aid-weighted alignment index above (and taken from the same sources). Sixth, we control for regional interactions with aid since governments of certain political ideology may be more common in particular regions (focusing on East Asia and Pacific, Latin America \& the Caribbean, Middle East and North Africa, South Asia, and Sub-Saharan Africa). Seventh, we control for multilateral aid/GDP*Alignment, and eighth, for perceived corruption and democracy (from the ICRG and Cheibub et al. 2010, respectively).

While we believe that the effect of ideological alignment should arise from the level of $A L I G N$ rather than changes, we include $A L I G N$ in differences rather than levels in our regressions. This is because using the variable in differences might alleviate concerns of spurious regression, given that such specification removes country-fixed effects that might be correlated with other omitted time-invariant country-specific influences. ${ }^{92}$

We split the sample in a number of ways. We separately investigate the Cold War and post-Cold War periods to investigate potential differences between the two. ${ }^{93}$ We distinguish democracies from autocracies, following Kosack (2003), among others, and more corrupt countries from less corrupt ones (separating the two groups according to the median). ${ }^{94} \mathrm{We}$ also investigate the effect of ideological alignment for countries with good policies compared to those without good policies, following the suggestion of Burnside and Dollar (2000). ${ }^{95}$ We provide pvalues testing the equality of coefficients for our variable of interest between the respective samples (in brackets in Table A4).

Table A4 shows the results for most robustness tests. To reduce clutter, only the coefficient of the interaction between aid and $A L I G N$ is shown, focusing on the specification in

\footnotetext{
${ }^{92}$ Note however that we already reported in the main text that our results are robust to using country-fixed effects regressions instead of first differences regressions.

${ }^{93}$ Several authors note that aid might be less effective during the Cold War, due to the prevalence of geo-strategic motives in the allocation of aid (e.g., Headey 2008, Bearce and Tirone 2010).

${ }^{94}$ We use the indicator from Cheibub et al. (2010) to identify democracies and the index of perceived corruption from the International Country Risk Guide (ICRG).

${ }^{95}$ We use Rajan and Subramanian's (2008) composite openness index derived from black market premium, tariffs and the existence of export marketing boards.
} 
column 3 of Table 1.1. As can be seen, our results are robust to these changes and refinements. The interaction between aid and $A L I G N$ is significant at the ten percent level at least, with a negative coefficient, in all regressions for the overall sample.

When we split the sample, we do not find any significant differences between the coefficients of our variables of interest across the four sample splits. Looking at the coefficients of the interaction terms themselves, we find that the effectiveness of aid on growth is reduced by ideological misalignment during the Cold War period, in autocracies, when corruption is low, and in countries with "good" as well as "bad" economic policies.

Finally, we replicate our main regressions focusing on early-impact aid, following Clemens et al. (2012). Early-impact aid contains those categories of aid that can reasonably be expected to affect growth in the short-term, like budget support and program aid and certain categories of project aid (e.g., infrastructure investment or support for production in agriculture and industry). Clemens et al. calculate disbursements of early-impact aid based on commitment data, given the unavailability of sectorally disaggregated aid disbursements for most of the sample period. Unfortunately, serious under-reporting of data was also prevalent for sectorspecific commitments until the mid-1990s, ${ }^{96}$ rendering this measure rather noisy. In our case, this is aggravated by the fact that we need to disaggregate aid at the donor-recipient-sector level rather than the recipient-sector level as in Clemens et al. (2012). Still, we think it is interesting to compare our results with those using this alternative measure of aid. We replicated all regressions from Tables 1 and 2 replacing total aid with early-impact aid. While we do not show the results in tables, we provide a short description of the main results here.

Overall, our results are substantially weaker when we focus on early-impact aid. In the regressions of Table 1.2, we do not find a significant effect of $A L I G N$ on the effectiveness of aid. Separately investigating early-impact aid between aligned and non-aligned donor-recipient pairs (Table 1.2), we find a significantly negative effect of early-impact aid from non-aligned donors once the amount of aid exceeds 0.3 percent of GDP, significant at one percent level. We do not find any evidence of differential effects between different pairs of ideological positions among the donor and recipient. Overall, the larger noise in the data on early-impact aid leads to weaker conclusions, even though the main result of Table 1.2 carries over to early-impact aid. 96 See OECD/DAC CRS Guide, Coverage $\quad$ Ratios, $\quad$ accessed $\quad$ on $\quad$ March 3, 2014:
http://www.oecd.org/dac/stats/crsguide.htm. 
In summary, our results are robust to the inclusion of a number of additional control variables and to how we measure aid. We do not find differential effects across four important dimensions: Cold War politics, democracy, perceived corruption, and good policy.

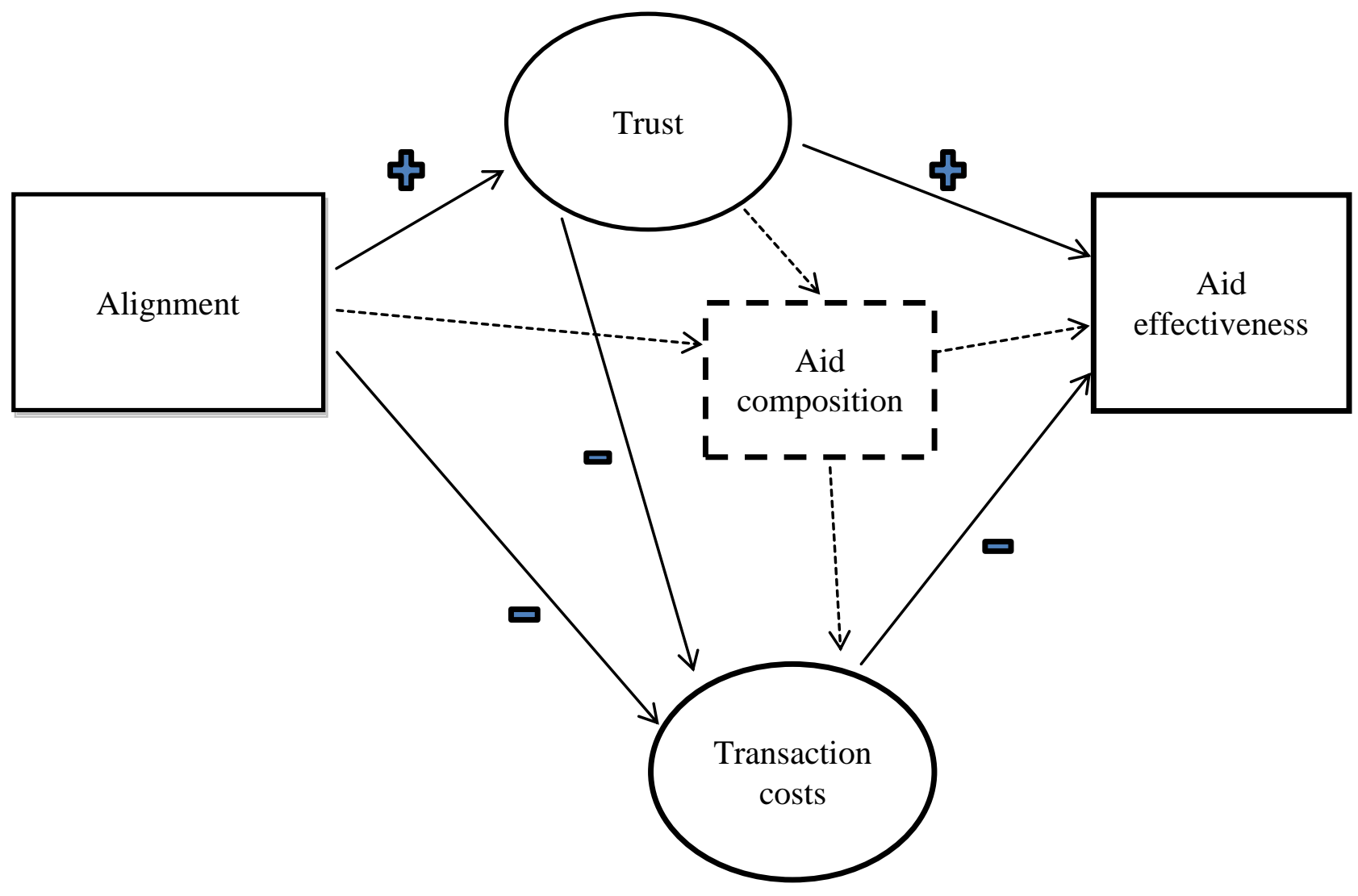

Figure A1 How ideological proximity improves the effectiveness of aid 
Table A 1 Definitions and sources

\begin{tabular}{|c|c|c|}
\hline Variable & Definition & Original Source \\
\hline Aid/GDP & $\begin{array}{l}\text { Average gross bilateral aid } \\
\text { disbursements in percent of GDP. }\end{array}$ & DAC (2012), Table DAC2a \\
\hline Alignment & $\begin{array}{l}\text { Aid-weighted average distance in } \\
\text { political orientation between a recipient } \\
\text { and donors in period } t \text {. }\end{array}$ & Calculated based on Beck et al. (2001), variable: EXECRLC \\
\hline GDP p.c. growth & $\begin{array}{l}\text { Average annual growth rate of real GDP } \\
\text { p.c. in constant international dollars. }\end{array}$ & $\begin{array}{l}\text { Penn World Table } 6.2 \text { and World Bank (2007) for the year 2005*. Penn World } \\
\text { Table } 7.1 \text { for 2006-2010. }\end{array}$ \\
\hline Multilateral repayments/GDP & $\begin{array}{l}\text { Average multilateral repayments in } \\
\text { percent of GDP. }\end{array}$ & DAC (2012), Table DAC2a \\
\hline Bilateral repayments/GDP & $\begin{array}{l}\text { Average bilateral repayments in percent } \\
\text { of GDP. }\end{array}$ & DAC (2012), Table DAC2a \\
\hline Openness & $\begin{array}{l}\text { Wacziarg-Welch's (2008) extension of } \\
\text { the initial Sachs and Warner (1995) } \\
\text { openness index. }\end{array}$ & $\begin{array}{l}\text { Wacziarg and Welch (2008), updated by Clemens et al. (2012)*. Extension of this } \\
\text { index was updated as in Clemens et al. (2012), using IMF Staff Reports and } \\
\text { Economic Freedom Dataset } 2013\end{array}$ \\
\hline Inflation $(\log )$ & $\begin{array}{l}\text { Natural logarithm of (1+consumer price) } \\
\text { inflation. }\end{array}$ & World Bank (2005, 2007, 2012), IMF (2005), Clemens et al. (2012)* \\
\hline Initial M2/GDP & Money and quasi-money (M2) to GDP. & World Bank $(2007,2012)^{*}$ \\
\hline Budget Balance/GDP & $\begin{array}{l}\text { Overall budget balance, including grants, } \\
\text { measured as cash surplus/deficit to GDP. }\end{array}$ & World Bank (2005, 2007, 2012), IMF (2005), Clemens et al. (2012)* \\
\hline Revolutions & $\begin{array}{l}\text { Average number of revolutions per } \\
\text { period. }\end{array}$ & Banks and Wilson (2012) \\
\hline Democracy & $\begin{array}{l}\text { Dummy for democratic and autocratic } \\
\text { regimes. Equals } 1 \text { if period average } \\
\text { larger than } 0.5,0 \text { otherwise. }\end{array}$ & Cheibub et al. (2010) \\
\hline Inflow of refugees $(\log )$ & $\begin{array}{l}\text { Natural logarithm of the average number } \\
\text { of refugee inflow in the recipent country. }\end{array}$ & United Nations High Commissioner for Refugees Data \\
\hline Civil wars & $\begin{array}{l}\text { Dummy for existance of civil wars, } \\
\text { period averages. }\end{array}$ & UCDP/PRIO Armed Conflict Dataset Codebook Version 4-2011 \\
\hline Natural disasters $(\log )$ & $\begin{array}{l}\text { Natural logarithm of estimated damage } \\
\text { from natural disasters in percent of GDP, } \\
\text { period averages. }\end{array}$ & International Disaster Database. http://emdat.be/ \\
\hline
\end{tabular}


Table A1 (continued)

\begin{tabular}{|c|c|c|}
\hline Variable & Definition & Original Source \\
\hline Cold War & $\begin{array}{l}\text { Cold War dummy equals } 1 \text { if period is } \\
\text { earlier than or same as } 1991-1995^{* *}, 0 \\
\text { otherwise. }\end{array}$ & $\begin{array}{l}\text { US Department of State Office of the Historian } \\
\text { http://history.state.gov/departmenthistory/short-history/endofcoldwar }\end{array}$ \\
\hline Good Policy (Openness) & $\begin{array}{l}\text { Dummy for open and closed economies, } \\
\text { averaged over period. Equals } 1 \text {, when } \\
\text { index larger than } 0.5,0 \text { otherwise. }\end{array}$ & $\begin{array}{l}\text { Wacziarg and Welch (2008), updated by Clemens et al. (2012)*. Extension of this } \\
\text { index was updated as in Clemens et al. (2012), using Freedom House (2013) and } \\
\text { IMF Staff reports for the 2006-2010 period. }\end{array}$ \\
\hline Recipient ideology & $\begin{array}{l}\text { Average party orientation of the chief } \\
\text { executive of the recipient country (left, } \\
\text { center, right). Original coding: Left=3, } \\
\text { Center=3, Right=1). }\end{array}$ & Calculated based on Beck et al. (2001), variable: EXECRLC \\
\hline Corruption & $\begin{array}{l}\text { ICRG corruption perception index. The } \\
\text { index ranges from } 1 \text { to } 6 \text {, with higher } \\
\text { values indicating less corruption. }\end{array}$ & $\begin{array}{l}\text { International Country Risk Guide. 2012. PRS Group. } \\
\text { http://www.prsgroup.com/ICRG.aspx. }\end{array}$ \\
\hline FDI & $\begin{array}{l}\text { Net bilateral foreign direct investment } \\
\text { from donor countries in percent of GDP. }\end{array}$ & $\begin{array}{l}\text { UNCTAD, Bilateral FDI Statistics } 2014 \\
\text { URL: http://unctad.org/en/Pages/DIAE/FDI-Statistics/FDI-Statistics- } \\
\text { Bilateral.aspx }\end{array}$ \\
\hline Trade & $\begin{array}{l}\text { Total bilateral trade (imports plus } \\
\text { exports) with donor countries in percent }\end{array}$ & Barbieri et al. (2009) \\
\hline Trade-weighted alignment & $\begin{array}{l}\text { Party orientation of the chief executive } \\
\text { weighed by the share of bilateral trade. }\end{array}$ & Authors' own calculation based on the sources \\
\hline FDI-weighted alignment & $\begin{array}{l}\text { Party orientation of the chief executive } \\
\text { weighed by the share of bilateral FDI. }\end{array}$ & Authors' own calculation based on the sources \\
\hline
\end{tabular}

Notes: * Our source is Clemens et al. (2012),

http://www.cgdev.org/doc/Working\%20Papers/CRBB-Replication-Files.zip. More details (also on early-impact aid composition) are provided in "Technical Appendix to Counting chickens when they hatch: Timing and the effects of aid on growth," http://www.cgdev.org/doc/Working\%20Papers/counting_chickens_technical_appendix.pdf, accessed 06.06.2012.

** Cold War dummy. When we define the indicator to cover one period earlier the difference between the periods remains insignificant. 
Table A2 Descriptive Statistics (Table 1.1, column 3)

\begin{tabular}{lcccc}
\hline Variables & Mean & Standard Deviation & Minimum & Maximum \\
\hline GDP p.c. growth & 1.35 & 3.01 & -12.30 & 10.12 \\
Bilateral Aid to GDP & 3.30 & 3.94 & 0.01 & 25.74 \\
Alignment & 0.95 & 0.32 & 0.04 & 1.89 \\
Initial GDP p.c. (log) & 8.14 & 0.88 & 5.85 & 10.21 \\
Multilateral Repayments to GDP & 0.19 & 0.32 & 0.00 & 2.32 \\
Multilateral aid to GDP & 1.83 & 3.16 & 0.00 & 19.01 \\
Bilateral repayments to GDP & 0.34 & 0.54 & 0.00 & 4.16 \\
Initial life expectancy (log) & 62.53 & 10.25 & 36.55 & 79.41 \\
Openness & 0.55 & 0.50 & 0.00 & 1.00 \\
Inflation (log) & 0.33 & 0.65 & 0.00 & 4.19 \\
Initial M2 to GDP & 6.30 & 14.26 & 0.00 & 105.70 \\
Budget Balance to GDP & -0.10 & 0.57 & -5.51 & 2.35 \\
Revolutions & 0.27 & 0.44 & 0.00 & 2.60 \\
Humanitarian Aid/GDP & 0.318 & 0.662 & 0 & 6.883 \\
New Donor Aid/GDP & 0.0237 & 0.107 & 0 & 1.04 \\
Recipient ideology & 2.013 & 0.649 & 1 & 3 \\
Trade/GDP & 13.288 & 19.711 & 0.000 & 122.242 \\
FDI/GDP & 0.525 & 1.033 & -3.452 & 5.521 \\
Corruption & 2.762 & 0.949 & 0.000 & 5.000 \\
Trade-weighted alignment & 0.933 & 0.407 & 0.000 & 1.994 \\
FDI-weighted alignment & 0.80426 & 0.5090267 & 0 & 2 \\
Democracy & 0.505 & 0.501 & 0 & 1 \\
Inflow of refugees (log) & 1.916 & 3.813 & 0 & 14.03 \\
Civil wars & 0.0615 & 0.201 & 0 & 1 \\
Natural disasters (log) & -6.113 & 4.656 & -15.94 & 0 \\
\hline
\end{tabular}


Table A3 Regression in levels with country-fixed effects

\begin{tabular}{lc}
\hline & $(1)$ \\
\hline Aid/GDP & $0.133^{*}$ \\
& {$[0.067]$} \\
Alignment & $-0.868^{*}$ \\
& {$[0.443]$} \\
Aid/GDP* Alignment & $-0.503^{* *}$ \\
& {$[0.191]$} \\
\hline Aid lagged? & Yes \\
Fixed Effects & Yes \\
Interaction demeaned & Yes \\
First differenced & No \\
Adj. R-Squared & 0.313 \\
Number of Countries & 68 \\
Number of Observations & 375 \\
\hline
\end{tabular}

Notes: The interacted variables are demeaned within each country before we interacted them. The regression includes the same control variables as Table 1.1.** (*) significant at the five (ten) percent level. 
Table A4 Tests for Robustness

\begin{tabular}{|c|c|}
\hline & (1) \\
\hline Burnside-Dollar & $-0.390 * *$ \\
\hline Net aid disbursements & $-0.521 * *$ \\
\hline Control for non-DAC aid & $-0.650 * * *$ \\
\hline Control for humanitarian aid & $-0.640 * * *$ \\
\hline Control for natural disasters & $-0.635 * * *$ \\
\hline Control for inflows of refugees & $-0.645^{* * *}$ \\
\hline Control for civil wars & $-0.646 * * *$ \\
\hline Control for trade/GDP and FDI/GDP & $-0.677^{* * *}$ \\
\hline Control for trade-weighted and FDI-weighted alignment & $-0.642 * * *$ \\
\hline Control for regional interactions with aid & $-0.675^{* * *}$ \\
\hline Control for multilateral Aid/GDP *Alignment & $-0.661 * * *$ \\
\hline Control for corruption and democracy & $-0.803 * * *$ \\
\hline Delta Alignment & $-0.323^{*}$ \\
\hline Cold War period & $-0.730 * * *$ \\
\hline Post-Cold War period & -0.368 \\
\hline p-value (F-test for group comparison) & [0.319] \\
\hline Democracies & -0.458 \\
\hline Autocracies & $-0.687 * *$ \\
\hline p-value (F-test for group comparison) & {$[0.428]$} \\
\hline Corruption high & -0.728 \\
\hline Corruption low & $-0.695 * * *$ \\
\hline$p$-value (F-test for group comparison) & [0.947] \\
\hline Good policy & $-0.684 * * *$ \\
\hline No good policy & $-0.818^{*}$ \\
\hline p-value (F-test for group comparison) & {$[0.714]$} \\
\hline
\end{tabular}

Notes: Shows the coefficients of the interaction between aid and ALIGN. All regressions include the same control variables as Table 1.1. "Democracies" are defined according to Cheibub et al. (2010). "Corruption" is the perceived corruption index of ICRG. "Good policy" refers to an index considering the black market premium, tariffs and existence of export marketing boards (as used in Rajan and Subramanian 2008). *** (**,*) significant at the one (five, ten) percent level. 
Table A5 Control for recipient ideology

\begin{tabular}{|c|c|c|c|c|}
\hline & (1) & $(2)$ & (3) & (4) \\
\hline \multirow[t]{2}{*}{ Aid/GDP } & $0.722 * * *$ & $1.239 * * *$ & & \\
\hline & {$[0.268]$} & {$[0.239]$} & & \\
\hline \multirow[t]{2}{*}{ Alignment } & & -0.348 & & \\
\hline & & {$[0.628]$} & & \\
\hline \multirow[t]{2}{*}{ Aid/GDP* Alignment } & & $-0.628 * * *$ & & \\
\hline & & {$[0.173]$} & & \\
\hline \multirow[t]{2}{*}{ Recipient ideology } & -0.236 & -0.022 & $-0.523^{* *}$ & -0.235 \\
\hline & {$[0.259]$} & {$[0.301]$} & {$[0.263]$} & {$[0.261]$} \\
\hline \multirow[t]{2}{*}{ Aid/GDP* Recipient ideology } & $-0.231^{*}$ & $-0.208 * *$ & & \\
\hline & {$[0.126]$} & {$[0.089]$} & & \\
\hline \multirow[t]{2}{*}{ Aid from center donors } & & & 0.308 & 0.304 \\
\hline & & & {$[0.293]$} & {$[0.291]$} \\
\hline \multirow[t]{2}{*}{ Aid from left donors } & & & $0.421^{* * *}$ & $0.440 * * *$ \\
\hline & & & {$[0.127]$} & {$[0.125]$} \\
\hline \multirow[t]{2}{*}{ Aid from right donors } & & & 0.098 & 0.114 \\
\hline & & & {$[0.141]$} & {$[0.137]$} \\
\hline Ideology first differenced & No & No & No & Yes \\
\hline Adj. R-Squared & 0.324 & 0.344 & 0.335 & 0.33 \\
\hline Number of Countries & 67 & 67 & 67 & 67 \\
\hline Number of Observations & 299 & 299 & 299 & 299 \\
\hline
\end{tabular}

Notes: The regression includes the same control variables as Table 1.1. *** (**,*) significant at the one (five, ten) percent level. 
Table A6 Comparison of means test in aid shares

\begin{tabular}{|c|c|c|c|c|}
\hline \multicolumn{5}{|c|}{ Mean share of tied, untied and partially tied aid for aligned and not aligned donor recipient pai } \\
\hline & Not aligned & Aligned & Difference & $p$-Value \\
\hline Share of tied aid & 0.206 & 0.162 & 0.0436 & 0.000 \\
\hline Share of untied aid & 0.761 & 0.799 & -0.0381 & 0.000 \\
\hline Share of partially tied aid & 0.0329 & 0.0384 & -0.00548 & 0.222 \\
\hline \multicolumn{5}{|c|}{ Mean share of budget and project aid for aligned and not aligned donor recipient pairs } \\
\hline Share of Budget Aid & 0.391 & 0.327 & 0.0642 & 0.068 \\
\hline Share of Project Aid & 0.957 & 0.956 & 0.00105 & 0.860 \\
\hline \multicolumn{5}{|c|}{ Mean share of social and private sector aid by left/left and right/right pairs } \\
\hline Social Aid Shares & 0.493 & 0.385 & 0.107 & 0.199 \\
\hline Private Aid Shares & 0.362 & 0.493 & -0.13 & 0.178 \\
\hline
\end{tabular}

Notes: Social sectors include: Education, Health, Population, Water and Sanitation, Government

/Civil Society, Other Social Infrastructure and Services. Private sector includes: Transport and

Storage, Communication, Energy Generation and Supply, Banking and Financial Services, Business and other Services, Agriculture/Fishing, Industry/Mining, Trade/Tourism. 
Table A7 Political alignment and growth controlled for tied aid, 1975-2010, OLS

\begin{tabular}{lc}
\hline & $(1)$ \\
\hline Aid/GDP & $0.840^{* * *}$ \\
Alignment & {$[0.202]$} \\
& -0.582 \\
Aid/GDP*Alignment & {$[0.529]$} \\
& $-0.644^{* * *}$ \\
Bilateral repayments/GDP & {$[0.180]$} \\
& -0.477 \\
Multilateral Aid/GDP & {$[0.323]$} \\
Multilateral repayments/GDP & -0.056 \\
Share of Tied Aid & {$[0.126]$} \\
Aid lagged? & -0.339 \\
Sumber of & {$[0.721]$} \\
Number of Observations & -0.046 \\
& {$[0.110]$} \\
& 0.030 \\
& {$[0.078]$} \\
\hline
\end{tabular}

Notes: The regression includes the same control variables as Table 1.1. *** significant at the one percent level. 


\section{Appendix B}

Table B1 Alternative measures of differences: Column 5, Table 2.1

\begin{tabular}{|c|c|c|c|c|c|c|c|}
\hline Dependant variable: $\Delta$ Growth & $(1)$ & $(2)$ & (3) & (4) & $(5)$ & $(6)$ & (7) \\
\hline \multirow[t]{2}{*}{ Aid } & -0.345 & -0.596 & 0.121 & 0.095 & 0.259 & $0.263^{*}$ & 0.224 \\
\hline & {$[0.464]$} & {$[0.887]$} & {$[0.186]$} & [0.995] & {$[0.158]$} & {$[0.156]$} & {$[0.138]$} \\
\hline \multirow[t]{2}{*}{ Aid-adjusted genetic distance (AwGD) } & $-1.073 * *$ & $-1.105^{* *}$ & $-1.033 * *$ & $-0.847 * *$ & -0.594 & -0.577 & $-0.983 * *$ \\
\hline & {$[0.441]$} & {$[0.446]$} & [0.436] & [0.426] & {$[0.428]$} & [0.429] & {$[0.441]$} \\
\hline \multirow[t]{2}{*}{ Aid*AwGD } & $-0.176 * *$ & $-0.268 * * *$ & $-0.152 *$ & $-0.220 * *$ & -0.169 & -0.184 & $-0.188 * *$ \\
\hline & {$[0.080]$} & {$[0.101]$} & {$[0.089]$} & {$[0.094]$} & {$[0.149]$} & {$[0.146]$} & {$[0.082]$} \\
\hline \multirow[t]{2}{*}{ DELF } & -0.424 & & & & & & \\
\hline & {$[1.066]$} & & & & & & \\
\hline \multirow[t]{2}{*}{ Aid*DELF } & 0.791 & & & & & & \\
\hline & {$[0.556]$} & & & & & & \\
\hline \multirow[t]{2}{*}{ Language (distance, aid-weighted) } & & 1.422 & & & & & \\
\hline & & {$[1.862]$} & & & & & \\
\hline \multirow{2}{*}{ Aid*Language } & & 1.037 & & & & & \\
\hline & & [1.029] & & & & & \\
\hline \multirow{2}{*}{ Religion (distance, aid-weighted) } & & & 0.265 & & & & \\
\hline & & & {$[0.428]$} & & & & \\
\hline \multirow[t]{2}{*}{ Aid*Religion } & & & 0.282 & & & & \\
\hline & & & {$[0.221]$} & & & & \\
\hline \multirow[t]{2}{*}{ Ethnicity (distance, aid-weighted) } & & & & $-3.029 * * *$ & & & \\
\hline & & & & [1.032] & & & \\
\hline \multirow[t]{2}{*}{ Aid*Ethnicity } & & & & 0.22 & & & \\
\hline & & & & {$[1.083]$} & & & \\
\hline \multirow[t]{2}{*}{ Political Ideology (distance, aid-weighted) } & & & & & $-0.919 * *$ & & \\
\hline & & & & & {$[0.423]$} & & \\
\hline Adj. R-Squared & 0.294 & 0.293 & 0.294 & 0.304 & 0.321 & 0.313 & 0.268 \\
\hline Number of Countries & 66 & 66 & 66 & 66 & 66 & 66 & 69 \\
\hline Number of Observations & 378 & 378 & 378 & 378 & 297 & 297 & 391 \\
\hline
\end{tabular}


Table B2 WVS's well-being cultural dimension and aid-adjusted genetic distance

\begin{tabular}{lccc} 
Dependant variable: $\Delta$ Growth & $(1)$ & $(2)$ & $(3)$ \\
\hline Aid & -0.177 & -0.441 & -0.496 \\
& {$[0.517]$} & {$[0.500]$} & {$[0.488]$} \\
Aid-adjusted genetic distance (AwGD) & 0.72 & 0.399 & $0.773 * *$ \\
& {$[0.520]$} & {$[0.386]$} & {$[0.373]$} \\
Aid*AwGD & $-0.578 * * *$ & $-0.562^{* * *}$ & $-0.571^{* * *}$ \\
& {$[0.185]$} & {$[0.180]$} & {$[0.188]$} \\
Aid*Authority & 0.031 & & \\
& {$[0.246]$} & & \\
Authority & -0.48 & & \\
Aid *Well-being & {$[0.295]$} & & \\
& & $0.351 *$ & \\
Well-being & & {$[0.204]$} & \\
& & 0.203 & 0.328 \\
Adj. R-Squared & 0.334 & 0.329 & 42 \\
Number of Countries & 42 & 42 & 152 \\
Number of Observations & 152 & 152 & \\
\hline \hline
\end{tabular}

OLS panel estimation in first differences: country fixed effects. All regressions include period dummies. Aid denotes gross bilateral aid as percent of recipient's GDP. Controls are: initial GDP p.c. (log), initial life expectancy (log), openness, inflation (log), initial M2/GDP, budget balance/GDP, revolutions as well as multilateral aid, multilateral and bilateral repayments. Significance levels $* \mathrm{p}<0.10, * * \mathrm{p}<0.05, * * * \mathrm{p}<0.01$. 
Table B3 Descriptive Statistics

\begin{tabular}{|c|c|c|c|c|c|}
\hline Table 2.1, Column 6 & Observations & Mean & Std. Dev. & Min & Max \\
\hline GDP p.c. growth & 378 & 1.55 & 3.05 & -12.30 & 10.12 \\
\hline Aid & 378 & 3.01 & 3.87 & 0.01 & 26.69 \\
\hline Aid-adjusted genetic distance (AwGD) & 378 & 1.02 & 0.53 & 0.06 & 2.22 \\
\hline Initial GDP p.c. (log) & 378 & 8.12 & 0.87 & 5.34 & 10.27 \\
\hline Multilateral Repayments & 378 & 0.16 & 0.30 & 0.00 & 2.08 \\
\hline Multilateral aid & 378 & 1.68 & 3.07 & 0.00 & 19.01 \\
\hline Bilateral repayments & 378 & 0.30 & 0.51 & 0.00 & 4.16 \\
\hline Initial life expectancy (log) & 378 & 61.68 & 10.06 & 36.55 & 79.41 \\
\hline Openness & 378 & 0.46 & 0.50 & 0.00 & 1.00 \\
\hline Inflation (log) & 378 & 0.31 & 0.61 & 0.00 & 4.19 \\
\hline Initial M2 to GDP & 378 & 5.07 & 12.92 & 0.00 & 105.70 \\
\hline Budget Balance to GDP & 378 & -0.09 & 0.51 & -5.51 & 2.35 \\
\hline Revolutions & 378 & 0.26 & 0.41 & 0.00 & 2.60 \\
\hline \multicolumn{6}{|l|}{ Table 2.2, Column 4} \\
\hline GDP p.c. growth & 378 & 1.55 & 3.05 & -12.30 & 10.12 \\
\hline Aid & 378 & 3.01 & 3.87 & 0.01 & 26.69 \\
\hline Western Education(leader) & 378 & 0.32 & 0.42 & 0.00 & 1.00 \\
\hline Education Abroad (leader) & 378 & 0.62 & 0.43 & 0.00 & 1.00 \\
\hline Education Level (leader) & 378 & 6.16 & 1.14 & 3.00 & 8.00 \\
\hline Initial GDP p.c. (log) & 378 & 8.12 & 0.87 & 5.34 & 10.27 \\
\hline Multilateral Repayments & 378 & 0.16 & 0.30 & 0.00 & 2.08 \\
\hline Multilateral aid & 378 & 1.68 & 3.07 & 0.00 & 19.01 \\
\hline Bilateral repayments & 378 & 0.30 & 0.51 & 0.00 & 4.16 \\
\hline Initial life expectancy (log) & 378 & 61.68 & 10.06 & 36.55 & 79.41 \\
\hline Openness & 378 & 0.46 & 0.50 & 0.00 & 1.00 \\
\hline Inflation (log) & 378 & 0.31 & 0.61 & 0.00 & 4.19 \\
\hline Initial M2 to GDP & 378 & 5.07 & 12.92 & 0.00 & 105.70 \\
\hline Budget Balance to GDP & 378 & -0.09 & 0.51 & -5.51 & 2.35 \\
\hline Revolutions & 378 & 0.26 & 0.41 & 0.00 & 2.60 \\
\hline
\end{tabular}




\section{Table B4 Variable Definition and Sources}

\begin{tabular}{|c|c|c|}
\hline Variable & Definition & Sources \\
\hline Aid & $\begin{array}{l}\text { Average gross bilateral aid disbursements in percent } \\
\text { of GDP. }\end{array}$ & DAC (2012), Table DAC2a \\
\hline $\begin{array}{l}\text { Aid-adjusted genetic distance } \\
\text { (AwGD) }\end{array}$ & $\begin{array}{l}\text { Weighted genetic distance between two populations, } \\
\text { time since two populations split apart. }\end{array}$ & Spolaore and Wacziarg (2009) \\
\hline Western education & $\begin{array}{l}\text { Dummy variable if leader has been educated either in } \\
\text { the US or the UK (in the analysis it is a continous } \\
\text { variable due to period average). }\end{array}$ & Dreher et al. (2013b) \\
\hline Education abroad & $\begin{array}{l}\text { Dummy variable if leader has been educated outside } \\
\text { of home country (in the analysis it is a continous } \\
\text { variable due to period average). }\end{array}$ & Dreher et al. (2013b) \\
\hline Education level & $\begin{array}{l}\text { Categorial variable on the level of leaders educated } \\
\text { stating from illiterate to doctoral level (in the analysis } \\
\text { continous variable due to period averages). }\end{array}$ & Dreher et al. (2013b) \\
\hline GDP p.c. growth & $\begin{array}{l}\text { Average annual growth rate of real GDP p.c. in } \\
\text { constant international dollars. }\end{array}$ & $\begin{array}{l}\text { Penn World Table } 6.2 \text { and World Bank } \\
\text { (2007) for the year } 2005 . \text { Penn World } \\
\text { Table } 7.1 \text { for 2006-2010. }\end{array}$ \\
\hline Multilateral aid & $\begin{array}{l}\text { Average gross multialetral disbursements in percent } \\
\text { of GDP. }\end{array}$ & DAC (2012), Table DAC2a \\
\hline Multilateral repayments & Average multilateral repayments in percent of GDP. & DAC (2012), Table DAC2a \\
\hline Bilateral repayments & Average bilateral repayments in percent of GDP. & DAC (2012), Table DAC2a \\
\hline Initial GDP p.c. (log) & $\begin{array}{l}\text { Natural logarithm of initial GDP p.c. in international } \\
\text { prices. }\end{array}$ & $\begin{array}{l}\text { Penn World Table 6.2, Penn World Table } \\
7.1 \text { for 2006-2010. }\end{array}$ \\
\hline Initial life expectancy (log) & $\begin{array}{l}\text { Natural logarithm of first non-missing value in each } \\
\text { period of total life expectancy. }\end{array}$ & World Bank (2007), World Bank (2012) \\
\hline Openness & $\begin{array}{l}\text { Wacziarg-Welch (2008) extension of the initial Sachs } \\
\text { and Warner (1995) openness index, based on black } \\
\text { market premium, average tariff rates, export } \\
\text { marketing board, socialist regime and etc. }\end{array}$ & $\begin{array}{l}\text { Wacziarg and Welch (2008), updated by } \\
\text { Clemens et al. (2012). Extension of this } \\
\text { index was updated as in Clemens et al. } \\
\text { (2012), using Economic Freedom Score } \\
\text { from Fraser Institute (2013) and IMF Staff }\end{array}$ \\
\hline Inflation (log) & Natural logarithm of (1+consumer price) inflation. & $\begin{array}{l}\text { World Bank }(2005,2007,2012), \text { IMF } \\
\text { (2005), Clemens et al. }(2012)\end{array}$ \\
\hline Initial M2/GDP & Money and quasi-money (M2) to GDP. & World Bank $(2007,2012)$ \\
\hline Budget Balance/GDP & $\begin{array}{l}\text { Overall budget balance, including grants. Measured as } \\
\text { cash surplus/deficit to GDP. }\end{array}$ & $\begin{array}{l}\text { World Bank }(2005,2007,2012) \text {, IMF } \\
(2005) \text {, Clemens et al. }(2012)\end{array}$ \\
\hline $\begin{array}{l}\text { Revolutions } \\
\text { Variables for Robustness tests }\end{array}$ & Average number of revolutions per period. & Banks and Wilson (2012) \\
\hline Humanitarian aid & $\begin{array}{l}\text { Average humanitarian aid received from all donors as } \\
\text { percent of GDP, averaged over the relevant period. }\end{array}$ & DAC (2012), Table DAC2a \\
\hline Rest bilateral aid & $\begin{array}{l}\text { Average gross bilateral aid received from recent DAC } \\
\text { member and non-member countries. (United Arab } \\
\text { Emirates, Cyprus, Czech Republic Estonia Hungry } \\
\text { Island Israel Kuwait Lithuenia Latvia Poland Romania } \\
\text { Slovak Republic Slovenia Thailand Turkey). }\end{array}$ & DAC (2012), Table DAC2a \\
\hline Democracy & $\begin{array}{l}\text { Continous variable }(-2,2) \text {, unified measure of } \\
\text { democracy. }\end{array}$ & Pemstein et al. (2013) \\
\hline Effective Executive & $\begin{array}{l}\text { The person exercising primary influence in the shaping } \\
\text { of the major decisions, affecting the nation's internal } \\
\text { and external affairs (Monarch, President, Premier, } \\
\text { Military or Other-communist regimes or ineffective } \\
\text { leader). }\end{array}$ & Banks and Wilson (2012) \\
\hline Head of State & $\begin{array}{l}\text { Head of the state (Monarch, Premier, President, } \\
\text { Military or Other-hard to identify). }\end{array}$ & Banks and Wilson (2012) \\
\hline Political alignment & $\begin{array}{l}\text { Aid-weighted average distance in political ideology } \\
\text { between a recipient and donors in period t. }\end{array}$ & $\begin{array}{l}\text { Dreher et al. (2013b). Calculated based on } \\
\text { Beck et al. (2001), variable: EXECRLC }\end{array}$ \\
\hline
\end{tabular}



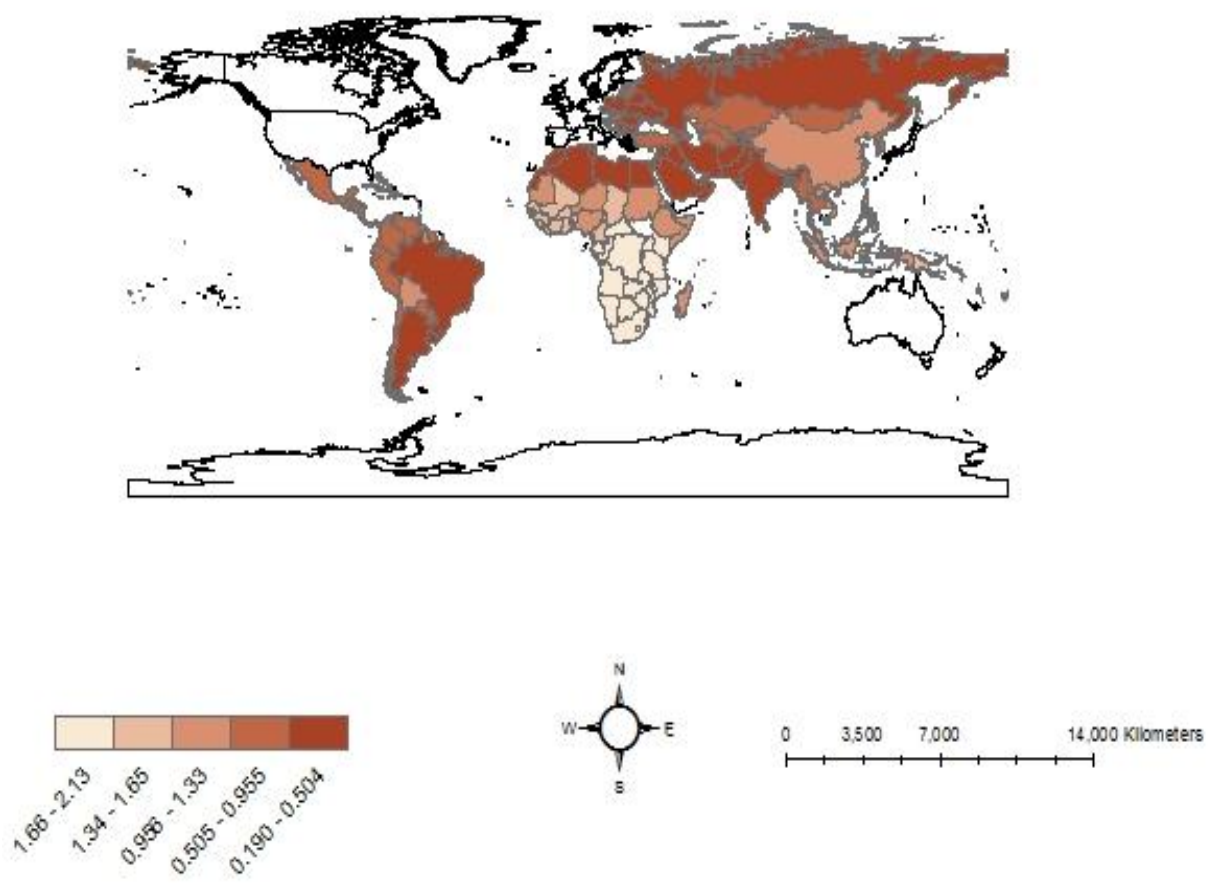

Figure B1 Map of the (weighted) genetic distance to donors

Figure B2 Map of the standard deviation of (weighted) genetic distance to donors

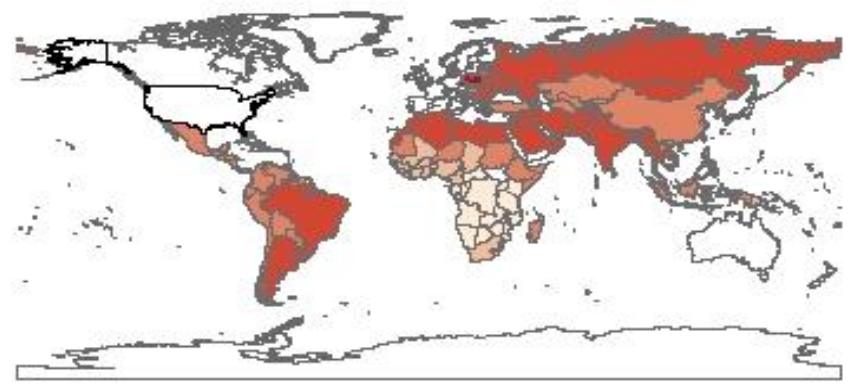

$1.5-2.3$ Std. Dev. $0.50-1.5$ Std. Dev (0.50) -0.50 Std. Dev.

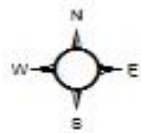

0 4.200 8.400 16,200 Kllometers $(1.5)-(0.50)$ Std. Dev $<(1.5)$ Std. Dev. 

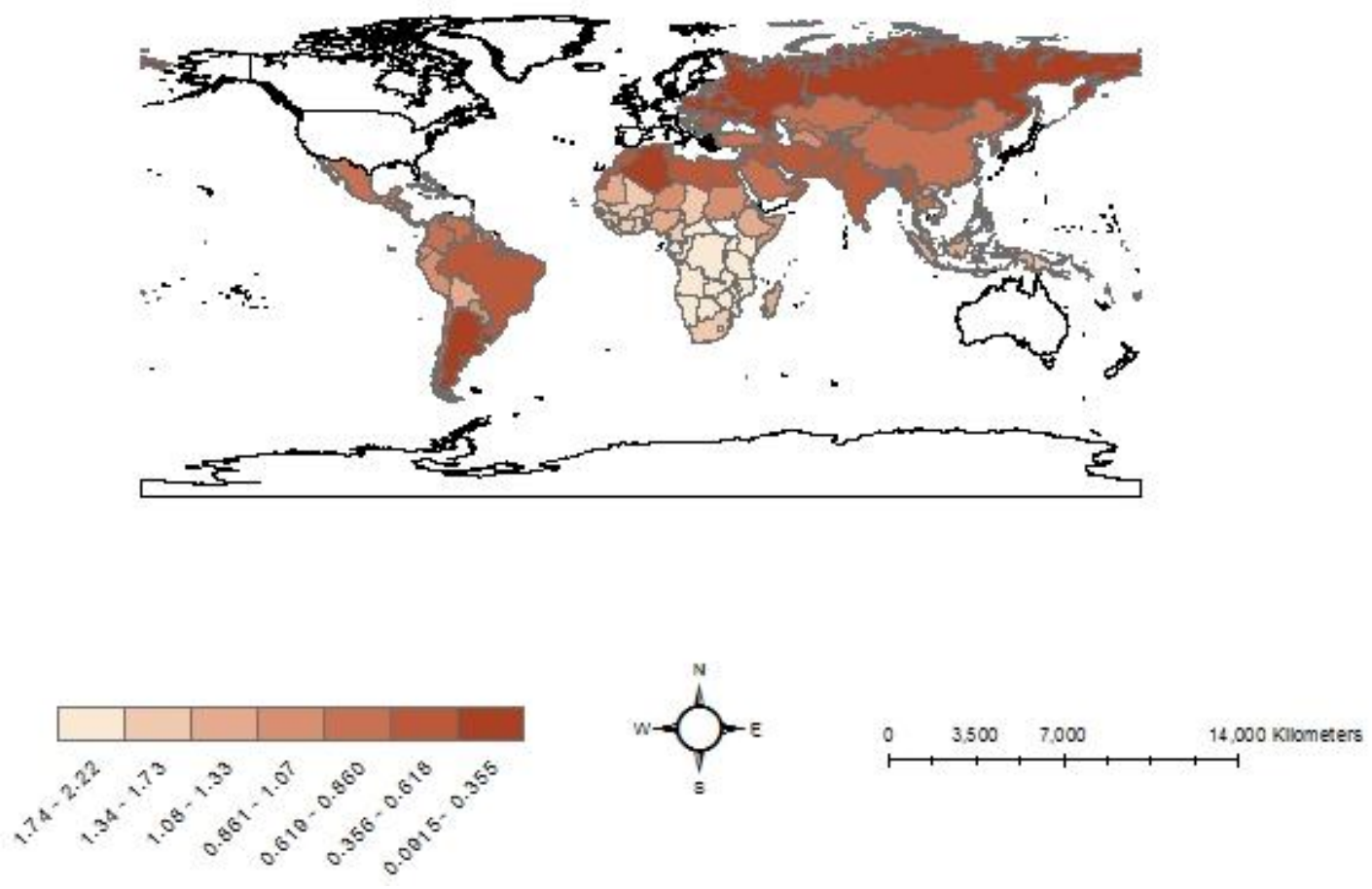

Figure B3 Map of the aid-adjusted (weighted) genetic distance to donors 


\section{Appendix C}

Table C1 Summary statistics, Column 2, Table 3.2

\begin{tabular}{lccccc} 
Variables & Observations & Mean & Std. Dev. & Min & Max \\
\hline Growth & 257 & 1.57 & 3.22 & -17.99 & 12.77 \\
Aid & 257 & 3.62 & 4.34 & 0.01 & 26.69 \\
Remittances/GDP & 257 & 0.42 & 0.24 & 0.07 & 1.90 \\
Initial GDP p.c. (log) & 257 & 8.10 & 0.92 & 5.34 & 10.21 \\
Multilateral repayments & 257 & 0.23 & 0.34 & 0.00 & 2.08 \\
Multilateral aid & 257 & 2.20 & 3.61 & 0.00 & 19.01 \\
Bilateral repayments & 257 & 0.38 & 0.59 & 0.00 & 4.16 \\
Initial life expectancy & 257 & 62.69 & 10.54 & 36.55 & 79.41 \\
Openness & 257 & 0.62 & 0.49 & 0.00 & 1.00 \\
Inflation (log) & 257 & 0.35 & 0.71 & 0.00 & 4.19 \\
Initial M2/GDP & 257 & 7.56 & 15.23 & 0.00 & 105.70 \\
Budget balance/GDP & 257 & -0.11 & 0.61 & -5.51 & 2.35 \\
Revolutions & 257 & 0.28 & 0.46 & 0.00 & 2.60 \\
\hline
\end{tabular}




\section{Table C2 Definition of variables and sources}

\begin{tabular}{|c|c|c|}
\hline Variable & Definition & Sources \\
\hline Aid & $\begin{array}{l}\text { Average gross bilateral aid disbursements in percent of } \\
\text { GDP. }\end{array}$ & DAC (2012), Table DAC2a. \\
\hline DonQual: remittances/GDP & $\begin{array}{l}\text { Workers' remittances and compensation of employees, } \\
\text { paid as percent of donor's GDP. }\end{array}$ & World Bank (2013).World Development Indicators. \\
\hline Growth & $\begin{array}{l}\text { Average annual growth rate of real GDP p.c. in constant } \\
\text { international dollars. }\end{array}$ & Clemens et al. (2012).* Penn World Table 7.1 for 2006-2010. \\
\hline Multilateral aid & $\begin{array}{l}\text { Average gross multialetral disbursements in percent of } \\
\text { recipient's GDP. }\end{array}$ & DAC (2012), Table DAC2a. \\
\hline Multilateral repayments & $\begin{array}{l}\text { Average multilateral repayments in percent of recipient's } \\
\text { GDP. }\end{array}$ & DAC (2012), Table DAC2a. \\
\hline Bilateral repayments & $\begin{array}{l}\text { Average bilateral repayments in percent of recipient's } \\
\text { GDP. }\end{array}$ & DAC (2012), Table DAC2a. \\
\hline Initial GDP p.c. (log) & $\begin{array}{l}\text { Natural logarithm of initial GDP p.c. in international } \\
\text { prices. }\end{array}$ & Clemens et al. (2012).** Penn World Table 7.1 for 2006-2010. \\
\hline Initial life expectancy & $\begin{array}{l}\text { Number of years of first non-missing value in each } \\
\text { period of total life expectancy. }\end{array}$ & Clemens et al. (2012).** World Bank (2012). \\
\hline Openness & $\begin{array}{l}\text { Wacziarg-Welch (2008) extension of the initial Sachs } \\
\text { and Warner (1995) openness index, based on black } \\
\text { market premium, average tariff rates, export marketing } \\
\text { board, socialist regime and etc. }\end{array}$ & $\begin{array}{l}\text { Wacziarg and Welch (2008), updated by Clemens et al. (2012).* } \\
\text { Extension of this index has been updated as in Clemens et al. } \\
\text { (2012) using Economic Freedom Data (2013) and IMF Staff } \\
\text { reports for the 2006-2010 period. }\end{array}$ \\
\hline Inflation (log) & Natural logarithm of (1+consumer price) inflation. & Clemens et al. (2012).** World Bank (2012). \\
\hline Initial M2/GDP & Money and quasi-money (M2) as percent of GDP. & Clemens et al. (2012).** World Bank (2012). \\
\hline Budget balance/GDP & $\begin{array}{l}\text { Overall budget balance, including grants. Measured as } \\
\text { cash surplus/deficit in percent of GDP. }\end{array}$ & Clemens et al. (2012).** World Bank (2012). \\
\hline Revolutions & Average number of revolutions per period. & Clemens et al. (2012).** Banks and Wilson (2012). \\
\hline
\end{tabular}

*Online access to Clemens et al. (2012) supplementary material: http://onlinelibrary.wiley.com/doi/10.1111/j.1468-

0297.2011.02482.x/suppinfo

** Online access to Clemens et al. (2012) dataset: http://www.cgdev.org/publication/counting-chickens-when-theyhatch-timing-and-effects-aid-growth-working-paper-44 
Table C 3 List of aid recipient countries

\begin{tabular}{|c|c|c|c|}
\hline 1 & Argentina & 36 & Morocco \\
\hline 2 & Burkina Faso & 37 & Madagascar \\
\hline 3 & Bulgaria & 38 & Mexico \\
\hline 4 & Bolivia & 39 & Mali \\
\hline 5 & Brazil & 40 & Malawi \\
\hline 6 & Botswana & 41 & Malaysia \\
\hline 7 & Chile & 42 & Nigeria \\
\hline 8 & China & 43 & Nicaragua \\
\hline 9 & Cote d'Ivoire & 44 & Pakistan \\
\hline 10 & Cameroon & 45 & Panama \\
\hline 11 & Congo, Rep. & 46 & Peru \\
\hline 12 & Colombia & 47 & Philippines \\
\hline 13 & Costa Rica & 48 & Papua New Guinea \\
\hline 14 & Cyprus & 49 & Poland \\
\hline 15 & Dominican Rep. & 50 & Paraguay \\
\hline 16 & Algeria & 51 & Romania \\
\hline 17 & Ecuador & 52 & Senegal \\
\hline 18 & Egypt, Arab Rep. & 53 & Singapore \\
\hline 19 & Ethiopia & 54 & Sierra Leone \\
\hline 20 & Gabon & 55 & El Salvador \\
\hline 21 & Ghana & 56 & Syrian Arab Rep. \\
\hline 22 & Gambia, The & 57 & Togo \\
\hline 23 & Guatemala & 58 & Thailand \\
\hline 24 & Honduras & 59 & Trinidad and Tobago \\
\hline 25 & Hungary & 60 & Tunisia \\
\hline 26 & Indonesia & 61 & Turkey \\
\hline 27 & India & 62 & Tanzania \\
\hline 28 & Iran, Islamic Rep. & 63 & Uganda \\
\hline 29 & Israel & 64 & Uruguay \\
\hline
\end{tabular}




$\begin{array}{ll}30 & \text { Jamaica } \\ 31 & \text { Jordan } \\ 32 & \text { Kenya } \\ 33 & \text { Korea, Rep. } \\ 34 & \text { Liberia } \\ 35 & \text { Sri Lanka }\end{array}$

$\begin{array}{ll}65 & \text { Venezuela } \\ 66 & \text { Yemen, Rep. } \\ 67 & \text { South Africa } \\ 68 & \text { Congo, Dem. Rep. } \\ 69 & \text { Zambia } \\ 70 & \text { Zimbabwe }\end{array}$




\section{Bibliography}

Acharya, A., A.T. Fuzzo de Lima and M. Moore. 2006. Proliferation and Fragmentation: Transaction Costs and The Value of Aid. Journal of Development Studies 42, 1-21.

Acht, M., T. Omar Mahmoud and R. Thiele. 2015. Corrupt Governments Receive Less Bilateral Aid: Governance and The Delivery Of Foreign Aid Through Non-Government Actors. Journal of Development Economics 114, 20-33.

ActionAid International. 2005. Real Aid: An Agenda for Making Aid Work. Johannesburg.

Adams, R.H. and J. Page. 2005. Do International Migration and Remittances Reduce Poverty in Developing Countries? World Development 33, 1645-1669.

AidData: Open Data for International Development; http://aiddata.org/

Aleman, J. 2009. The Politics of Tripartite Cooperation in New Democracies: A Multi-Level Analysis. International Political Science Review 30, 141-162.

Alesina, A., A. Devleeschauwer, W. Easterly, S. Kurlat and R. Wacziarg. 2003. Fractionalization. Journal of Economic Growth 8, 155-194.

Algan, Y. and P. Cahuc. 2010. Inherited Trust and Growth. American Economic Review 100, 2060-2092.

Allee, T. and C. Peinhardt. 2010. Delegating Differences: Bilateral Investment Treaties and Bargaining Over Dispute Resolution Provisions. International Studies Quarterly 54, 1-26.

Altaf, S.W. 2011. So Much Aid, So Little Development: Stories from Pakistan. Woodrow Wilson Center Press; Johns Hopkins University Press, Washington, D.C. Baltimore.

Angrist, J.D. and A.B. Krueger. 1999. Empirical Strategies in Labor Economics. Handbook of Labor Economics 3, 1277-1366.

Anyanwu, J.C. and E.O. Erhijakpor. 2010. Do International Remittances Affect Poverty in Africa? African Development Review 22, 51-91. 
Armingeon, K., L. Knöpfel, D. Weisstanner, S. Engler, P. Potolidis, and M. Gerb. 2011. Comparative Political Data Set I 1960-2011. Institute of Political Science, University of Berne.

Azam, J.-P. and J.-J. Laffont. 2003. Contracting for Aid. Journal of Development Economics 70, $25-58$.

Banks, A. S. and A. W. Kenneth. 2012. Cross-National Time-Series Data Archive. Databanks International, Jerusalem, Israel. http://www.databanksinternational.com.

Barbieri, K., O.M.G. Keshk, and B. Pollins. 2009. Trading Data: Evaluating Our Assumptions and Coding Rules. Conflict Management and Peace Science 26, 471-491.

Bauer, P. T. 1971. Dissent on Development: Studies and Debates in Development Economics. London: Weidenfeld and Nicholson.

Bazzi, S. and M.A. Clemens. 2013. Blunt Instruments: Avoiding Common Pitfalls in Identifying The Causes of Economic Growth. American Economic Journal: Macroeconomics 5, 152186.

Bearce, D.H. and D.C. Tirone. 2010. Foreign Aid Effectiveness and The Strategic Goals of Donor Governments. Journal of Politics 72, 837-851.

Beck, T., G. Clarke, A. Groff, P. Keefer and P. Walsh. 2001. New Tools In Comparative Political Economy: The Database of Political Institutions. The World Bank Economic Review 15, 165-176.

Bermeo, S. B. 2010. Development and Strategy: Aid Allocation in an Interdependent World. Draft.

Berthélemy, J.-C. 2006. Bilateral Donors' Interest vs. Recipients’ Development Motives in Aid Allocation: So All Donors Behave the sSame? Review of Development Economics 10, 179-194.

Berthélemy, J.-C., M. Beuran and M. Maurel. 2009. Aid and Migration: Substitutes or Complements? World Development 37, 1589-1599. 
Bigsten, A. 2006. Donor Coordination and the Uses of Aid. Revue d'économie du développement 14, 77-103.

Birdsall, N. and D. Roodman. 2003. The Commitment to Development Index: A Scorecard of Rich-Country Policies. Center for Global Development. Washington, DC.

Bisin, A. and T. Verdier. 2000. Beyond the Melting Pot: Cultural Transmission, Marriage, and the Evolution of Ethnic and Religious Traits. The Quarterly Journal of Economics 115, 955-988.

Bisin, A. and T .Verdier. 2001. The Economics of Cultural Transmission and the Dynamics of Preferences. Journal of Economic Theory 97, 298-319.

Bjørnskov, C. and P.-G. Méon. 2013. Is Trust The Missing Root of Institutions, Education, And Development? Public Choice 157, 641-669.

Bjørnskov, C. 2013. Types of Foreign Aid. University of Aarhus Working Paper 08.

Braw, E., 2014. Educating Their Children Abroad Is the Russian Elite's Guilty Secret. Newsweek. July 30 .

Brückner, M. 2013. On The Simultaneity Problem in the Aid and Growth Debate. Journal of Applied Econometrics 28, 126-150.

Bueno de Mesquita, B. and A. Smith. 2009. A Political Economy of Aid. International Organization 63, 309-340.

Burnside, C. and D. Dollar. 2000. Aid, Policies, and Growth. American Economic Review 90, $847-868$.

Caldwell, J.C. 1976. Toward a Restatement of Demographic Transition Theory. Population and Development Review 2, 321-366.

Carter, D. and R. Stone. 2015. Democracy and Multilateralism: The Case of Vote Buying in the UN General Assembly. International Organization 69, 1-33.

Cavalli-Sforza, L.L., 2001. Genes, Peoples, and Languages. University of California Press.

Cavalli-Sforza, L.L.L., Menozzi, P., Piazza, A., 1994. The History and Geography Of Human Genes. Princeton University Press. 
Cheibub, J. A., J. Gandhi and J. R. Vreeland. 2010. Democracy and Dictatorship Revisited. Public Choice, 67-101.

Clay, E.J., M. Geddes, L. Natali and D.W. van te Velde. 2008. The Development Effectiveness of Untied Aid: Evaluation Of The Paris Declaration. Phase 1 report. Copenhagen: Ministry of Foreign Affairs.

Clemens, M.A., S. Radelet, R.R. Bhavnani and S. Bazzi. 2012. Counting Chickens When They Hatch: Timing and The Effects of Aid on Growth. The Economic Journal 122, 590-617.

Coats, A.W. 1997. The Post-1945 Internationalization of Economics. Duke University Press.

Collier, P. 1997. The Failure of Conditionality. In Perspectives on Aid and Development, eds. Catherine Gwin and Joan M. Nelson. Washington, DC: John Hopkins University Press, $51-77$.

Constant, A. and B. Tien, 2010. African Leaders: Their Education Abroad and FDI Flows. IZA Discussion Paper No. 5353

Cordella, T. and G. Dell'Ariccia. 2007. Budget Support Versus Project Aid: A Theoretical Appraisal. Economic Journal 117 (523): 1260-1279.

Cosmides, L. and J. Tooby. 1994. Better than Rational: Evolutionary Psychology and the Invisible Hand. American Economic Review 84, 327-32.

Costa e Silva, S., F. Bradley and C.M.P. Sousa. 2012. Empirical Test of the Trust-Performance Link in an International Alliances Context. International Business Review 21 (2): 293306.

Coyne, C. 2013. Doing Bad by Doing Good: Why Humanitarian Action Fails. Stanford University Press.

Czaika, M. and C. Vargas-Silva (eds.). 2012. Migration and Economic Growth. Cheltenham: Edward Elgar Publ.

Dalgaard, C.J., H. Hansen and F. Tarp. 2004. On The Empirics of Foreign Aid and Growth. The Economic Journal 114, F191-F216. 
Dayton-Johnson, J. and L.T. Katseli. 2006. Migration, Aid and Trade: Policy Coherence for Development. Policy Brief 28. OECD Development Centre. Paris.

De Haas, H. (2005). International Migration, Remittances and Development: Myths and Facts. Third World Quarterly 26, 1269-1284.

Desmet, K., M.L. Breton, I. Ortuño-Ortín and S. Weber. 2011. The Stability and Breakup of Nations: A Quantitative Analysis. Journal of Economic Growth 16, 183-213.

Development Assistance Committee (DAC). 2012. Table DAC2a.

Dietrich, S. 2013. Bypass or Engage? Explaining Donor Delivery Tactics in Foreign Aid Allocation. International Studies Quarterly 57, 698-712.

Dollar, D., and A. Kraay. 2000. Growth Is Good For The Poor. Policy Research Working Paper. World Bank.

Doucouliagos, H. and M. Paldam. 2009. The Aid Effectiveness Literature: The Sad Results of 40 Years of Research. Journal of Economic Surveys 23, 433-461.

Doucouliagos, H. and M. Paldam. 2011. The Ineffectiveness of Development Aid on Growth: An Update. European Journal of Political Economy 27, 399-404.

Dreher, A., A. Minasyan and P. Nunnenkamp 2015a. Government Ideology in Donor and Recipient Countries: Does Ideological Proximity Matter for the Effectiveness of Aid? European Economic Review, 79, 80-92.

Dreher, A., N. Gaston, and P. Martens. 2008. Measuring Globalization-Gauging its Consequences. Springer. New York.

Dreher, A., R. Jong-A-Pin and S. Yu. 2013. The Alma Mater Effect. Does Foreign Education of Political Leaders Influence Voting Behavior in the United Nations General Assembly? mimeo

Dreher, A., Lamla, M.J., Lein, S.M., Somogyi, F. 2009. The Impact of Political Leaders' Profession and Education on Reforms. Journal of Comparative Economics 37, 169-193. 
Dreher, A., V. Eichenauer and K. Gehring. 2014. Geopolitics, Aid and Growth. CEPR Discussion Paper 9904. London.

Dreher, Axel and N. M. Jensen. 2013. Country or Leader? Political Change and UN General Assembly Voting. European Journal of Political Economy 29, 183-196.

Dreher, A., M. Schmaljohann and P. Nunnenkamp. 2015b. The Allocation of German Aid: Selfinterest and Government Ideology. Economics \& Politics 27, 160-184.

Dutt, P. and D. Mitra. 2005. Political Ideology and Endogenous Trade Policy: An Empirical Investigation. Review of Economics and Statistics 87, 59-72.

Dutt, P. and D. Mitra. 2006. Labor Versus Capital in Trade-Policy: The Role of Ideology and Inequality. Journal of International Economics 69, 310-320.

Dyer, J. H. and W. Chu. 2003. The Role of Trustworthiness in Reducing Transaction Costs and Improving Performance: Empirical Evidence from the United States, Japan, and Korea. Organization Science 14, 57-68.

Easterly, W. 2007. Are Aid Agencies Improving? Economic Policy 22, 633-678.

Easterly, W. 2002. The Elusive Quest for Growth: Economists Adventures and Misadventure in the Tropics. The MIT Press.

Easterly, W. 2006. The White Man's Burden: Why the West's Efforts to Aid the Rest Have Done So Much Ill and So Little Good. Penguin.

Elkins, Z., A. T. Guzman and B. A. Simmons. 2006. Competing for Capital: The Diffusion of Bilateral Investment Treaties, 1960-2000. International Organization 60, 811-846.

Escobar, A., 1995. Encountering Development: The Making and Unmaking of Development. Princeton University Press. Princeton.

Faye, M. and P. Niehaus. 2012. Political Aid Cycles. American Economic Review 102, 35163530.

Fernández-Huertas Moraga, J. and H. Rapoport. 2013. Tradable Immigration Quotas. CESifo Working Paper 4087. Center for Economic Studies and Ifo Institute. Munich. 
Fischer, J. 2011. Living Under the 'Right' Government: Does Political Ideology Matter to Trust in Political Institutions? http://papers.ssrn.com/paper.taf?abstract_id=1944169.

Fishbein, M., Ajzen, I. 1975. Belief, Attitude, Intention and Behavior: An Introduction to Theory and Research. Addison-Wesley.

Fleck, R. K. and C. Kilby. 2006. How Do Political Changes Influence US Bilateral Aid Allocations? Evidence from Panel Data. Review of Development Economics 10, 210223. .

Fuchs, A., A. Dreher and P. Nunnenkamp. 2014. Determinants of Donor Generosity: A Survey of the Aid Budget Literature. World Development 56, 172-199.

Gammeltoft, P. 2002. Remittances and Other Flows to Developing Countries. International Migration 40, 181-210.

Gibson, C.C., K. Andersson, E. Ostrom and S. Shivakumar. 2005. The Samaritan's Dilemma: The Political Economy of Development Aid. Oxford University Press.

Gift, T. and D. Krcmaric. 2015. Who Democratizes? Western-educated Leaders and Regime Transitions. Journal of Conflict Resolution. Forthcoming.

Gilman, N. 2003. Mandarins of the Future: Modernization Theory in Cold War America. JHU Press.

Goldring, L. 2004. Family and Collective Remittances to Mexico: A Multi-Dimensional Typology. Development and Change 35, 799-840.

Gorodnichenko, Y. and G. Roland. 2010. Culture, Institutions and the Wealth of Nations. NBER Working Paper No. 16368

Gould, D.M. 1994. Immigrant Links to the Home Country: Empirical Implications for US Bilateral Trade Flows. Review of Economics and Statistics 76, 302-316.

Grieco, E. and K.A. Hamilton. 2004. Realizing the Potential of Migrant "Earn, Learn, and Return" Strategies: Does Policy Matter? (http://www.cgdev.org/doc/CDI/Migration_2004.pdf; accessed: January 2015). 
Guiso, L., P. Sapienza and L. Zingales. 2009. Cultural Biases in Economic Exchange? The Quarterly Journal of Economics 124, 1095-1131.

Gwartney, J., R. Lawson and J. Hall. 2013. Economic Freedom Dataset. Economic Freedom of the World. Fraser Institute.

Ha, Eunyoung. 2012. Globalization, Government Ideology, and Income Inequality in Developing Countries. Journal of Politics 74, 541-557.

Hansen, H. and F. Tarp. 2001. Aid and Growth Regressions. Journal of Development Economics 64, 547-570.

Hasty, J., 2005. The Press and Political Culture in Ghana. Indiana University Press.

Hatzigeorgiou, A. and M. Lodefalk. 2015. Trade, Migration and Integration: Evidence and Policy Implications. World Economy. Forthcoming.

Head, K. and J. Ries. 1998. Immigration and Trade Creation: Econometric Evidence from Canada. Canadian Journal of Economics 31, 47-62.

Headey, D. 2008. Geopolitics and the Effect of Foreign Aid on Economic Growth: 1970-2001. Journal of International Development 20, 161-180.

Heston, A., R. Summers and B. Aten (2006, 2012). Penn World Table Version 6.2, 7.1. 2006, 2012. Center for International Comparisons of Production, Income and Prices at the University of Pennsylvania.

Higgins, A. and M. Fan. 2012. Chinese Communist Leaders Denounce US Values but Send Children to US Colleges. Washington Post.

Hodler, R. and A. Dreher. 2012. Development (Paradigm) Failures. Journal of Development Economics 101, 63-74.

Hofstede, G.H. and G. Hofstede. 2001. Culture's Consequences: Comparing Values, Behaviors, Institutions, and Organizations across Nations. Sage Publications, Inc.

Huber, J. and R. Inglehart. 1995. Expert Interpretations of Party Space and Party Locations in 42 Societies. Party Politics 1, 73-111. 
Hume, D. 1912 [1777], An Enquiry Concerning the Principles Of Morals, Project Gutenberg Edition, part I (originally published in 1751).

Inglehart, R. and W.E. Baker. 2000. Modernization, Cultural Change and the Persistence of Traditional Values. American Sociological Review 65, 19-51.

Inglehart, R. and C. Welzel. 2005. Modernization, Cultural Change and Democracy: The Human Development Sequence. Cambridge University Press.

International Country Risk Guide. 2012. PRS Group. http://www.prsgroup.com/ICRG.aspx.

International Disaster Database. 2013. http://emdat.be/

International Monetary Fund. 2005. International Financial Statistics. Washington, D.C.: International Monetary Fund.

International Monetary Fund. Staff Reports. 2006-2010.

http://www.imf.org/external/np/sec/aiv/index.aspx

Javorcik, B.S., C. Özden, M. Spatareanu and C. Neagu. 2011. Migrant Networks and Foreign Direct Investment. Journal of Development Economics 94, 231-241.

Jiang, Z., S. C. Henneberg and P. Naudé. 2011. The Importance of Trust vis-à-vis Reliance in Business Relationships: Some International Findings. International Marketing Review 28, 318-339.

Jones, B.F. and B.A. Olken. 2005. Do Leaders Matter? National Leadership and Growth since World War II. The Quarterly Journal of Economics 120, 835-864.

Kahneman, D. 2003. A Perspective on Judgment and Choice: Mapping Bounded Rationality. American Psychologist 58, 697-720.

Kanbur, R. 2006. The Economics of International Aid. In Handbook of the Economics of Giving, Altruism, and Reciprocity. Volume 2: Applications, eds. Serge-Christophe Kolm and Jean Mercier Ythier. Amsterdam: North-Holland, 1559-1588.

Keefer, P. 2012. Database of Political Institutions: Changes and Variable Definitions. Development Research Group, World Bank. 
Kilby, C. and A. Dreher. 2010. The Impact of Aid On Growth Revisited: Do Donor Motives Matter? Economics Letters 107, 338-340.

Kilby, C. 2013. The Political Economy of Project Preparation: An Empirical Analysis of World Bank Projects. Journal of Development Economics 105, 211-225.

Kilby, C. 2015. Assessing the Contribution of Donor Agencies to Aid Effectiveness: The Impact of World Bank Preparation on Project Outcomes. Journal of Development Economics $115,111-123$.

Klasen, S. 2004. In Search of the Holy Grail: How to Achieve Pro Poor Growth? In Tungodden, B., N. Stern, and I. Kolstad (Eds.). Toward Pro Poor Policies-Aid, Institutions, and Globalization. New York: Oxford University Press (2004), S. 63-94. Reprinted in Krakowski, M. (ed.) Attacking Poverty: What makes Growth Pro-Poor? HWWA Studies 75, Hamburg: Nomos.

Knack, S. and A. Rahman. 2007. Donor Fragmentation and Bureaucratic Quality in Aid Recipients. Journal of Development Economics 83, 176-197.

Kodama, M. 2012. Aid Unpredictability and Economic Growth. World Development 40, 266272.

Koeberle, S. and Z. Stavreski. 2006. Budget Support: Concept and Issues. In Budget Support as More Effective Aid? Recent Experiences and Emerging Lessons, eds. Stefan Koeberle, Zoran Stavreski and Jan Walliser. Washington, DC. The World Bank, 3-26.

Kolo, P. 2012. Measuring a New Aspect of Ethnicity: The Appropriate Diversity Index. Ibero America Institute for Economic Research Discussion Papers No. 221

Kosack, S. 2003. Effective Aid: How Democracy Allows Development Aid to Improve the Quality of Life. World Development 31, 1-22.

Kugler, M., O. Levintal and H. Rapoport. 2013. Migration and Cross-Border Financial Flows. Institute for the Study of Labor. Discussion Paper 7548. Bonn. 
Lahiri, S. and P. Raimondos-Møller. 2000. Lobbying by Ethnic Groups and Aid Allocation. Economic Journal 110, C62-C79.

Lawson, A., D. Booth, A. Harding, D. Hoole and F. Naschold. 2003. General Budget Support. Phase 1: Synthesis Report, Volume I. Evaluation Report EV643. London: Department of International Development.

Leblang, D. 2010. Familiarity Breeds Investment: Diaspora Networks and International Investment. American Political Science Review 104, 584-600.

Lensink, R. and O. Morrissey. 2000. Aid Instability as a Measure of Uncertainty and the Positive Impact of Aid on Growth. Journal of Development Studies 36, 31-49.

Lister, S. and R. Carter. 2006. Evaluation of General Budget Support: Synthesis Report. A Joint Evaluation of General Budget Support 1994- 2004. London: Department of International Development.

Lskavyan, V. 2014. Donor-recipient Ideological Differences and Economic Aid. Economics Letters $123,345-347$.

McKenzy, D. and D. Yang. 2014. Evidence on Policies to Increase the Development Impacts of International Migration. Institute for the Study of Labor. IZA Discussion Paper 8523. Bonn.

Milner, Helen V. and D.H. Tingley. 2010. The Political Economy of US Foreign Aid: American Legislators and the Domestic Politics of Aid. Economics \& Politics 22, 200-232.

Moyo, D. 2009. Dead Aid: Why Aid is Not Working and How there is a Better Way for Africa. Farrar, Straus and Giroux, New York.

Mukherjee, B., D. Smith and Q. Li. 2009. Labor ( $\mathrm{Im})$ mobility and the Politics of Trade Protection in Majoritarian Democracies. Journal of Politics 71 (1): 291-308.

Nizalova, O. and I. Murtazashvili. 2012. Exogenous Treatment and Endogenous Factors: Vanishing of Omitted Variable Bias on the Interaction Term. IZA Discussion Paper 6282. Nunn, N. and N. Qian. 2012. Aiding Conflict: The Impact of US Food Aid on Civil War. 
National Bureau of Economic Research Working Paper Working Paper 17794.

Nunn, N. and N. Qian. 2014. US Food Aid and Civil Conflict. American Economic Review 104, 1630-1666.

Odedokun, M. 2004. Multilateral and Bilateral Loans Versus Grants: Issues and Evidence. World Economy 27, 239-263.

OECD 2012. Aid Statistics, Table DAC 2a: Destination of Official Development Assistance Disbursements. Paris: OECD.

Özden, C., C.R. Parsons, M. Schiff and T.L. Walmsley. 2011. Where on Earth is Everybody? The Evolution of Global Bilateral Migration 1960-2000. World Bank Economic Review $25,12-56$.

Ozer-Balli, H. and B. E. Sørensen. 2013. Interaction Effects in Econometrics, Empirical Economics 45, 583-603.

Parsons, C.R. 2012. Do Migrants Really Foster Trade? The Trade-Migration Nexus, A Panel Approach 1960-2000. World Bank. Policy Research Working Paper 6034. Washington, DC.

Parsons, T. 1951. The Social System. Free Press.

Pemstein, D., S.A. Meserve and J. Melton. 2010. Democratic Compromise: A Latent Variable Analysis of Ten Measures of Regime Type. Political Analysis 18, 426-449.

Radcliffe, S.A. and N. Laurie. 2006. Culture and Development: Taking Culture Seriously in Development for Andean Indigenous People. Environment and Planning D: Society and Space 24, 231-248.

Ravallion, M., and S.Chen.1997. What Can New Survey Data Tell Us About Recent Changes In Distribution And Poverty? The World Bank Economic Review, 11, 357-382

Rajan, R.G. and A. Subramanian. 2008. Aid and Growth. Review of Economics and Statistics 90, 643-665. 
Ratha, D. and N. Shaw. 2007. South-South Migration and Remittances. World Bank Working Paper 102. Washington, DC. (http://siteresources.worldbank.org/INTPROSPECTS/Resources/3349341110315015165/SouthSouthMigrationandRemittances.pdf; accessed: June 2015).

Ratha, D., S. Mohapatra and E. Scheja. 2011. Impact of Migration on Economic And Social Development: A Review of Evidence and Emerging Issues. World Bank, Policy Research Working Paper 5558. Washington, DC.

Rathbun, B. C. 2011. Before Hegemony: Generalized Trust and the Creation and Design of International Security Organizations. International Organization 65, 243-273.

Rauch, J. 2001. Business and Social Networks in International Trade. Journal of Economic Literature 39, 1177-1203.

Roodman, D. 2004. The Commitment to Development Index: 2004 Edition. Center for Global Development. Technical Paper. Washington, DC.

Roodman, D. 2013. The Commitment to Development Index: 2013 Edition. Center for Global Development. Technical Paper. Washington, DC.

Roodman, D. 2015. A Replication of "Counting Chickens When They Hatch" (Economic Journal 2012). Public Finance Review 43, 256-281.

Roodman, D. 2007. The Anarchy of Numbers: Aid, Development, and Cross-country Empirics. World Bank Economic Review 21, 255-277.

Rostow, W.W. 1990. The Stages of Economic Growth: A Non-Communist Manifesto. Cambridge University Press.

Schech, S. and J. Haggis. 2000. Culture and Development: A Critical Introduction. WileyBlackwell.

Schwartz, S.H. 1994. Beyond Individualism/Collectivism: New Cultural Dimensions of Values. In: U.Kim, H.Triandis, C.Kagitcibasi, S.C. Choi, and G. Yoon (HrsG): Individualism and 
Collectivism, 85-119. Sage.

Sen, A. 2004. How Does Culture Matter. In: R. Vijayendra and M. Walton: Culture and Public Action, 37-58. Stanford University Press.

Smets, L., S. Knack and N. Molenaers. 2013. Political Ideology, Quality at Entry and the Success of Economic Reform Programs. Review of International Organizations 8, 447476.

Spilimbergo, A. 2009. Democracy and Foreign Education. The American Economic Review 99, $528-543$.

Spolaore, E. and R. Wacziarg. 2009. The Diffusion of Development. The Quarterly Journal of Economics 124, 469-529.

Spring, E. and V. Grossmann. 2013. Does Bilateral Trust Affect International Movement of Goods and Labor? Université de Fribourg Working Paper 442.

Stone, R. 2004. The Political Economy of IMF Lending in Africa. American Political Science Review 98, 577-92.

Strange, A., B.C. Parks, M.J. Tierney, A. Fuchs, A. Dreher and V. Ramachandran. 2013. China's Development Finance to Africa: A Media-Based Approach to Data Collection. Center for Global Development Working Paper 323.

Survey on Monitoring the Paris Declaration. 2008. OECD.

Svensson, J. 2003. Why Conditional Aid Does Not Work and What Can Be Done About It? Journal of Development Economics 70, 381-402.

Swank, D. 2009. Comparative Political Parties Dataset. Department of Political Science, Marquette University.

Thacker, S.C. 1999. The High Politics of IMF Lending. World Politics 52, 38-75.

Tierney, M.J., D.L. Nielson, D.G. Hawkins, T.J. Roberts, M.G. Findley, R.M. Powers, B. Parks, S.E. Wilson, R.L. Hicks. 2011. More Dollars than Sense: Refining Our Knowledge of Development Finance Using AidData. World Development. 39, 1891-1906. 
Torsvik, G. 2005. Foreign Economic Aid: Should Donors Cooperate? Journal of Development Economics 77, 503-515.

Tschudi, E.A. 2013. Westernized and Authoritarian. Brown Political Review.

Turner, T. 1999. Talcott Parsons Reader. John Wiley \& Sons, New York.

United Nations Conference on Trade and Development, Bilateral FDI Statistics. 2014. http://unctad.org/en/Pages/DIAE/FDI-Statistics/FDI-Statistics-Bilateral.aspx

United Nations High Commissioner for Refugees Data. 2013. http://www.unhcr.org/pages/49c3646c4d6.html.

Uppsala Conflict Data Program/Peace Research Institute Oslo Armed Conflict Dataset. Version 4-2011. http://www.pcr.uu.se/research/ucdp/datasets/ucdp_prio_armed_conflict_dataset/

United States Department of State Office of the Historian http://history.state.gov/departmenthistory/short-history/endofcoldwar

Vreeland, J. R. and A. Dreher. 2014. The Political Economy of the United Nations Security Council. Money and Influence. Cambridge University Press. Cambridge

Vreeland, J.R. 2006. IMF Program Compliance: Aggregate Index versus Policy Specific Research Strategies. Review of International Organizations 1, 359-378.

Wacziarg, R.T. and K.H. Welch. 2008. Trade Liberalization and Growth: New evidence. World Bank Economic Review 22,187-231.

World Bank. 1998. Assessing Aid: What Works, What Doesn't, and Why? Oxford University Press. Oxford.

World Bank 2007, 2012, 2013. World Development Indicators. World Bank. Washington, D.C. Zak, P. J. and S. Knack. 2001. Trust and Growth. Economic Journal 111, 295-321. 